University of Louisville

ThinkIR: The University of Louisville's Institutional Repository

Electronic Theses and Dissertations

8-2015

\title{
Combination treatment with conjugated linoleic acid and nitrite protects against myocaridal infarction.
}

Natia Qipshidze Kelm
University of Louisville

Follow this and additional works at: https://ir.library.louisville.edu/etd

Part of the Biological and Chemical Physics Commons, and the Physiology Commons

\section{Recommended Citation}

Kelm, Natia Qipshidze, "Combination treatment with conjugated linoleic acid and nitrite protects against myocaridal infarction." (2015). Electronic Theses and Dissertations. Paper 2227.

https://doi.org/10.18297/etd/2227

This Doctoral Dissertation is brought to you for free and open access by ThinkIR: The University of Louisville's Institutional Repository. It has been accepted for inclusion in Electronic Theses and Dissertations by an authorized administrator of ThinkIR: The University of Louisville's Institutional Repository. This title appears here courtesy of the author, who has retained all other copyrights. For more information, please contact thinkir@louisville.edu. 


\title{
COMBINATION TREATMENT WITH CONJUGATED LINOLEIC ACID AND NITRITE PROTECTS AGAINST MYOCARIDAL INFARCTION
}

\author{
By
}

\author{
Natia Qipshidze Kelm \\ M.D. , Tbilisi State Medical University \\ A Dissertation \\ Submitted to the Faculty of the \\ School of Medicine of the University of Louisville \\ in Partial Fulfillment of the Requirements \\ for the Degree of
}

Doctor of Philosophy in Physiology and Biophysics

\author{
Department of Physiology \& Biophysics \\ University of Louisville \\ Louisville, KY
}

August 2015 
Copyright 2015 by Natia Qipshidze Kelm

All rights reserved 



\section{COMBINATION TREATMENT WITH CONJUGATED LINOLEIC ACID AND NITRITE PROTECTS AGAINST MYOCARIDAL INFARCTION}

\section{By}

Natia Qipshidze Kelm

A Dissertation Approved on

August $5^{\text {th }}, 2015$

by the following Dissertation Committee:

Marsha P. Cole, PhD

Dale A. Schuschke, PhD

Aruni Bhatnagar, $\mathrm{PhD}$

Bradley B. Keller, MD

Claudio Maldonado, PhD

Nolan L. Boyd, PhD 


\section{DEDICATION}

This dissertation is dedicated to

my parents

Neli Metreveli and Ushangi Qipshidze

And

my husband

David A. Kelm

for believing in me and encouraging me throughout my life. 


\section{ACKNOWLEDGEMENTS}

The work within this dissertation represents the culmination of years of training, during which time I have been extremely fortunate to receive help from my multitalented and supportive mentor, Dr. Marsha Cole. Thanks to Dr. Cole for providing me with an outstanding pre-doctoral training, intellectual challenges, her well-timed humor, and endless support of my current and future endeavors. I would also like to thank my committee members: Dr. Schuschke, Dr. Bhatnagar, Dr. Keller, Dr. Maldonado, and Dr. Boyd for their support and sage advice. I am especially grateful to Dr. Keller and Dr. Bhatnagar for their guidance and support. The Department of Physiology has provided the support and equipment I have needed to produce and complete my thesis. Finally, I would like to thank my parents, sister and husband for their encouragement.

To acknowledge the team approach to science, the following text frequently uses the term "we" to describe collaborative experiments executed during my doctoral thesis work. 


\begin{abstract}
COMBINATION TREATMENT WITH CONJUGATED LINOLEIC ACID AND NITRITE PROTECTS AGAINST MYOCARIDAL INFARCTION
\end{abstract}

\author{
Natia Qipshidze Kelm
}

August 5, 2015

According to the CDC, the most common type of heart disease is coronary artery disease, which frequently leads to myocardial infarction (MI). Therapeutic approaches to lessen the resulting cardiovascular injury associated with MI are limited. Recently, the management paradigm for cardiac injury has entered the molecular era and microRNAs (miRNAs) have been shown to act as negative regulators of gene expression by inhibiting mRNA translation and/or stimulating mRNA degradation. A single miRNA can modulate physiological or disease phenotypes by regulating whole functional systems. Importantly, miRNAs can regulate cardiac function, thereby modulating heart muscle contraction, heart growth and morphogenesis. MicroRNA-499 (miRNA-499) is a cardiac-specific miRNA that when elevated causes cardiomyocyte hypertrophy, in turn preventing cardiac dysfunction during MI. Previous studies revealed that the combination treatment of conjugated linoleic acid (cLA) and nitrite preserved cardiovascular 
function in mice. Therefore, we hypothesized that CLA and nitrite may regulate miRNA-499, thus providing cardiac protection during MI. To test this hypothesis, 12-week old mice were treated with CLA (10 mg/kg/d-via osmotic mini-pump) or CLA and nitrite (50 ppm-drinking water) 3 days prior to $\mathrm{MI}$ (ligation of the left anterior descending artery). Echocardiography and pressure-volume (PV)-loop analysis revealed that CLA and nitrite-treated $\mathrm{Ml}$ mice had improved heart function (10 days following MI) compared to untreated MI mice. Treatment with CLA and nitrite significantly induced levels of miRNA-499 compared to untreated MI mice. In addition, treatment with $\mathrm{CLA}$ and nitrite abolished MI-induced protein expression of p53 and dynamin-related protein-1 (DRP-1). Moreover, the antioxidant enzyme expression of heme oxygenase-1 (HO-1) was elevated in $\mathrm{Ml}$ mice treated with CLA and nitrite compared to untreated MI mice. Confocal imaging on heart tissue confirmed expression the levels of $\mathrm{HO}-1$ and p53. Taken together, these results suggest that therapeutic treatment with CLA and nitrite may provide significant protection during $\mathrm{Ml}$ through regulation of both cardiac specific miRNA-499 and upregulation of phase 2 antioxidant enzyme expression.

As we demonstrate in our study CLA and nitrite co administration decreased apoptosis though the HO-1 and/or miRNA-499 pathway. To investigate more deeply the role of HO-1 and/or miRNA-499 in apoptosis, we used $\mathrm{HO}-1 \mathrm{Tg}$ and $\mathrm{HO}-1 \mathrm{KO}$ mice. Our data supported the hypothesis that $\mathrm{HO}-1$ regulates miRNA-499 levels and thus decreases apoptosis after MI. As others and we have demonstrated before, $\mathrm{Ml}$ is known to cause cardiomyocyte ischemia, in turn, leading to cardiomyocyte apoptosis [1, 2]. The current study 
extends previous findings by demonstrating that ischemia causes an increased ratio of $\mathrm{Bax} / \mathrm{Bcl}-2$ following $\mathrm{Ml}$ in non-treated $\mathrm{C} 57$ mice and in $\mathrm{HO}-1 \mathrm{KO}$ mice. Our data demonstrate that in $\mathrm{HO}-1 \mathrm{KO}$ mice the expression of miRNA-499 is not detectable.

Overall, these data reveal links among p53, HO-1, miRNA-499, and Drp1 with regard to regulation of the apoptotic programed cell death in the heart. Taken together, these results suggest that therapeutic treatment with CLA and nitrite may provide cardiac protection during $\mathrm{Ml}$ through the regulation of induction of cardiac specific $\mathrm{HO}-1$ expression, which further regulated cardiac specific miRNA-499. 


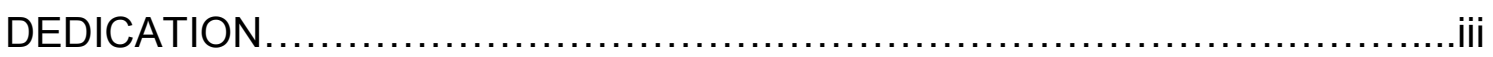

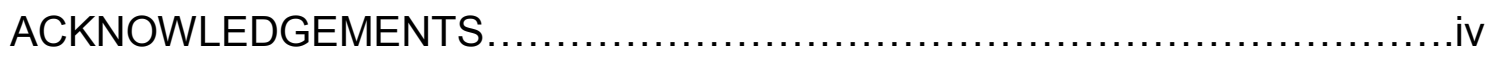

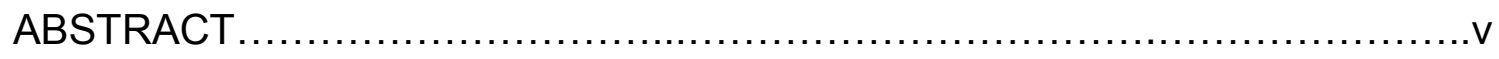

LIST OF FIGURES AND TABLES:

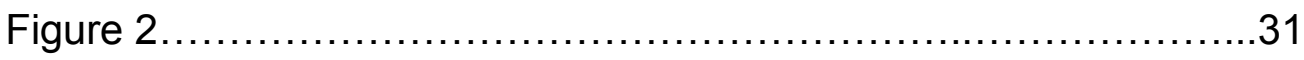

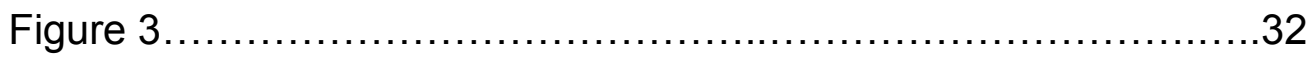

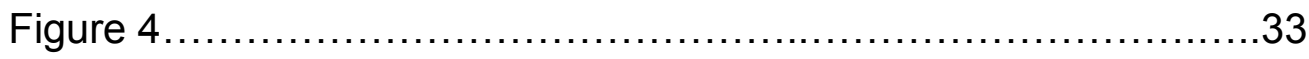

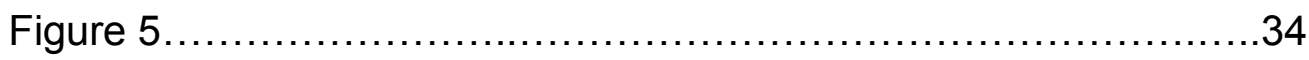

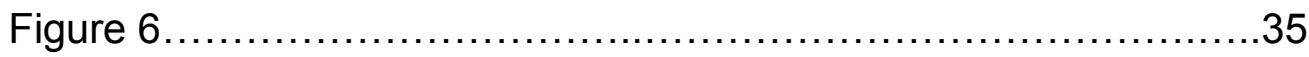

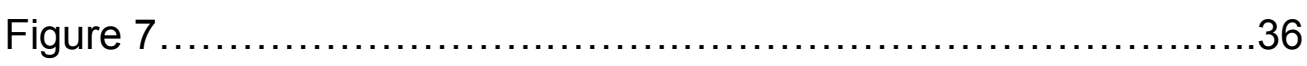

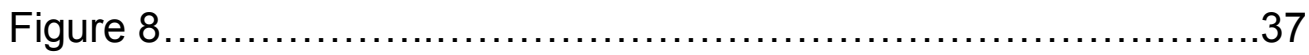

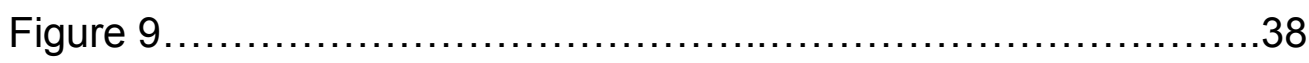

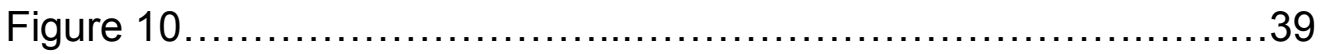

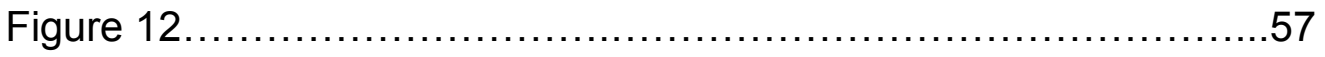

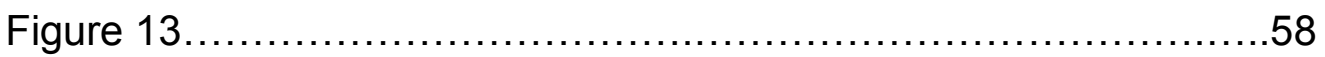

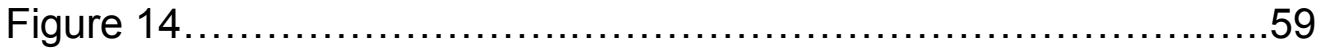

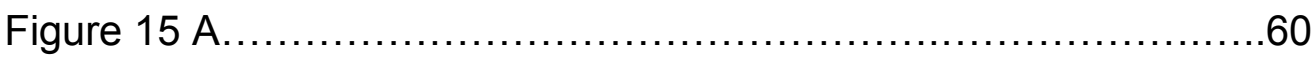

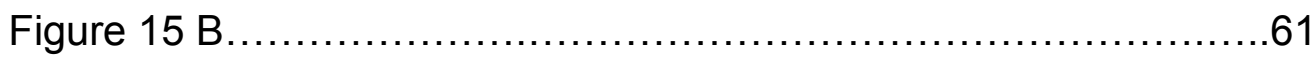

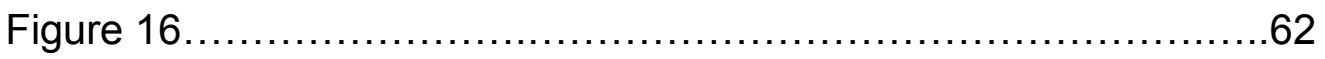




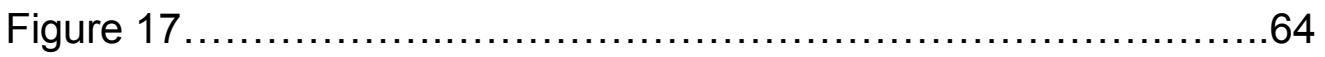

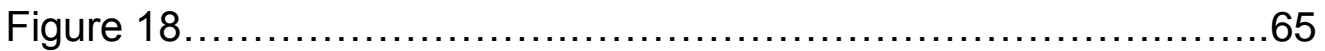

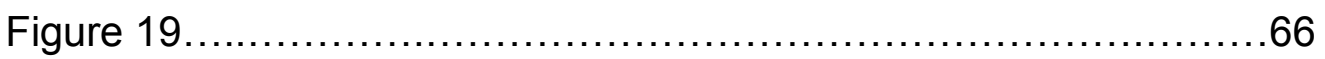

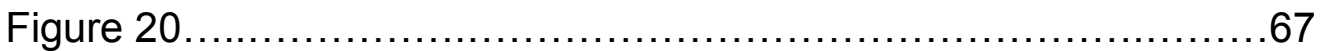

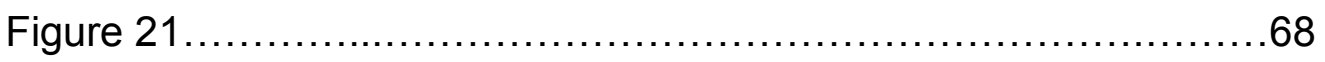

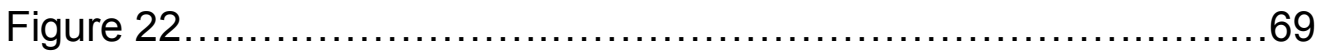

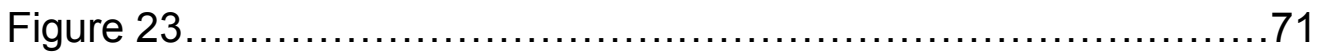

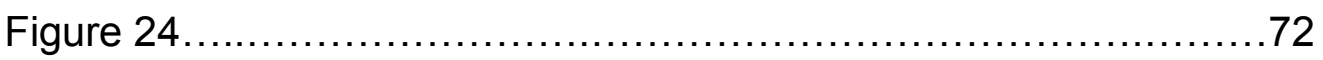

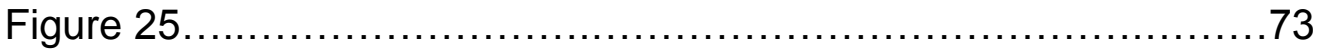

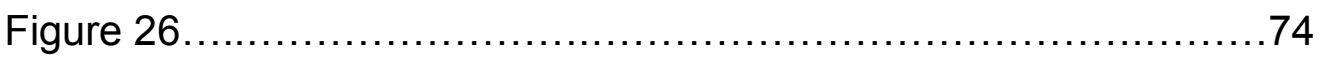

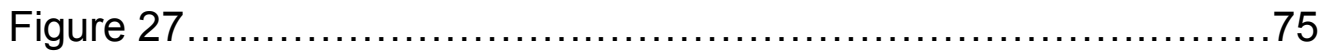

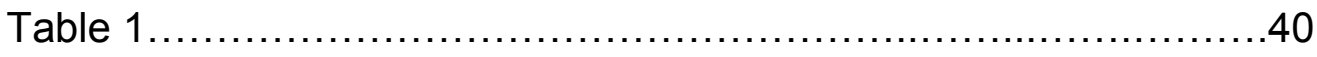

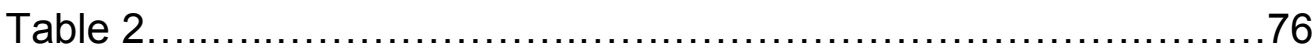




\section{CHAPTER I:}

\section{INTRODUCTION}
A. Myocardial infarction 1
B. Apoptosis and myocardial infarction....................................
C. miRNA-499 protects heart from apoptosis..............................6

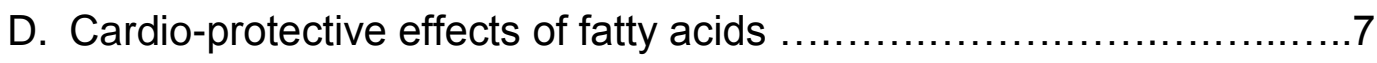
E. Heme oxygenase-1 in cardiovascular disease ....................... 9

\section{CHAPTER II:}

HYPOTHESIS AND SPECIFIC AIM

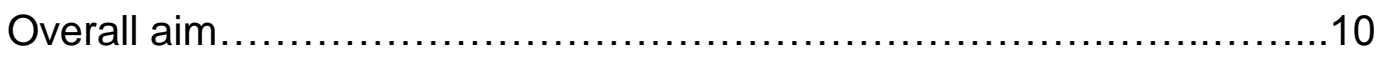

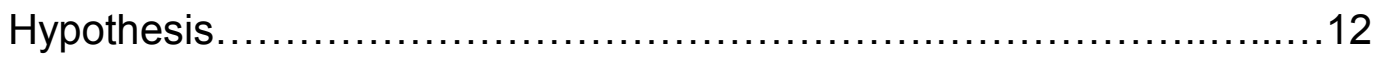

\section{CHAPTER III:}

\section{MATERIALS AND METHODS}
A. Materials.
.13
B. Animals.
C. Mouse model of myocardial infarction
D. Measurement of cardiac function

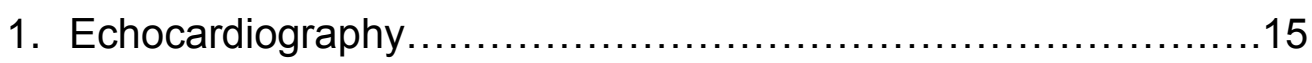

2. In vivo hemodynamic measurements........................... 15

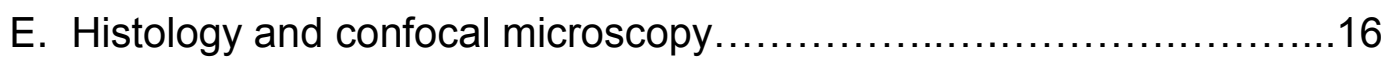

1. Immunohistochemisty .......................................... 17 
2. TUNEL assay.

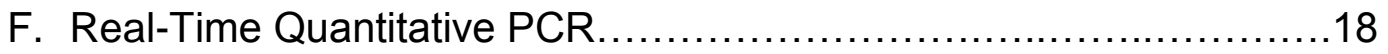

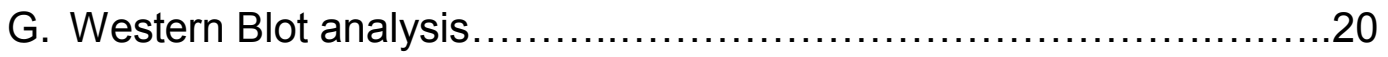

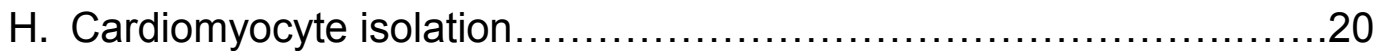

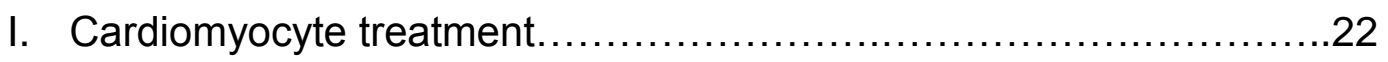

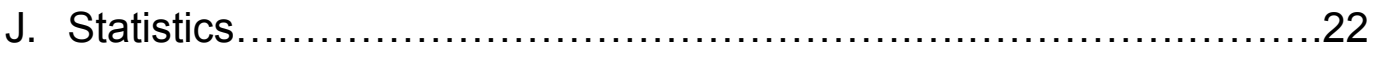

\section{CHAPTER IV:}

\section{SPECIFIC AIM 1}

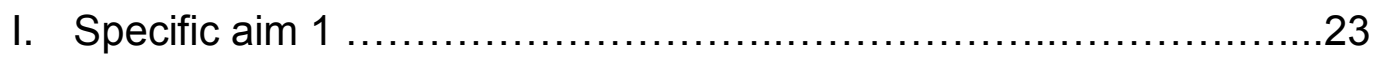

Schematic diagram of overall hypothesis............................24

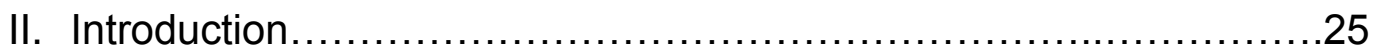

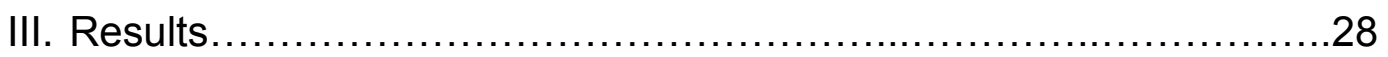

1.1 ST-segment elevation is an early marker of MI...................28

1.2 Combination treatment with $\mathrm{CLA}$ and nitrite improves survival in $\mathrm{Ml}$

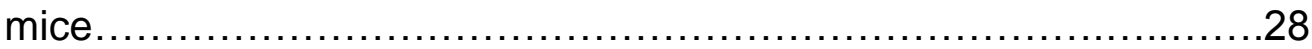

1.3 Co-administration of CLA and nitrite increases heart weight and

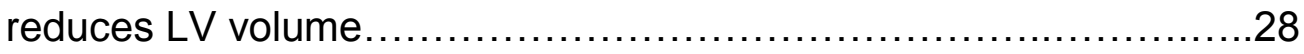

1.4 Co-treatment with CLA and nitrite improve LV function following

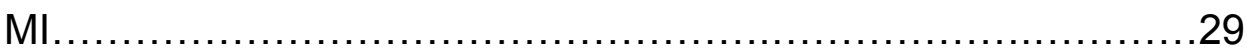

1.5 Co-administration of CLA and nitrite eliminates $\mathrm{MI}$ induced oxidative stress in LV ventricle after MI...................................29 
1.6 Co-treatment with CLA and nitrite eliminates apoptosis in ischemic zone of $\mathrm{Ml}$

30

1.7 Co-administration of CLA and nitrite decreases ANP and BNPmarkers for heart failure after MI.

IV. Discussion 41

\section{CHAPTER V}

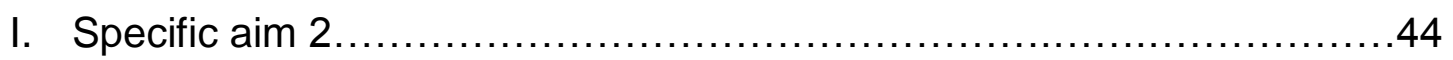

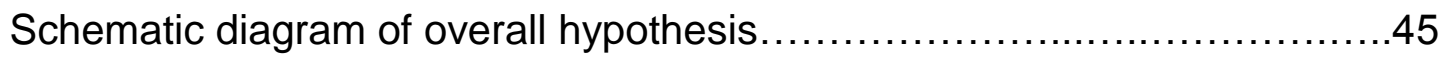

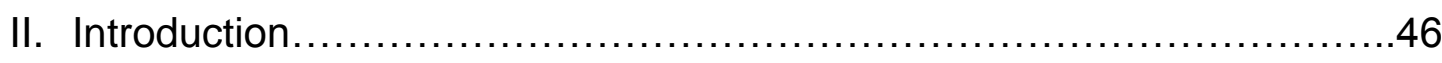

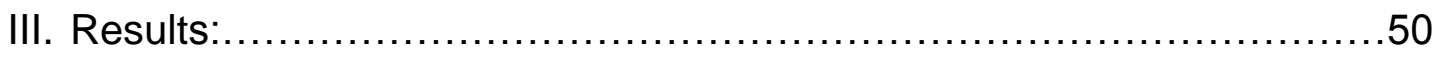

2.1 miRNA-499 biomarker of acute MI....................................50

2.2 Co-treatment of CLA and nitrite regulates miRNA-499 during M..50

2.3 Mitochondrial fission factor DRP-1 is significantly increased in mice

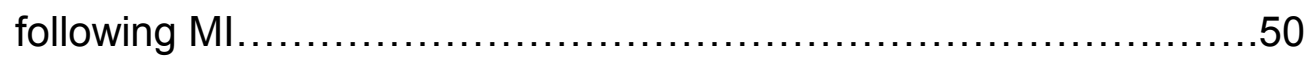

$2.4 \mathrm{CLA}$ and nitrite treatment attenuates p53 expression following M.51

$2.5 \mathrm{HO}-1$ expression increases in Ml following $\mathrm{CLA}$ and nitrite treatment. .51

2.6 Co-treatment with CLA and nitrite attenuates pro-apoptotic markers

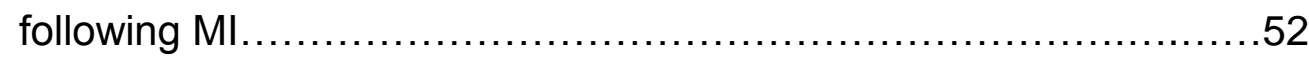

2.7 Induction of HO-1 attenuates LV dysfunction in MI mice. .52 
2.8 HO-1 Attenuates p53 Levels in HO-1 Tg mice Following MI........53

$2.9 \mathrm{HO}-1$ induces miNRA-499 expression in mice following Ml.......54

$2.10 \mathrm{HO}-1$ attenuates ratio of Bax/Bcl-2 following Ml.................54

2.11 The heart failure markers (ANP and BNP) are lowered in $\mathrm{HO}-1 \mathrm{Tg}$

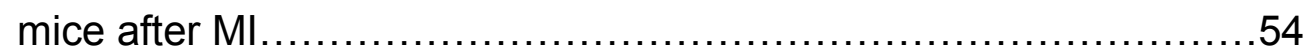

2.12 CLA and nitrite induces miRNA-499 and HO-1 expression in

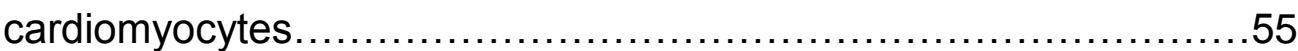

2.13 CLA and nitrite induces miRNA-499 through HO-1 induction in

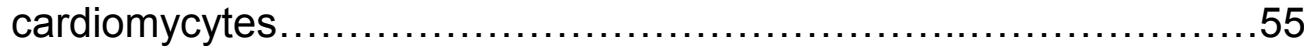

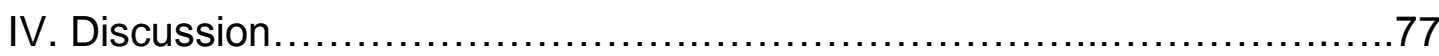

CHAPTER VI

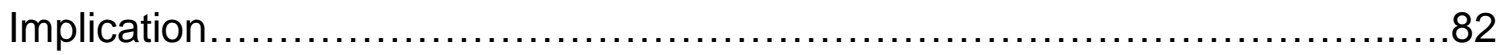

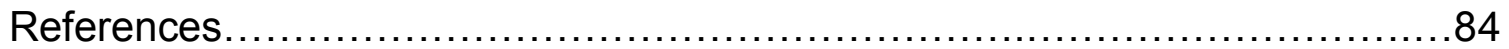

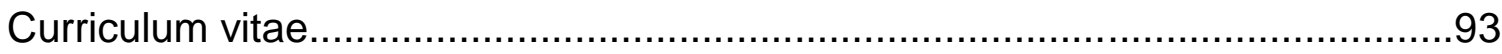




\section{CHAPTER I}

\section{INTRODUCTION}

\section{A. Myocardial infarction}

Myocardial infarction (MI) caused by coronary artery blockage is the major cause of death worldwide [3]. Over the last two decades, health care professionals, consumers, and payer organizations have sought to improve outcomes for patients hospitalized with acute MI [4]. In the United States (US) alone, nearly 8 million people have a history of MI [5]. Subsequently, in 1990 the American College of Cardiology and the American Heart Association jointly published the first in a series of clinical practice guidelines for MI that include a significant emphasis on evidence-based hospital care [6].

In 1992 the Health Care Financing Administration, now the Centers for Medicare \& Medicaid Services (CMS), initiated an ongoing national effort, aided by quality improvement organizations, to measure and improve hospital care for patients with acute MI [7]. According to the World Health Organization, ischemic

heart disease is one of the leading causes of death worldwide, with about 3.8 million men and 3.4 million women dying yearly from this disease. In the US 
ischemic heart disease resulting from coronary artery disease is devastating, with 1.5 million US citizens developing MI-s that account for nearly 200,000 deaths per year $[8,9]$. The National Heart, Lung, and Blood Institute estimate that an average of 14.2 years of life may be lost due to heart attack [10].

Acute $\mathrm{MI}$ remains a leading cause of morbidity and mortality worldwide [11]. Ml occurs when myocardial ischemia, a diminished blood supply to the heart, exceeds a critical threshold and overwhelms myocardial cellular repair mechanisms designed to maintain normal operating function and homeostasis [12]. Ischemia at this critical threshold level for an extended period results in irreversible myocardial cell damage or death [13]. Critical myocardial ischemia can occur as a result of increased myocardial metabolic demand, decreased delivery of oxygen and nutrients to the myocardium via the coronary circulation, or both [14]. Acute MI results from blockage of a coronary artery leading to insufficient blood supply to cardiac tissue, ultimately resulting in cardiomyocyte death [15] and cardiac dysfunction [13]. MI is characterized by significant changes in gene expression, many of which represent adaptive or maladaptive responses to stress [16-20]. The resulting cardiac stress induces rapid changes in gene expression immediately following MI [21]. Cardiomyocyte cell death is a consequence of myocardial injury, which occurs as early as the initiation of acute MI [22]. Cardiomyocyte death or apoptosis is a key factor in transition from cardiac hypertrophy to heart failure [23]. 


\section{B. Apoptosis and myocardial infarction}

Apoptosis or programmed cell death is a highly regulated and energy requiring process [24]. Apoptosis is characterized by shrinkage of the cell and the nucleus [24]. The nuclear chromatin is cut into sharply defined masses, and eventually breaks up into the small particles [25]. At this stage, extensions bud out from their membranes, which eventually seal off to form membrane enclosed vesicles, called apoptotic bodies, containing condensed cellular organelles and nuclear fragments $[25,26]$. These apoptotic bodies are either rapidly phagocytosed by neighboring cells or undergo degradation, which resembles necrosis in a process called secondary necrosis [26]. However, apoptosis is generally considered not to trigger an inflammatory response [27].

Apoptosis plays a role in the tissue damage after MI, it has pathological and therapeutic implications [28]. Apoptosis is highly regulated and the consequences of the cellular mechanisms that control apoptosis during and/or after $\mathrm{Ml}$ are well understood $[26,29]$. Thus, the apoptotic pathway becomes an important therapeutic target with regard to attenuation of tissue damage in patients with $\mathrm{Ml}$ and consequent heart failure.

During MI-induced heart damage, cardiomyocyte apoptosis contributes to dilatation of the infarcted chamber, and thus leads to cardiac dysfunction or eventual heart rupture following MI [30]. MI represents one of the major etiologies that emphasizes the expansion of congestive heart failure [31]. Damage of cardiomyocytes secondary to prolonged ischemia has been thought to be 
resulted from the manifestation of necrosis [32]. Whereas this form of cell death remains a main cause of tissue injury, recent studies have suggested that damage of cardiomyocytes after MI can also be caused by apoptosis [33-37]. Overall, myocyte death in $\mathrm{Ml}$ is attributed to necrosis, but recently myocardial apoptosis has been observed in humans during acute MI [36, 37]. Apoptosis is the early manifestation of cell death in infarcted myocardium [38], which is primarily seen in cardiomyocytes in hypoxic regions during MI [36]. p53 is a wellknown transcription factor which mediates apoptosis by initiating the expression of pro-apoptotic genes, including Bax, caspase, etc. [39]. Previous studies have demonstrated that p53 transcriptional activity is enhanced in $\mathrm{MI}$ [40] and that p53 plays a critical role in the regulation of hypoxia-induced apoptosis of cardiomyocytes [1]. Importantly, p53 signaling is proposed to be part of the proapoptotic pathways which eventually lead to cardiac apoptosis [39]. Enlargement of the LV chamber is a distinctive alteration of the failing heart regardless of cause [31]. For example, chronic ventricular dilatation and failure can be an outcome of long-standing volume overload. LV chamber dilation is associated with the loss of cardiac myocytes [41]. Previous studies have shown that myocardial stretch is associated with cardiomyocyte apoptosis [42, 43]. More recent studies have shown that myocardial stretch alone, under conditions of acute or chronic volume overload, may be associated with cardiomyocyte loss through apoptosis [31].

Bcl-2, Bax and p53 have been recognized to play a significant role in the management of cell death and apoptosis [44]. Apoptosis is a tightly regulated 
process, as previously mentioned, and the imbalance between Bax and Bcl-2 proteins decides the outcome of the cell [38]. The expression of these regulatory proteins, Bcl-2 and Bax, has been studied following MI in cardiac tissue [45]. Bax is a member of the Bcl-2 family and its overexpression accelerates apoptosis [15, 46]. It also counters the death repressor activity of $\mathrm{Bcl}-2$, the $\mathrm{Bcl}-2$ family proteins are involved in the p53 apoptotic pathway and the balance between those positively and negatively regulatory proteins is essential for forming apoptosis [47]. Bcl-2 is known as anti-apoptotic protein, and Bax is widely described as a pro-apoptotic factor, thus the balance between $\mathrm{Bax}$ and $\mathrm{Bcl}-2$ contributes to the signaling of programmed cell death through apoptosis $[47,48]$. It has been shown that Bcl-2 expression can inhibit apoptosis in ischemic cardiomyocytes after $\mathrm{MI}[49,50]$ and myocardial ischemia induces a reduction in the expression of Bcl-2 protein and increases in the expression of Bax and p53 proteins $[51,52]$. Therefore an imbalance in anti- and pro-apoptotic proteins expressed during myocardial ischemia is involved in initiating myocyte cell death $[53,54]$. Overall, if the $\mathrm{Bax}$ to $\mathrm{Bcl}-2$ ratio is high, this may indicate apoptotic cell death infarcted myocardium [45]. 


\section{C. miRNA-499 protects the heart from apoptosis}

MicroRNAs (miRNAs) quantitatively regulate mature-RNAs, which affect the cardiac transcriptional output and cardiac function [55]. miRNAs are endogenous, single-stranded non-coding RNAs ranging 18 to 24 nucleotides in length, that play an important role in gene regulation $[55,56]$. In screening for miRNAs enriched in the heart, miRNA-499 is abundant and is known to be an evolutionarily conserved muscle-specific microRNA that is encoded within the intron of myosin heavy chain and is highly expressed in the cardiac ventricles [55-57]. Plasma miRNA-499 is a known biomarker of acute $\mathrm{Ml}$, as plasma miRNA-499 has been observed in individuals with MI [58-60].

The balance between cell proliferation and apoptosis is required for living cells and miRNA-499 plays a big role in maintaining this balance [61]. Previous studies show that overexpression of miRNA-499 reversed enhanced proliferation and shows an anti-apoptotic effect in cardiomyocytes [61].

Ultimately, heart function is highly dependent on ATP generation. The heart is enriched with mitochondria that provide the energy required for cardiomyocyte function [62]. Therefore, it is known that mitochondria play a critical role in development and progression of many cardiac diseases such as hypertrophy and MI. Previous studies suggest that mitochondria are highly dynamic and that changes in mitochondrial shape can affect a variety of biological processes such as apoptosis and fibrosis [63, 64]. Mitochondria are organelles which constantly undergo fission and fusion [63-65]. These two 
opposing processes are regulated by the mitochondrial fusion proteins mitofusin and the mitochondrial fission protein Drp-1 [62]. During apoptosis, Drp-1 foci accumulates on mitochondria and can enhance mitochondrial fission $[66,67]$.

miRNA-499 has been shown to be involved in inhibiting apoptosis and MI induced by anoxia and ischemia through mechanisms involving p53 and Drp-1 in accomplishing apoptosis in the MI heart [57]. The modulation of miRNA-499 may be a novel therapeutic approach to treat apoptosis-related cardiac disease, including MI [68, 69].

\section{Cardio-protective effects of fatty acids}

Conjugated linoleic acid (CLA) refers to a group of positional and geometrical isomers of octadecadienoic acid, with two alternating double bonds. Rumen bacteria has the unique ability to convert linoleic acid into CLA via an enzymatic isomerase reaction, and therefore at least 28 possible isomers of linoleic acid as a naturally occurring trans fat are possible, and it is commonly found in ruminant animal sources such as beef, lamb, and dairy products (e.g., milk and cheese) [70]. Incidentally this is also where the concentrations are highest -beef, lamb, and dairy products [71-73]. Seafood, pork, most poultry products and vegetable oils are not notable sources of $\operatorname{CLA}[72,73]$. CLA has also 
been identified as occurring naturally in foods such as white button mushrooms [74] and pomegranate seed oil [73].

In addition to ingestion through ruminant food products, CLA is commercially available as a dietary supplement, prominent isomers are cis-9, trans-11-cLA and trans-10, cis-12-cLA, but cis-9, trans-11 accounts for 72-94\% of total CLA in foods $[9,72]$. There is emerging evidence that individual CLA isomers may be responsible for specific biological or biochemical changes in the body [75].

Numerous studies have reported positive effects of cLA consumption, including weight loss in obese individuals [76], modulation of immune function $[77,78]$, anti-carcinogenic activity [79], protection against atherogenesis [80, 81], reversal of atherosclerosis [82], and normalization of glucose and insulin homeostasis in pre-diabetic animal models [83, 84]. However, recent studies from our lab suggest that cLA lowers survival in a murine model of myocardial ischemia, causing life threatening spontaneous ventricular tachycardia (VT) and sudden cardiac death (SCD) (Fig. 1). In addition, we have previously shown that cLA treatment lowers physiological nitric oxide (NO) levels and impairs heart function in aged mice [85]. 


\section{E. Heme oxygenase-1 in cardiovascular disease}

Recent literature suggests that dietary $\operatorname{cLA}$ and nitrite supplementation in rodents elevates nitrated-cLA $\left(\mathrm{NO}_{2}-\mathrm{CLA}\right)$ levels in the plasma and tissues, inducing heme oxygenase-1 (HO-1) expression in the target tissue [86]. $\mathrm{HO}-1$ catalyzes the oxidation of heme, producing biliverdin, iron, and carbon monoxide (CO) $[87,88]$. Importantly, biliveridin is converted to bilirubin, a known potent antioxidant. Additionally, iron can be sequestered by ferritin, leading to off target anti-apoptotic effects and carbon monoxide has similar characteristics to nitric oxide, facilitating numerous biological functions including anti-inflammatory effects [88-90]. Induction of $\mathrm{HO}-1$ is considered an important cardioprotective response in the failing heart that reverses pathological LV remodeling, and this effect is mediated through inhibition of apoptosis [90]. Increased expression and activity of HO-1 represents a therapeutic strategy for amelioration of LV failure [90]. It has been shown that induction of $\mathrm{HO}-1$, eliminates inflammatory response and apoptotic events after MI [91]. HO-1 increases oxidative stress resistance and eliminates apoptosis [92]. Apoptosis consists of multiple mechanisms during heart failure that produces increased activity of extrinsic pathways of cell death [93]. HO-1 becomes a very important part of treatment to reduce apoptosis after MI. 


\section{CHAPTER II}

\section{HYPOTHESIS AND SPECIFIC AIM}

\section{Overall aim}

$\mathrm{MI}$ affects over five million individuals in the US and remains a significant and yet unsolved health problem. MI results in an insufficient blood supply to cardiac tissue resulting in myocardial cell death and fibrosis [12, 94, 95]. MI is characterized by significant changes in gene expression, many of which represent adaptive or maladaptive responses to stress [16-20]. p53 is a wellknown transcription factor which mediates apoptosis by activating the manifestation of pro-apoptotic genes [96]. Thus, p53 becomes an important therapeutic target, with regard to attenuation of cardiac apoptosis and consequent heart failure.

Recent literature suggests that dietary conjugated linoleic acid (cLA) and nitrite supplementation in rodents elevates nitrated $\mathrm{CLA}\left(\mathrm{NO}_{2}-\mathrm{CLA}\right)$ levels in the plasma and tissues, inducing heme-oxygenase-1 (HO-1) expression in the target tissue [86]. HO-1 has anti-apoptotic effects and facilitates numerous biological functions including anti-inflammatory effects [88-90]. In addition, miRNA-499, a 
cardiac specific microRNA, can attenuate apoptosis via regulation of the p53 pathway [57]. Present data indicates that co-treatment with CLA and nitrite is cardio-protective through increased expression of miRNA-499 and HO-1, although the mechanism is unclear [97]. 


\section{HYPOTHESIS}

Co-treatment with CLA and nitrite is protective in heart failure through induction of HO-1 expression in cardiac tissue, leading to regulation of miRNA-499 expression and a reduction of myocyte apoptosis.

To address this hypothesis, this work will examine two aspects of the mechanism(s) involving HO-1 mediated miRNA-499 upregulation and heart function improvement following MI.

Two specific aims are proposed to test this hypothesis:

Specific aim 1: To determine whether the co-treatment with $C L A$ and nitrite protects heart function in mice following MI.

Hypothesis: Co-treatment with $\mathrm{CLA}$ and nitrite reduces LV volume and diameter in mice following MI.

Specific aim 2: To determine whether co-treatment with $C L A$ and nitrite increases HO-1 level in cardiac tissue, thereby increasing miRNA-499 and inhibiting p53-induced apoptosis.

Hypothesis: HO-1 expression increases miRNA-499 and provides a cardioprotective effect. 
CHAPTER III

\section{MATERIALS AND METHODS}

\section{A. Materials:}

CLA (cis-9, trans-11 was purchased from NU-CHEKPREP, INC (Elysian, MN). Antibody against 4 Hydroxynonenal was purchased from Abcam (Burlingame, CA). Antibody against GAPDH was purchased from Trevigen, (Gaithersburg, MD), antibody against p53 was purchased from Calbiochem, (Billerica, MA) and antibody against $\mathrm{HO}-1$ was purchased from Stressgen Biotechnologies, (Farmingdale, NY). TUNEL assay kit was purchased from Promega (Fitchburg, WI).

\section{B. Animals:}

Mice were fed standard chow and water ad libitum. All animal procedures were reviewed and approved by an independent Institutional Animal Care and Use Committee of the University of Louisville, School of Medicine. In addition, all studies were performed in accordance with animal care and use guidelines of the National Institutes of Health. 


\section{Mouse model of MI:}

Male C57BL/6 mice, 10- to 12-wks old, were anesthetized with isoflurane, intubated and ventilated with CWE advanced ventilator (Webster,TX). Body temperature was maintained with an Indus Temperature feedback/surgical table and ECG system. Aseptic procedure was used for preparation of the surgical site through scrubbing with a $0.8 \%$ chlorhexidine solution. A left thoracotomy was performed via the fourth intercostal space and the lungs retracted to expose the heart. After opening the pericardium, the left anterior descending (LAD) coronary artery was ligated with an 8-0 silk suture near its origin between the pulmonary outflow tract and the edge of the atrium. Ligation was deemed successful when the anterior wall of the left ventricle (LV) became pale in color. The lungs were inflated by increasing positive end-expiratory pressure, and the thoracotomy side was closed in layers. The lungs were re-expanded, and the chest was closed. The animals were removed from the ventilator and allowed to recover on a heating pad. Mice were checked daily for signs of pain or distress and buprenorphine at $0.05 \mathrm{mg} / \mathrm{kg} \mathrm{SQ}$ is given before and every $12 \mathrm{~h}$ for 48 hours. Mice

were treated with $\mathrm{CLA}(10 \mathrm{mg} / \mathrm{kg} / \mathrm{d}$-via osmotic mini-pump) or $\mathrm{cLA}+$ nitrite (50ppm-drinking water) 3 days prior to ligation of the LAD artery and treatment continued 10 days after ligation (Fig.2). 


\section{Measurement of Cardiac function:}

\section{Echocardiography:}

Mice were anesthetized with inhaled isoflurane and chest hair removed for baseline pre-MI and 10 days post-MI. Ultrasounds were obtained using a VisualSonics Vevo 2100 and a $40 \mathrm{MHz}$ linear probe. Wall thickness and left ventricular cavity size were measured in at least 3 beats from each projection and averaged. Interventricular septum and posterior wall thickness, as well as internal dimensions at diastole and systole were measured. In addition, LV fractional shortening, relative wall thickness, and LV mass were calculated from the M-mode measurements [98].

\section{In vivo hemodynamic measurements:}

Isoflurane was used to anesthetize the mouse and conductance readings were made for $\sim 15-20$ min prior to harvesting heart tissue. Briefly, the mouse was placed in a supine position on a $37^{\circ} \mathrm{C}$ pad under the surgical microscope and the limbs were restrained with tape. A $0.5 \mathrm{~cm}$ skin incision was performed in the right neck area and the carotid artery was isolated using silk sutures. The cranial aspect of the carotid artery was ligated and a microsurgical clip was placed on the proximal carotid artery for hemostasis. An arteriotomy was performed with microsurgical scissors, and a 1.2 French conductance catheter 
(Transonic, London, ON, Canada) was introduced into the carotid artery and advanced retrograde across the aortic valve into the LV. The catheter was advanced under continuous hemodynamic monitoring to issue proper placement in the LV. The catheter was secured within the carotid artery with the proximal suture. LV pressure-volume loops were recorded in the steady state. Loops were recorded using the iWorks data acquisition software package, and analyzed using the LabScribe2 pressure-volume data analysis software package (iWorks, St. Albans, Vermont).

\section{E. Histology and confocal microscopy:}

Hearts were collected from the mice and thoroughly washed in PBS. Using Peel-A-Way disposable plastic tissue embedding molds (Polysciense Inc, Washington, PA) filled with tissue freezing media (Triangle Biomedical Sciences, Durham, NC), hearts were preserved and stored at $-80 \mathrm{C}$ until analysis. Tissue sections (5 $\mu \mathrm{m}$ in thickness) were made using a Leica CM 1850 Cryocut microtome (Bannockburn, IL, USA). Sections were placed on super frost plus glass slides, air-dried, and processed for Immunohistochemistry (IHC) staining. 


\section{Immunohistochemistry:}

Immunohistochemistry and laser-scanning confocal microscopy were used to visualize Ml-induced changes in p53 and HO-1 expression and localization. Immunohistochemistry was performed on frozen tissue sections using a standard IHC protocol. Primary antibodies were applied overnight (anti-p53, Calbiochem and anti HO-1, Stressgen). Secondary antibodies labeled with Alexa Fluor 488 and Alexa Fluor 568 (Invitrogen, Carlsbad, CA) were applied for protein immunodetection. Stained slides were analyzed for fluorescence using a laser scanning confocal microscope (Olympus FluoView-1000, objective 40X) set at the appropriate filter settings. The total fluorescence (green or red) intensity in 5 random fields (for each experimental sample) was measured with image analysis software (Image-Pro Plus, Media Cybernetics). Fluorescence intensity values for each experimental group were averaged and presented as fluorescent intensity units (FIU).

\section{TUNEL assay:}

LV frozen sections were defrosted, and rehydrated with xylene and graded alcohol series. The sections were stained using the Apoptosis Detection System (Promega, Madison, WI) per the manufacturer's instructions. Briefly, the sections were incubated with terminal deoxynucleotidyl transferase and fluoresceinlabeled dUTP. To identify cardiomyocytes, sections were incubated with mouse 
anti-myosin heavy chain monoclonal antibody (Chemicon International, Temecula, CA). Finally, to identify all nuclei (non-apoptotic and apoptotic), sections were stained with propidium iodide (Sigma-Aldrich, St Louis, MO). The samples were analyzed under a fluorescence microscope. Four sections randomly picked from each of four pieces were analyzed per animal. Cardiomyocyte nuclei were determined by random counting of 10 fields per section. The number of apoptotic nuclei was calculated per 10,000 cardiomyocytes.

\section{F. Real-Time Quantitative PCR:}

Total heart tissue was isolated with TRIzol and RNA was isolated. Complimentary DNA was isolated using oligo (dT) primers (Promega Corporation, Madison, WI) and stored at $-80^{\circ} \mathrm{C}$ until experiments were performed.

Reactions were done using 2000ng/uL cDNA and SYBR Green Master Mix (BioRad Laboratories, Hercules, CA). BioRad CFX Manager (BioRad Laboraties, Hercules, CA) software was used to analyze results. Gene expression was normalized with mRNA expression of 18S. Samples were analyzed in triplicate using $\mathrm{N}=3$ for each independent experiment. 


\section{Primers:}

Mouse ANP:

Forward: 5'-TGACAGGATTGGAGCCCAGAG-3'

Reverse: 5'-AGCTGCGTGACACACCACAAG-3'

Mouse BNP:

Forward: 5'-ATCGGATCCGTCAGTCGTTTG-3'

Reverse: 5'-CCAGGCAGAGTCAGAAACTGGAG-3'

Mouse miRNA-499

Forward: 5'-GGG-TGG-GCA-GCT-GTT-AAG-AC-3'

Reverse: 5'-AGG-CAG-CAG-CAC-AGA-CTT-G -3'

Mouse DRP-1

Forward: 5'-AAA CTC CTA TCA CGC TCA TCA-3'

Reverse: 5'-CTC ATC CTC CAC GCA TCC T-3'

Mouse Bax

Forward: 5'- ATC AGA ACC ATC ATG GGC TGG ACA -3'

Reverse: 5'-AGC CAA TCT TCT TCC AGA TGG TGA -3'

Mouse Bcl-2

Forward: 5'- AAA GCC AGT GTT CCA TGC ACC AAG -3'

Reverse: 5'- CAC ATG GCC GGC ACA CTT AAC ATT -3'

Mouse HO-1

Forward: 5'-TCA GTC CCA AAC GTC GCG GT-3' 
Reverse: 5'-GTC GTG CAG GRG TTG AGC C-3'

Mouse 18S

Forward: 5'- AGA AAC GGC TAC CAC ATC CAA-3'

Reverse: 5'- GGG TCG GGA GGT AAT TT -3'

\section{G. Western Blot analysis:}

Heart tissue homogenate $(100 \mu \mathrm{g})$ was electrophoresed using SDS-PAGE method as previously described [99, 100]. An affinity purified rabbit anti-GAPDH antibody (1:3000) was purchased from Trevigen (Gaithersburg, MD) and p53 (1:1000) (Calbiochem) and HO-1 (1:1000) (Stressgen Biotechnologies) were detected using secondary antibodies.

\section{H. Cardiomyocyte isolation:}

Mouse cardiomyocytes were isolated from the whole heart by Liberase digestion as described previously with some modifications [101]. Briefly, mice were injected intraperitoneally with heparin (300 units) 30 min prior to sodium pentobarbital anesthetization $(5 \mathrm{mg})$. The heart was rapidly excised, placed in 
ice-cold PBS and the aorta was rapidly cannulated with a blunted, 22 gauge needle. The heart was then perfused in retrograde fashion with oxygenated Tyrode's solution maintained at $37^{\circ} \mathrm{C}$ to flush all blood from the coronary vasculature. After 5 minutes, the perfusion solution was exchanged with the Liberase digestion solution and the heart was digested for approximately 8 minutes. The ventricles were then cut off the cannula and placed in the mincing solution in which heart tissue was teased apart with forceps and triturated using a serological pipette until cardiomyocytes were fully dispersed. Cardiomyocytes were passed through a 100 mesh filter to remove any undigested material, an allowed to settle to aspirate most of the mincing solution. The cardiomyocytes were suspended in re-suspension solution 1 and transferred to a $15 \mathrm{~mL}$ tube and allowed to settle for 10 minutes. This solution was aspirated, along with any unsettled, hypercontracted cardiomyocytes and replaced with re-suspension solution 2 . This process was repeated 5 times with increasing [Ca++] until only rod-shaped cardiomyocytes remained. The cell pellet was then resuspended in culture media and cells were plated on laminin-coated $37 \mathrm{~mm}$ cell culture dishes and incubated at in a $5 \% \mathrm{CO}_{2}$ incubator at $37^{\circ} \mathrm{C}[101]$. 


\section{Cardiomyocyte treatment:}

Once plated, and at the appropriate confluence, cells were incubated with Culture media (500 mL MEM (GIBCO), $5 \mathrm{~mL}$ Insulin-transferrin, selenium (GIBCO), 1\% pen-strep, glutamine 2mM, NaHCO3 4mM, HEPES 10mM, BSA

$0.2 \%, \mathrm{BDM} 1 \mathrm{mg} / \mathrm{ml}$ ) for $24 \mathrm{~h}$. The cells were then treated with $\mathrm{MeOH}$ or 2.5 and $5 \mu \mathrm{M}$ cLA and nitrite [85].

\section{J. Statistics:}

Data are shown as mean \pm SEM. The $n$ values represent the number of independent experiments. Each experiment was performed in triplicate unless otherwise indicated. P values were calculated by Student's t-test or by one-way or two-way ANOVA, followed by Bonferroni analysis using GraphPad Prism software. A P value $<0.05$ was considered statistically significant. 


\section{CHAPTER IV}

\section{SPECIFIC AIM 1}

Specific aim 1: To determine whether the co-treatment with $C L A$ and nitrite protects heart function in mice following MI.

Hypothesis: Co-treatment with $\mathrm{CLA}$ and nitrite reduces LV volume and diameter in mice following MI. 
FIGURE 1

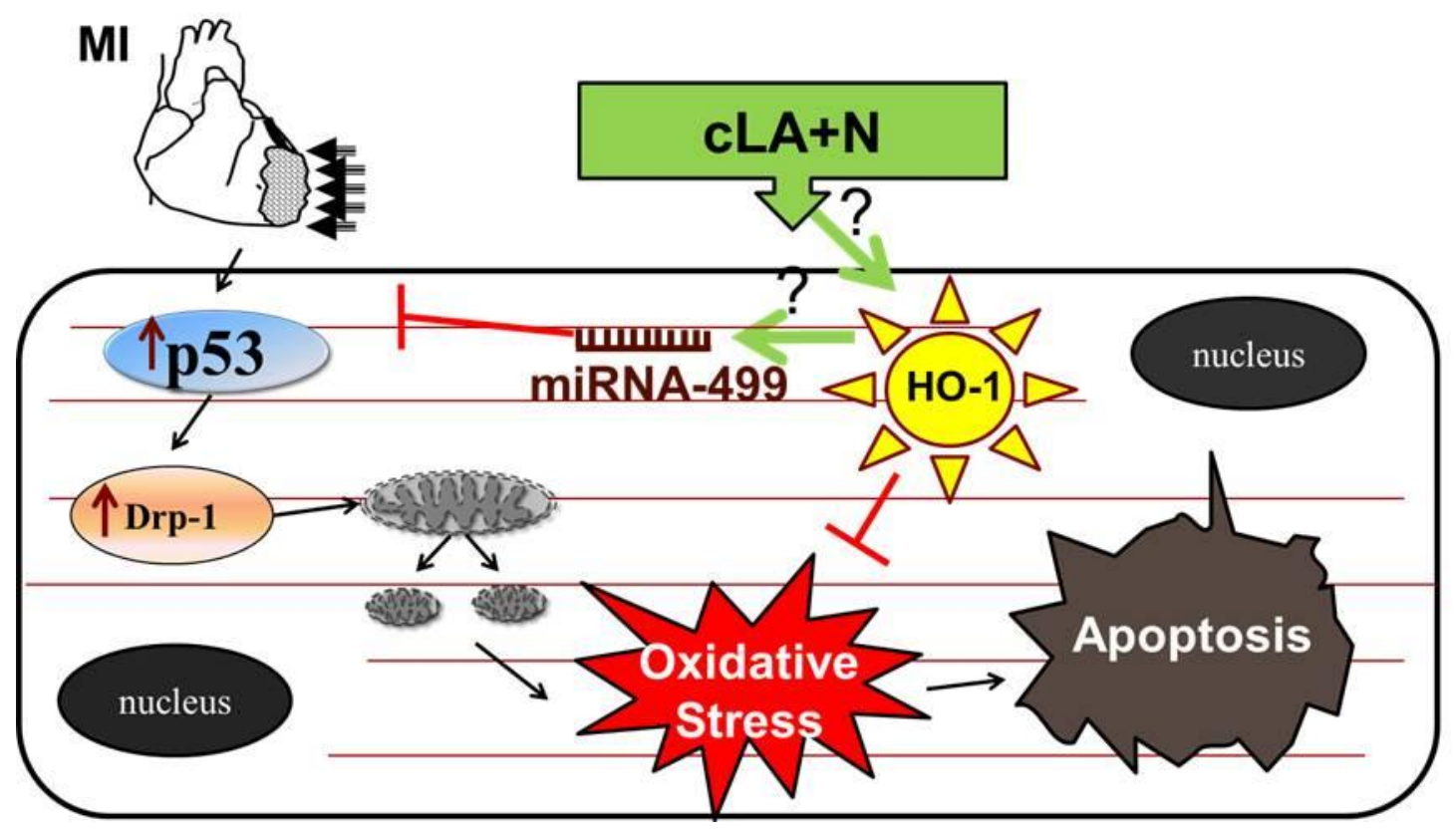

Figure 1: Schematic diagram of overall hypothesis. Co-treatment with CLA and nitrite may enhance levels of $\mathrm{HO}-1$ in heart tissue, leading to regulation of miRNA-499 and thus protecting heart from failure through induction of myocyte apoptosis. 


\section{Introduction}

$\mathrm{MI}$, a result of coronary artery occlusion, is a major healthcare problem within the United States [4]. According to the CDC, the most common type of heart disease is coronary artery disease, which commonly leads to $\mathrm{Ml}$, approximately 720,000 people annually within the United States present clinically with $\mathrm{MI}$, and the subsequent costs exceed $\$ 108.9$ billion. Current therapies for coronary artery disease are mostly preventative measures, such as healthy diet, exercise, and weight loss, highlighting the need for further research into effective therapies for $\mathrm{Ml}$. Ml results from blockage of a coronary artery leading to insufficient blood supply to cardiac tissue, ultimately resulting in cardiomyocyte death [15] and cardiac dysfunction [13].

CLA is an $18: 2$ fatty acid isomer of linoleic acid and the cis-9 trans-11 isomer of cLA is the preferential fatty acid substrate for nitration, where nitration occurs only at positions 9 and 12 in vivo [86]. Co-treatment of CLA and nitrite in mice leads to an increase in nitrated-cLA within plasma and urine.

This specific aim examines the effects of CLA with and without nitrite supplementation on cardiovascular injury following MI. Considering the initiative to replace saturated fats with so-called 'healthy fats', to promote overall weight 
loss and maintenance, the health effects of fats such as cLA require investigation. The principal findings demonstrated here, are that CLA is not protective in Ml, but instead worsens survival after MI (Fig. 4). However, supplementation with nitrite in $\mathrm{CLA}-(10 \mathrm{mg} / \mathrm{kg} / \mathrm{d}$-via osmotic mini-pump) treated mice, leads to cardioprotection in MI injury. Specifically, CLA and nitrite cotreatment significantly reduces LV dilatation (Fig. 6-8) after MI and improves heart function (Fig. 6-7).

Atrial natriuretic peptide (ANP) is released from myocardial cells in the atria and in some cases the ventricles in response to volume overload and conceivably increased wall stress [102]. Brain natriuretic peptide (BNP) is initially identified in the brain but released primarily from the heart, particularly the ventricles [103]. The release of both ANP and BNP is increased in heart failure $(\mathrm{HF})$, as ventricular cells are recruited to secrete both ANP and BNP in response to the high ventricular filling pressures [103].

4-HNE is a major and toxic aldehyde generated by free radical attack on $\omega-6$ polyunsaturated fatty acids (arachidonic, linoleic, and linolenic acids) [104] and is considered a toxic messenger of oxygen free radicals [102, 103]. 4-HNE undergoes many reactions with various proteins, peptides, phospholipids, and nucleic acids; 4-HNE has a high biological activity and displays numerous cytotoxic, mutagenic, genotoxic, and signal effects [102, 103, 105], including inhibition of protein and DNA synthesis, inactivation of enzymes, modulation of platelet aggregation, and variety of the expression of numerous genes [104, 105]. 
In addition, 4-HNE may be an important mediator of oxidative stress-induced apoptosis [104], cellular proliferation, and signaling pathways. CLA and nitrite supplementation ameliorates MI induced oxidative stress and supports cardioprotection in this MI model (Fig. 9). Overall, CLA and nitrite mediate protection and result in improved heart function following MI. 


\section{Results:}

\subsection{ST-segment elevation is an early marker of MI}

ECG was recorded during surgery, Fig. 3 A was recorded before surgery;

Fig. 3 B was recorded after Ml surgery. ST-segment elevation was recorded as an early sign of MI. After persistent ST-segment elevation on ECG, mouse chest was closed and moved to cage for recovery.

\subsection{Combination treatment with cLA and nitrite improves survival in MI mice}

Co-treatment of CLA and nitrite increased survival following MI. Survival in MI mice without treatment was between $70-80 \%$ and decreased to $35-40 \%$ with cLA treatment. Survival following MI was improved with co-administration of CLA and nitrite (Fig. 4).

\subsection{Co-administration of CLA and nitrite increases heart weight and reduces}

\section{LV volume}

Co-treatment of CLA and nitrite increased heart weight following MI. Hearts isolated from Ml (10 days) and treated mice were found to be enlarged, with ventricular dilatation caused to increase EDV (Table 1). The heart weight / tibia length ratio was significantly increased in $\mathrm{Ml}$ and single treated mice compared to control hearts, where co-administration CLA and nitrite was significantly higher than $\mathrm{Ml}$ hearts with or without single treatment (Fig. 5). 


\subsection{Co-treatment with CLA and nitrite improve LV function following MI}

$\mathrm{Ml}$ is characterized by ventricular chamber dilation and dysfunction (Table 1). We observed a significant rightward shift of the PV loop in $\mathrm{MI}$ and single treated mice (Fig. 7). Chamber dilation also resulted in significant increase in both end-systolic and end-diastolic volume (Fig. 7, Table 1). As shown in Fig. 7, invasive hemodynamic measurements showed a reduction in EF in $\mathrm{Ml}$ vs. the control groups (Fig. 7, Table 1). Treatment did not change EF in control animals (Fig. 7, Table 1). However, co-administration with CLA and nitrite shifted PV-loop to the left compared to MI PV-loop, indicating that the overall heart function is improved in CLA and nitrite-treated mice following MI.

Ultrasound showed similar changes in MI mice. LV end diastolic and endsystolic diameters were increased in mice, which caused LV Fraction Shortening (FS) reduction (Fig. 6). Treatment with CLA and nitrite improved LV function. FS was improved from $23 \%$ to $42 \%$ (Fig. 6).

\subsection{Co-administration of CLA and nitrite eliminates MI induces oxidative stress in LV ventricle after MI}

4-HNE is an indicator of lipid peroxidation and protein damage, and is considered to be a second toxic messenger of ROS [106]. There was brown pigmentation in tissue section from MI mice, which was a stain marker of 4-HNEpositive cells (Fig. 8). Brown spots were ameliorated in mice treated with CLA and 
nitrite, meaning oxidative stress was reduced in mice treated with $\mathrm{CLA}$ and nitrite following Ml (Fig. 8).

\subsection{Co-treatment with cLA and nitrite eliminates apoptosis in ischemic zone} of MI

TUNEL staining was used to detect apoptosis in LV of control, MI mice treated with or without CLA and nitrite. Apoptosis was detected in MI and single treated MI mice on ischemic part of LV (Fig. 9). Apoptosis was not visible in MI and single treated MI mice on non-ischemic part of LV (Fig. 9). Apoptosis was eliminated in MI mice treated with CLA and nitrite on ischemic zone of LV (Fig. 9). TUNEL staining did not stain the tissue from control mice (Fig. 9).

\subsection{Co-administration of CLA and nitrite decreases ANP and BNP- markers} for heart failure after MI

Ml drastically increased ANP and BNP expression in heart, molecular markers of heart failure, by 4.2 and 3.4 fold, respectively (Fig. 10). However coadministration of $\mathrm{CLA}$ and nitrite eliminated ANP and BNP expression following MI (Fig.10). Single treatment did protect heart from failure, as well as heart failure markers, ANP and BNP were increased by 4.2 and 2.9 fold respectively (Fig. 10). 
FIGURE 2

\section{Experimental Study Design}

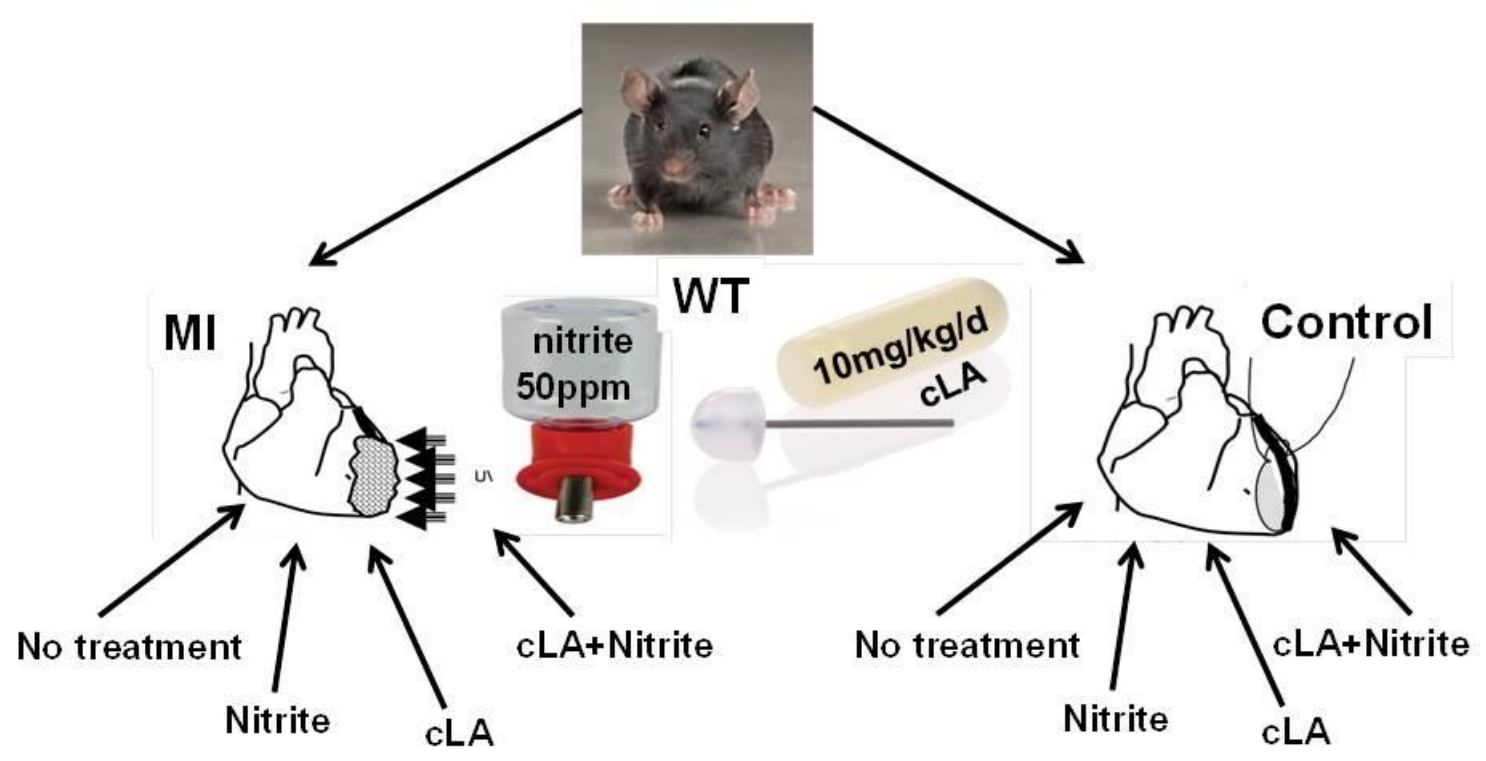

Figure 2: Experimental study design. Mice were treated with CLA, nitrite, and cLA and nitrite 3 days prior to Ml surgery. On day $3, \mathrm{Ml}$ surgery was induced and after 10 days PV-loop analysis was performed. Mice were killed and tissue was collected for additional analysis. 


\section{FIGURE 3}

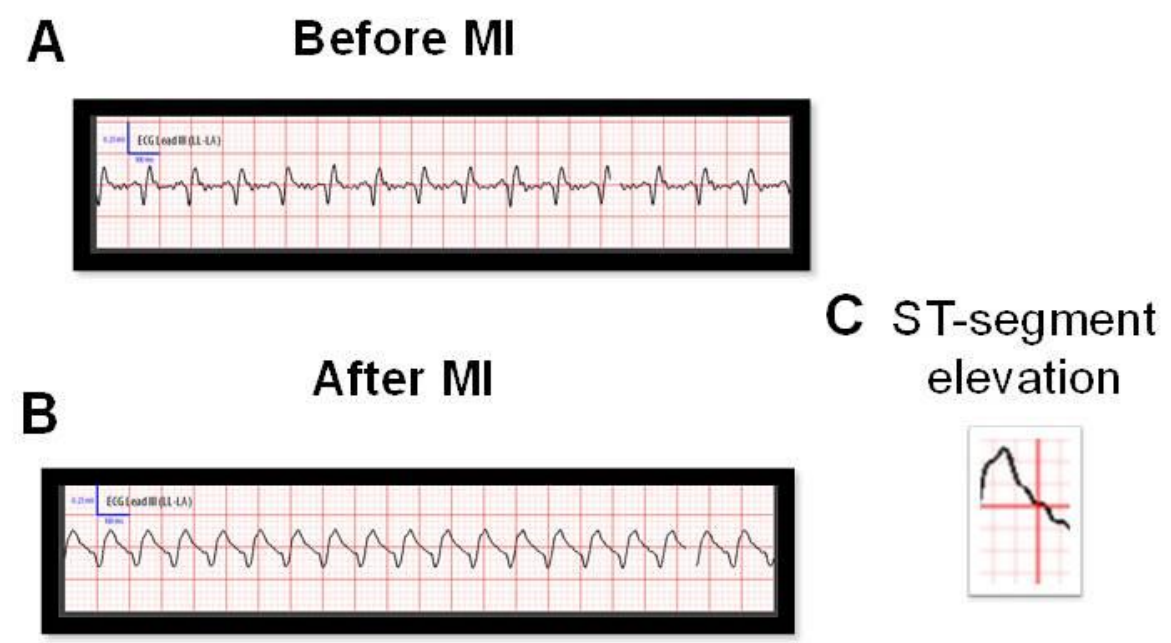

Figure 3: ST segment elevation is an early marker of MI. ECG was recorded during MI surgery. A. ECG recorded before the MI surgery, B. ECG recorded during the Ml surgery. C. Example of ST segment elevation. ST-segment elevation was the marker of successful coronary artery ligation. After STsegment elevation on ECG, the chest was closed and mouse was placed on a warming pad in the home cage for recovery. 
FIGURE 4

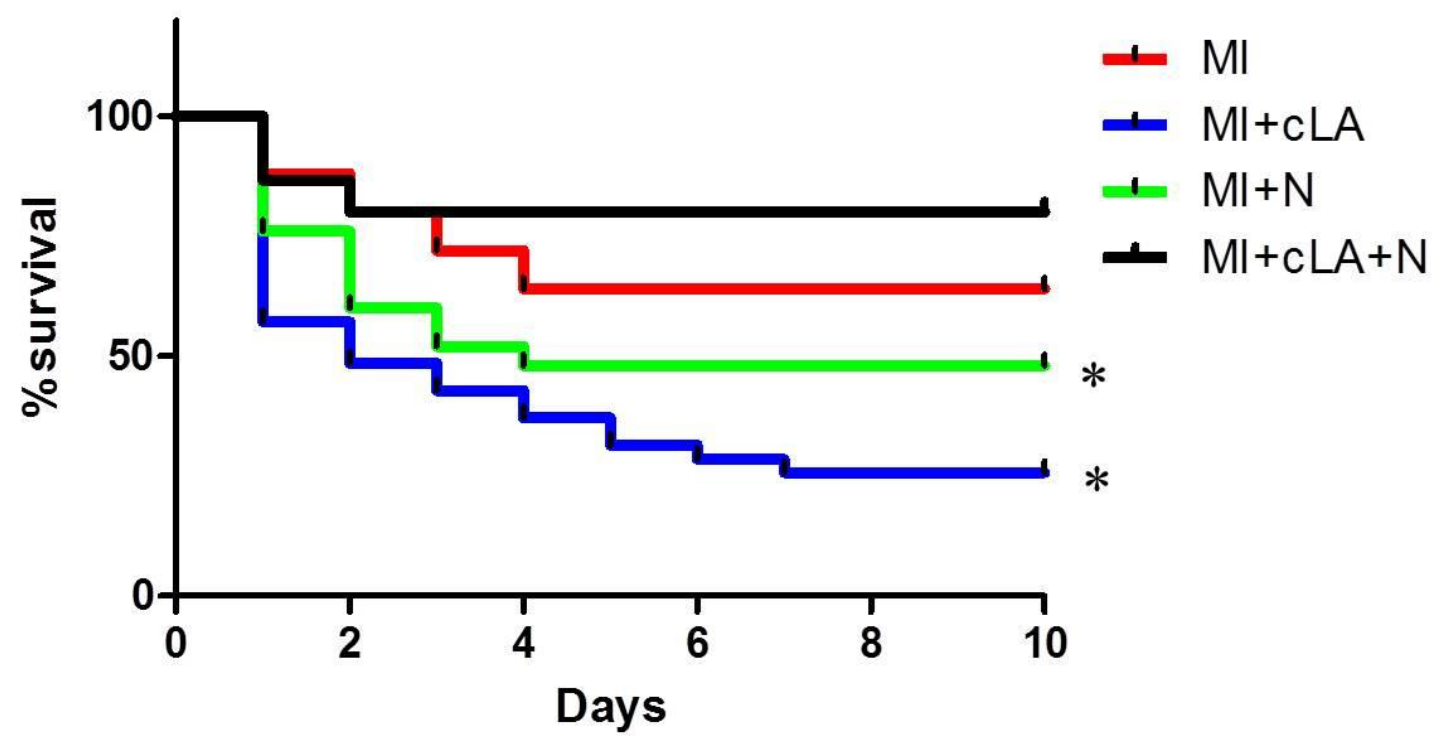

Figure 4: Co-treatment with $\operatorname{cLA}$ and nitrite increases survival in mice following MI. Survival was increased in $\mathrm{CLA}$ and nitrite treated mice following MI compare to single treated $\mathrm{MI}$ mice $\left({ }^{\star} p<0.05\right.$ to $\mathrm{MI} \operatorname{cLA~N}, \mathrm{n}=24$ per group). 


\section{FIGURE 5}

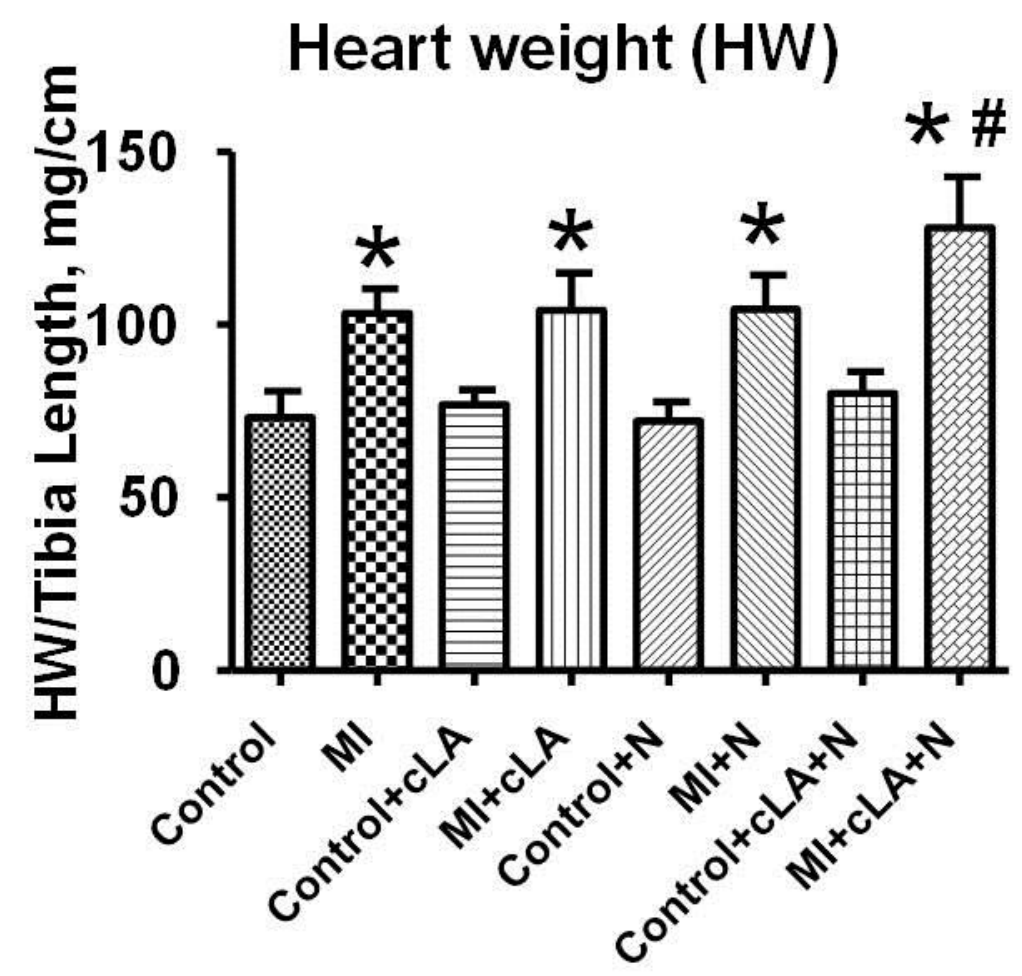

Figure 5: Co-treatment with CLA and nitrite increases heart weight following Ml. Heart weight was significantly increased following CLA or nitrite following $\mathrm{MI}$, or in $\mathrm{MI}$ alone. CLA and nitrite co-treatment resulted in a further increase in heart weight, which was significant compared to $\mathrm{Ml}$ alone. $\left({ }^{\star} p<0.05\right.$ to control, $\# p<0.05$ to $\mathrm{MI}, n=24$ per group) 


\section{FIGURE 6}
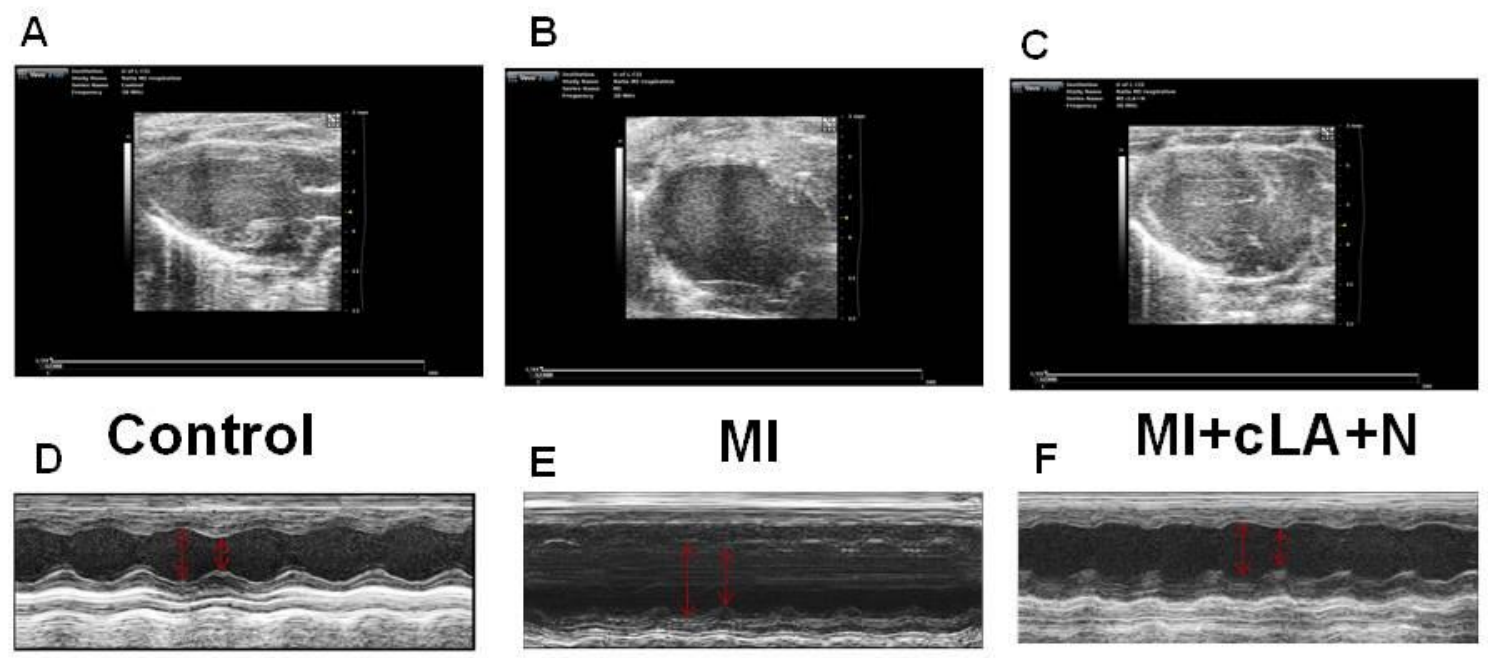

FS $52 \pm 1.7 \%$

FS $23 \pm 2.3 \%$ *

FS $42 \pm 3.2 \% * \#$

G

$F S=\frac{(\text { LVEDd-LVESd) }}{\text { LVEDd }}$

Figure 6: Co-treatment with cLA and nitrite improves LV fraction shortening in mice following MI. A and D illustrate control mouse heart in B-mode and Mmode respectively. B and $\mathbf{E}$ illustrate $\mathrm{MI}$ mouse heart in B-mode and $\mathrm{M}$-moderespectively. $\mathbf{C}$ and $\mathbf{F}$ illustrate $\mathrm{MI}$ mouse heart treated with $\mathrm{CLA}$ and nitrite in $\mathrm{B}$ mode and M-mode respectively. G illustrates formula - how to calculate FS. ( ${ }^{\star} p<0.05$ to control, ${ }_{\#} p<0.05$ to $\mathrm{Ml}, n=24$ per group) 


\section{FIGURE 7}

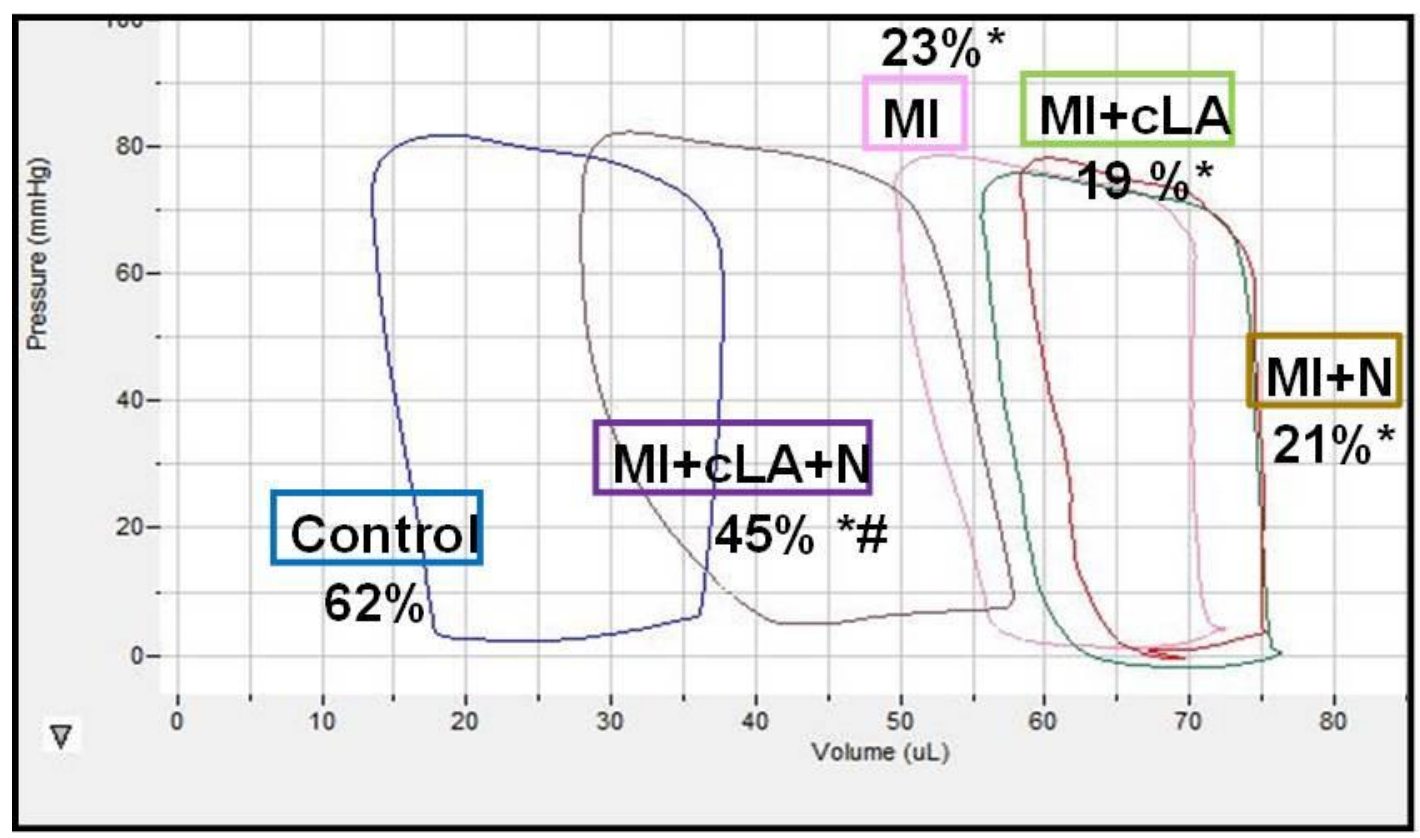

Figure 7: Co-treatment with cLA and nitrite significantly improves cardiac function after MI. Treatment with CLA exacerbated cardiac injury after MI, where combination treatment (supplementation with nitrite) rescued heart function following MI. ( ${ }^{*} p<0.05$ to control, ${ }_{\#} p<0.05$ to $\mathrm{MI}, n=10$ per group). 


\section{FIGURE 8}

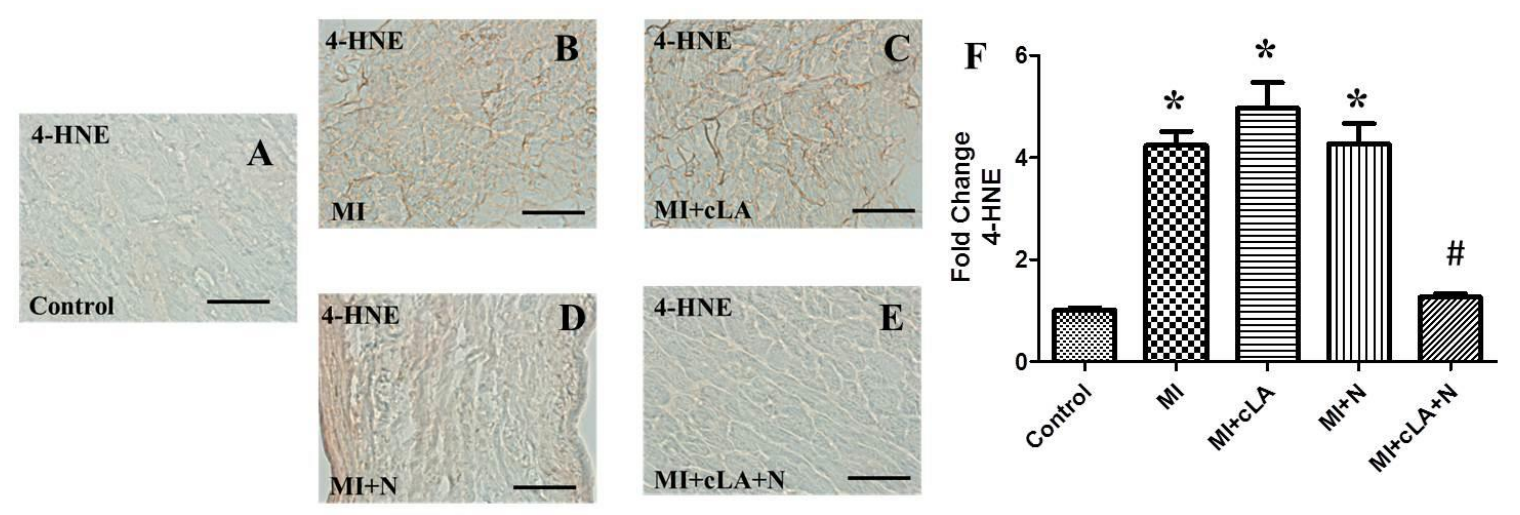

Figure 8: Co-treatment with CLA and nitrite reduces oxidative stress following MI. A. represents control heart tissue, where 4-HNE-brown pigment was not expressed. B, C, and $\mathbf{D}$ represent tissue from $\mathrm{MI}$ and single treated mice with CLA or nitrite, brown pigment stain-4-HNE was highly expressed in those samples. E represents tissue from the MI mouse heart, which was treated with cLA and nitrite, brown pigmentation-4-HNE was eliminated in this sample. F represents quantification using Adobe Photoshop. ( ${ }^{*} p<0.05$ to control, ${ }_{\#} p<0.05$ to MI, $n=10$ per group). 


\section{FIGURE 9}

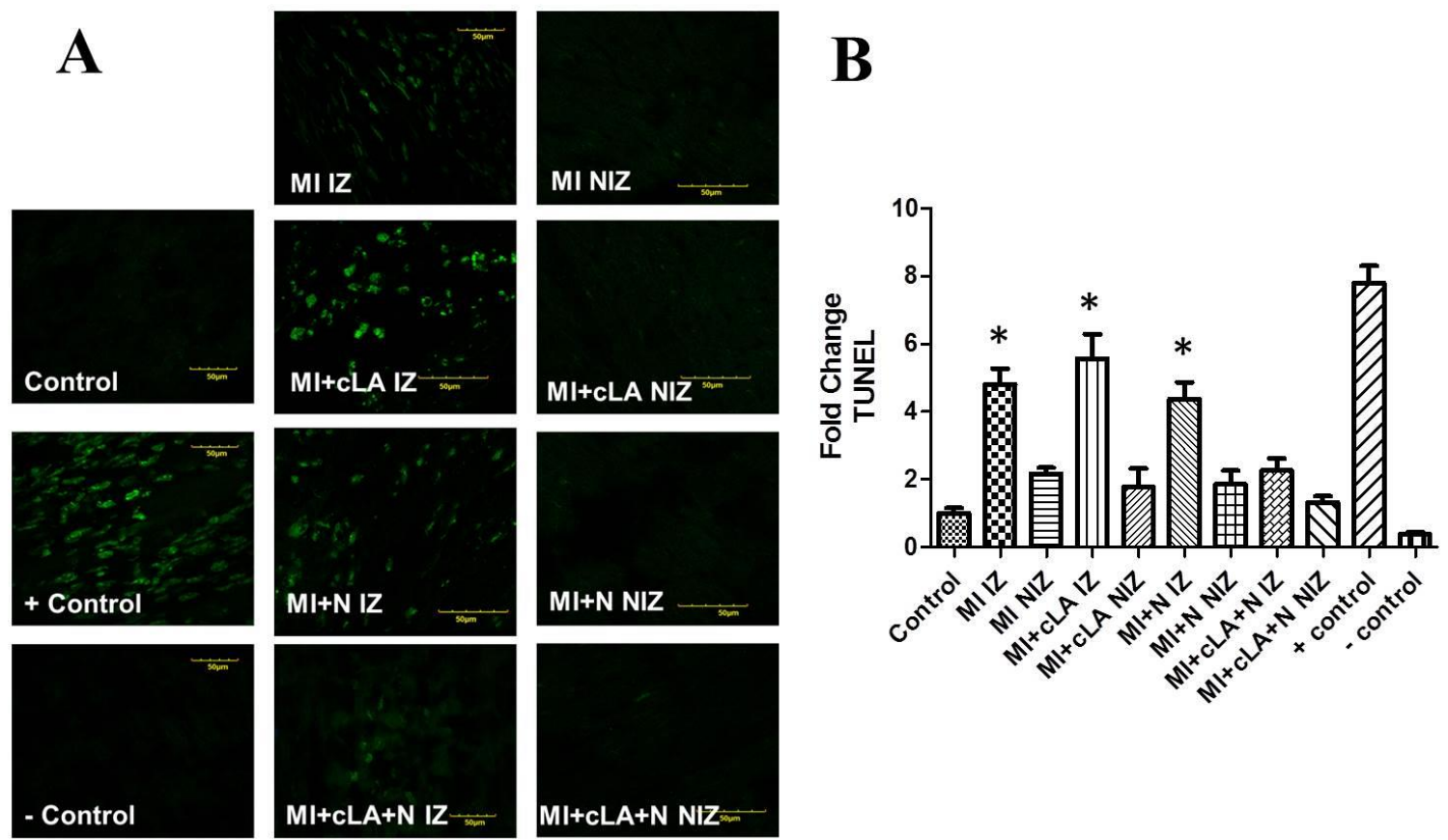

Figure 9: Co treatment with cLA and nitrite attenuates myocyte apoptosis following MI. Apoptosis was detected on tissue using TUNEL staining. Pictures were collected from ischemic zone (IZ) and from non-ischemic zone (NIZ) in MI mice. A represents confocal images from experimental groups, and $\mathbf{B}$ represents quantification using Adobe Photoshop. ( ${ }^{*} p<0.05$ to control, $n=6$ per group). 
FIGURE 10

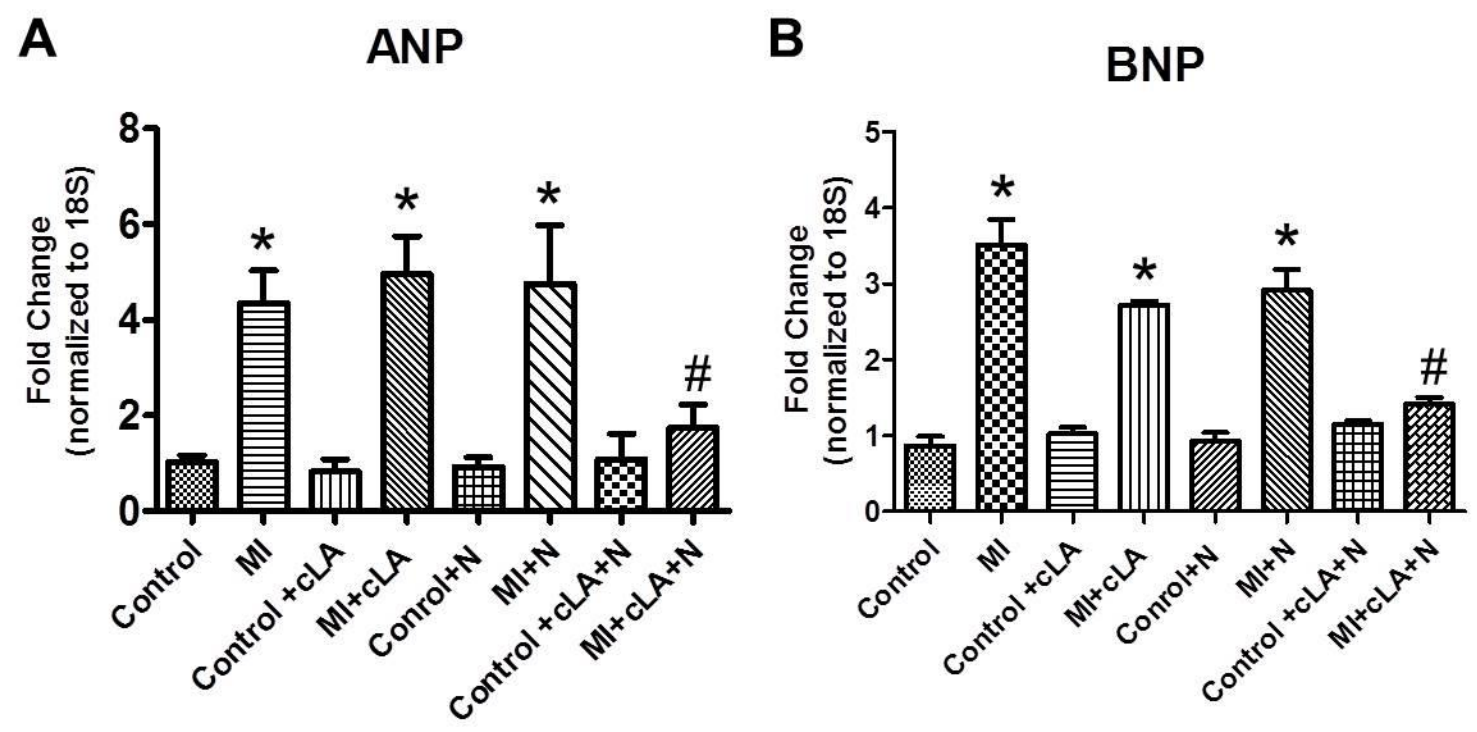

Figure 10: Co-treatment with CLA and nitrite ameliorates heart failure markers following MI. relative fold changes of (A) ANP and (B) BNP expression in mouse hearts. ANP-atrial natriuretic peptide; BNP- B-type natriuretic peptide. ( ${ }^{\star} p<0.05$ to control, $\# p<0.05$ to $\mathrm{Ml} ; n=6$ per group). 


\section{TABLE 1}

\begin{tabular}{|c|c|c|c|c|c|c|c|c|}
\hline & HR & ESP & EDP & ESV & EDV & SV & $\mathrm{CO}$ & EF \\
\hline & BPM & $\mathrm{mmHg}$ & $\mathrm{mmHg}$ & $\mathrm{uL}$ & $\mathrm{uL}$ & $\mathrm{uL}$ & $\mathrm{ul} / \mathrm{min}$ & $\%$ \\
\hline Control & $552 \pm 1.79$ & $80.88 \pm 0.49$ & $6.95 \pm 0.67$ & $15.43 \pm 0.37$ & $40.66 \pm 1.72$ & $25.23 \pm 1.53$ & $13926.93 \pm 449.70$ & $62.05 \pm 2.13$ \\
\hline Ml & $555.78 \pm 8.67$ & $78.36 \pm 3.72$ & $2.73 \pm 1.25^{\wedge}$ & $55.43 \pm 3.72$ * & $72.77 \pm 2.40$ * & $17.66 \pm 3.72$ * & $9800.19 \pm 1218.05$ * & $23.00 \pm 4.17$ * \\
\hline$M l+c L A$ & $546.82 \pm 4.30$ & $79.80 \pm 9.78$ & $2.83 \pm 2.55^{\wedge}$ & $60.90 \pm 2.34$ * & $75.40 \pm 0.47$ * & $14.51 \pm 2.19$ * & $7644.82 \pm 1008.05$ * & $19.66 \pm 1.88$ * \\
\hline $\mathrm{Ml}+\mathrm{N}$ & $538.98 \pm 12.14$ & $75.75 \pm 0.85$ & $3.77 \pm 0.10$ & $59.21 \pm 4.57$ * & $75.46 \pm 3.89$ * & $16.23 \pm 1.93$ * & $8608.74 \pm 1898.04^{*}$ & $21.35 \pm 2.46$ * \\
\hline $\mathrm{Ml}+\mathrm{CLA}+\mathrm{N}$ & $556.82 \pm 4.30$ & $85.79 \pm 0.75$ & $10.26 \pm 3.26$ & $30.90 \pm 2.34$ *\# & $56.90 \pm 2.34$ *\# & $26.56 \pm 2.36 \#$ & $14767.36 \pm 11213.05$ \# & $45.42 \pm 2.13 * \#$ \\
\hline
\end{tabular}

Table 1: Hemodynamics of $\mathrm{Ml}$ and control mice based on pressure-volume. All values are expressed as mean \pm SD. BPM - beats per minute; ESP - endsystolic pressure; EDP - end-diastolic pressure; ESV - end-systolic volume; EDV- end-diastolic volume, SV - stroke volume; CO - cardiac output; EF ejection fraction; ( ${ }^{*} p<0.05$ to control, $\# p<0.05$ to $\mathrm{Ml}, n=10$ per group). 


\section{Discussion}

Here we examine the effects of CLA with and without nitrite supplementation on cardiovascular injury following MI. Considering the initiative to replace saturated fats with so-called 'healthy fats', to promote overall weight loss and maintenance, the health effects of fats such as CLA require further investigation. The principal findings demonstrated here, are that CLA is not protective in MI, but instead worsens survival following MI (Fig. 4). However, supplementation with nitrite in $\mathrm{CLA}$ (10mg/kg/d-via osmotic mini-pump)-treated mice, leads to improved survival in mice following MI (Fig. 4). Specifically, CLA and nitrite co-treatment significantly decreases MI induced ANP and BNP mRNA levels following MI (fig. 10). Co-treatment with $\mathrm{CLA}$ and nitrite also decreases oxidative stress - 4-HNE expression following MI (Fig. 8). Overall, CLA and nitrite mediate protection and result in improved heart function and reduced LV volume in this murine model of MI (F. 6,7 and Table 1).

Previous studies reported the correlation between hemodynamics and neurohumoral factors such as plasma cardiac natriuretic peptides, and plasma levels of ANP and BNP were thought to be a hemodynamic predictor in patients with CHF [105]. It is well known that plasma levels of ANP and BNP are markedly increased in patients with acute $\mathrm{Ml}$ as well as in those with congestive heart failure [107, 108]. Our study shows increased ANP following MI and in single

treated mice, which was lowered in CLA and nitrite treated mice (Fig. 10). Our physiological data demonstrates similar correlation with ANP and BNP, it shows 
LV dilatation in $\mathrm{MI}$ and single treated mice, LV volume and diameter is decreased in CLA and nitrite treated MI mice (Fig 7, Table 1).

A prominent lipid peroxidation product, 4-HNE, can be cytotoxic and is generated during various physiological and pathophysiological conditions based on the generation and cellular location of ROS $[109,110]$. 4-HNE is also known as a measure of oxidative injury $[111,112]$. Consequently, $4-\mathrm{HNE}$ has biological relevance and displays a number of cytotoxic, mutagenic, genotoxic and further signal effects $[113,114]$. Our data shows that 4-HNE was increased in $\mathrm{Ml}$ and $\mathrm{MI}$ treated with CLA or nitrite mice, however oxidative stress was reduced after combination treatment with $\mathrm{CLA}$ and nitrite. CLA and nitrite supplementation ameliorates MI induced oxidative stress and supports cardioprotection in this MI model (Fig. 8). Overall, CLA and nitrite mediate protection and result in improved heart function following MI.

Many studies have shown that TUNEL staining of nuclei to conclude that apoptosis occurs following MI [115]. The presence of apoptotic nuclei suggested that apoptosis was present in all cells in acute $\mathrm{MI}$ as a primary form of cell death [42]. LV remodeling during $\mathrm{MI}$ is characterized by progressive LV chamber dilation and systolic and diastolic dysfunction [116-118]. The LV remodeling involves cellular and molecular mechanisms at the site of infarction and the surviving unaffected area [119]. Myocyte apoptosis occurs in the ischemic zone of myocardium post MI [15, 34]. The amount of apoptotic myocytes correlates with an increase in the ventricular diameter after MI [119]. Apoptosis in the 
infarcted area of myocardium plays a big role in LV remodeling after $\mathrm{MI}$ in mice [99]. Overall our study demonstrates that apoptosis was increased in $\mathrm{Ml}$ and single treated MI mice, based on TUNEL staining of nuclei, which was reduced after combination treatment with cLA and nitrite (Fig. 9). As observed in our studies where we measured LV volume, TUNEL staining was reduced along with reduction of LV size and volume (Fig. 9, Table 1).

Based on our data we conclude that treatment with CLA and nitrite reduces $L V$ volume and $L V$ size after $M I$, as well as reduces oxidative stress and attenuates apoptosis in ischemic area of myocardium after MI. 


\section{CHAPTER V}

\section{SPECIFIC AIM 2}

Specific aim 2: To determine whether co-treatment with CLA and nitrite increases HO-1 level in cardiac tissue, thereby increasing miRNA-499 and inhibiting p53-induced apoptosis.

Hypothesis: HO-1 expression increases miRNA-499 and provides a cardioprotective effect. 
FIGURE 11

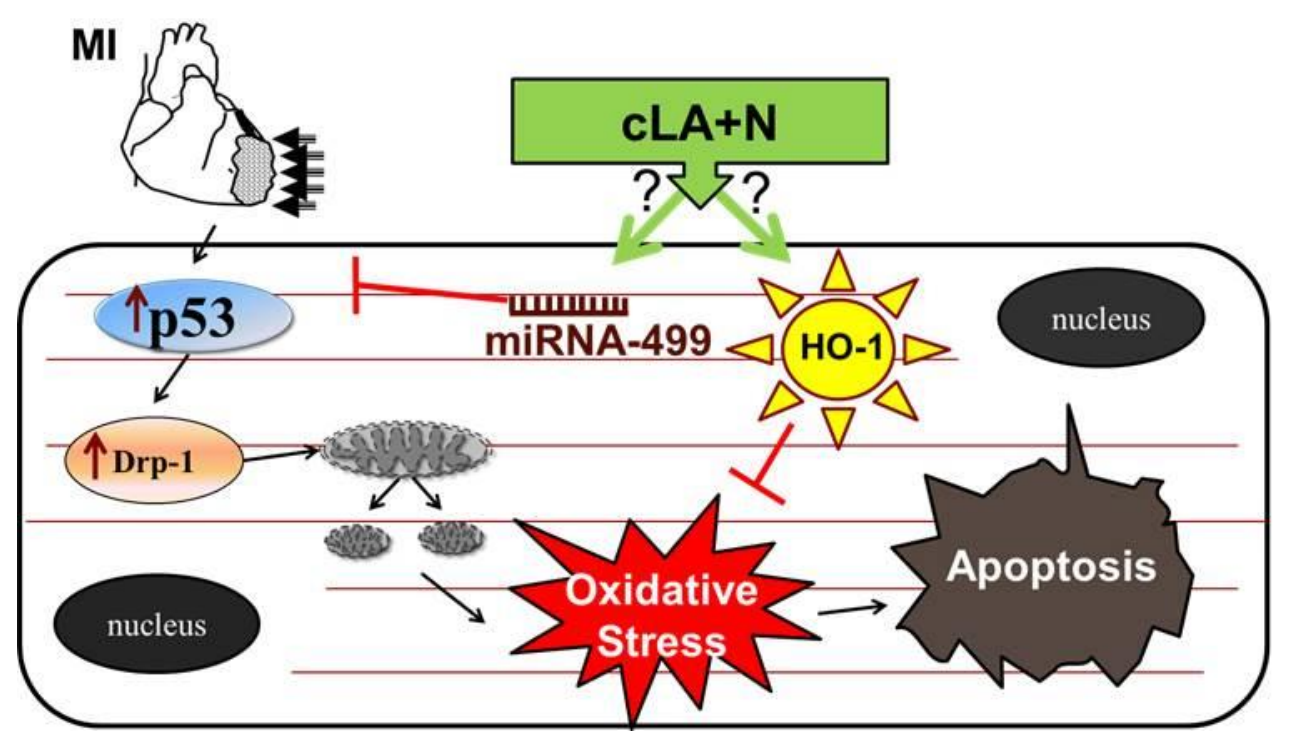

Figure 11: Schematic diagram of specific aim 2 hypothesis. Co-treatment with CLA and nitrite may enhance levels of HO-1 and/or miRNA-499 in heart tissue, leading to regulating oxidative stress and thus protecting heart from failure through induction of myocyte apoptosis 


\section{Introduction}

$\mathrm{MI}$ is characterized by significant changes in gene expression, many of which represent adaptive or maladaptive responses to stress [16-20]. The resulting cardiac stress induces rapid changes in gene expression immediately following MI [21]. Cardiomyocyte cell death is a consequence of myocardial injury, which occurs as early as the initiation of acute MI [22] . Cardiomyocyte death or apoptosis is a key factor in transition from cardiac hypertrophy to heart failure [23]. p53 is a well-known transcription factor which mediates apoptosis by activating the manifestation of pro-apoptotic genes [96]. Previous studies have demonstrated that p53 activity is enhanced during $\mathrm{MI}$ and that p53 plays a critical role in the regulation of hypoxia-induced apoptosis of cardiomyocytes [1, 40] . Thus, p53 becomes an important therapeutic target, with regard to attenuation of cardiac apoptosis and consequent heart failure.

Apoptosis is controlled by several genes and the most crucial regulators are members of the Bcl-2 gene family. Bcl-2 is an anti-apoptotic gene that was first identified in follicular non-Hodgkin lymphoma $[102,104]$. It has the capability to block an inclusive selection of apoptotic signals [103]. Bax is another member of the $\mathrm{Bcl}-2$ family, but compared to $\mathrm{Bcl}-2$ it has an apoptosis-stimulating function [105]. Gene products of the Bcl-2 family can form homo- and heterodimers with 
each other [107]. Therefore, it has been proposed that the cellular Bcl-2/Bax ratio is a key factor in the regulation of apoptosis; a high $\mathrm{Bcl}-2 / \mathrm{Bax}$ ratio makes cells resistant to apoptotic stimuli, while a low ratio induces cell death [108]. The Bax to $\mathrm{Bcl}-2$ ratio is increased in cells induced to die by an apoptotic stimulus [107, 108]. Therefore, the overexpression of Bax after MI may be related to the pathogenesis of apoptosis and congestive heart failure following MI.

MicroRNAs quantitatively regulate mature-RNAs, which affect the cardiac transcriptional output and cardiac function [55]. miRNAs are endogenous, singlestranded non-coding RNAs ranging from 18 to 24 nucleotides in length, that play an important role in gene regulation $[55,56]$. In screening for miRNAs enriched in the heart, we found an abundant miRNA, miRNA-499, which is an evolutionarily conserved muscle-specific microRNA that is encoded within the intron of myosin heavy chain and is highly expressed in the cardiac ventricles [55-57]. Plasma miRNA-499 is known as a biomarker of acute Ml, as plasma miRNA-499 has been observed in individuals with $\mathrm{MI}$ [58].

Studies have shown that diets with diversified fats may be an effective strategy in decreasing risk of cardiovascular disease (CVD) $[120,121]$. Conjugated linoleic acid (cLA) is a fatty acid that occurs as a mixture of positional and geometric isomers of linoleic acid (LA), which is produced in ruminant animals via an enzymatic isomerase reaction [122]. cLA contains 18 carbon atoms with two conjugated double bonds separated by a single bond [123]. CLA is found naturally in food products from these animals predominantly as the cis9,trans-11 form, whereas synthetic CLA preparations consist of a few different 
isomers with an approximately equal amount of cis-9,trans- 11 and trans-10,cis12 cLA $[121,124]$. Select modified fatty acids, such as nitrated fatty acids are known to induce pluripotent anti-inflammatory effects [125]. Recent literature suggests that dietary CLA and nitrite supplementation in rodents elevates $\mathrm{NO}_{2}$ CLA levels in the plasma and tissues, inducing heme oxygenase-1 (HO-1) expression in the target tissue [86]. HO-1 catalyzes the oxidation of heme producing biliverdin, iron, and carbon monoxide (CO) [87, 88]. Importantly, biliveridin is converted to bilirubin, a known potent antioxidant. Additionally, iron can be sequestered by ferritin, leading to off target anti-apoptotic effects and carbon monoxide has similar characteristics to nitric oxide, facilitating numerous biological functions including anti-inflammatory effects [88-90].

Ultimately, heart function is highly dependent on ATP generation. The heart is enriched with mitochondria that provide the energy required for cardiomyocyte function [62]. Therefore, it is known that mitochondria play a critical role in the development and progression of many cardiac diseases such as hypertrophy and MI. Previous studies suggest that mitochondria are highly dynamic and that changes in mitochondrial shape can affect a variety of biological processes such as apoptosis and fibrosis [63, 64]. Mitochondria are dynamic organelles, which constantly undergo fission and fusion [63-65]. These two opposing processes are regulated by the mitochondrial fusion proteins mitofusin and the mitochondrial fission protein Drp-1 [62]. During apoptosis, Drp1 foci accumulates on mitochondria and can enhance mitochondrial fission [66, 67]. 
In the present study an in vivo model of $\mathrm{Ml}$ is used to further elucidate the possible mechanism whereby combination treatment with CLA and nitrite is cardioprotective. Herein we demonstrate that CLA and nitrite significantly induced levels of miRNA-499 in the heart compared to untreated MI mice. Additionally, co-treatment significantly reduced levels of p53 expression and induced expression of HO-1. These results suggest that treatment with CLA and nitrite may provide significant protection during $\mathrm{Ml}$ through regulation of cardiac specific miRNA and upregulation of phase 2 antioxidant enzyme expression. 


\section{Results:}

\section{1 miRNA-499 biomarker of acute MI}

miRNA-499 was measured in isolated hearts from $\mathrm{Ml}$ and control mice after $24 \mathrm{~h}$ and 10 days after MI (Fig. 12). In the control, miRNA-499 almost had undetectable concentrations. Compared to the healthy control mice, miRNA-499 levels were higher in Ml mice after 24h (Fig. 12). Furthermore, the level of miRNA-499 was lowered in MI mice after 10 days compare to MI 24h mice (Fig. 12).

\subsection{Co-treatment of CLA and nitrite regulates miRNA-499 during MI}

To investigate the specific role of miRNA-499 in regulation of improved heart function following MI, miRNA-499 levels were measured in the heart (Fig. 13). miRNA-499 was increased following MI with combination treatment of $c L A$ and nitrite (Fig. 13). There were no significant differences in single treated MI mice or with Ml alone (Fig. 13).

\subsection{Mitochondrial fission factor DRP-1 is significantly increased in mice following MI}

Ml caused a robust increase in Drp-1 expression in MI (Fig. 14). Individual treatments with CLA or nitrite increased expression of Drp-1 compared to control 
mice, but the expression was overall lower than with Ml-induction (Fig. 14). Cotreatment with $\mathrm{CLA}$ and nitrite attenuated Drp-1 expression in MI mice (Fig. 14).

\subsection{CLA and nitrite treatment attenuates p53 expression following MI}

Expression of p53 was defined by immunohistochemical staining of cryosectioned hearts (Fig. 15A). To support the immunohistochemical results that miRNA-499 blocks p53 after co-administration treatment with cLA and nitrite

during Ml, the level of p53 was assessed by Western blot analysis (Fig. 15B). The protein level of p53 was increased following $\mathrm{Ml}$ and in single treated mice, but was abolished after co-treatment with CLA and nitrite (Fig. 15B). The p53 staining support the data obtained via Western blot analysis (Fig. 15B).

\subsection{HO-1 expression increases in MI following cLA and nitrite treatment}

HO-1 expression was increased, as demonstrated using immunohistochemical staining of cryo-sectioned heart tissue (Fig. 15A). To support the hypothesis that co-treatment with CLA and nitrite during $\mathrm{MI}$ induces HO-1 level, the expression of HO-1 was assessed using Western blot analysis (Fig. 15B). Following treatment with $\mathrm{CLA}$ and nitrite, $\mathrm{HO}-1$ protein expression is significantly increased (Fig. 15B). 


\subsection{Co-treatment with cLA and nitrite attenuates pro-apoptotic markers following MI}

The total Bax mRNA level was increased and the Bcl-2 mRNA level was decreased in the $\mathrm{Ml}$ and single treated $\mathrm{Ml}$ mice leading to an induction in the Bax/Bcl-2 ratio (Fig. 16). mRNA level of Bax was increased compared to control, levels were not as high as in $\mathrm{Ml}$ and single treated MI mice (Fig. 16) and mRNA of $\mathrm{Bcl}-2$ was not changed in $\mathrm{CLA}$ and nitrite treated $\mathrm{MI}$ mice. Ratio of $\mathrm{Bax} / \mathrm{Bcl}-2$ was induced in co-treated $\mathrm{MI}$ mice, but was lower than in $\mathrm{MI}$ and single treated mice (Fig. 16).

\subsection{Induction of HO-1 attenuates LV dysfunction in MI mice}

As we mentioned before, $\mathrm{Ml}$ was characterized by ventricular chamber dilation and dysfunction (Table 2). We observed a significant rightward shift of the PV loop in MI mice (Fig. 18). Chamber dilation also resulted in significant increase in both end-systolic and end-diastolic volume (Fig. 18, Table 2). As shown in Fig. 8, invasive hemodynamic measurements showed a reduction in \%EF in MI vs. the control groups (Fig. 18, Table 2). HO-1 Tg mice had decreased \%EF compared to control mice (Fig. 18, Table 2). However, \%EF in HO-1 Tg mice was higher than in WT MI mice (Fig. 8). 
Ultrasound showed similar changes in MI mice. LV end diastolic and endsystolic diameters were increased in mice, which caused LV Fractional Shortening (FS) reduction (Fig. 19). \%FS in HO-1 Tg mice was improved following MI. FS was improved from $23 \%$ to $47 \%$ (Fig. 19).

\subsection{HO-1 attenuates p53 levels in HO-1 Tg mice following MI}

$\mathrm{HO}-1$ protein level was greater in $\mathrm{HO}-1 \mathrm{Tg}$ mice compared to $\mathrm{C} 57$ control mice (Fig. 20). As we demonstrated previously, $\mathrm{HO}-1$ protein level was high in $\mathrm{Ml}$ mice treated with CLA and nitrite. HO-1 protein level expression stayed high in HO-1 Tg mice compared to control HO-1 Tg control mice (Fig. 20). HO-1 protein level was not expressed in $\mathrm{HO}-1 \mathrm{KO}$ mice regardless of treatment (Fig. 20).

From the previously demonstrated blot we saw that p53 protein level was high in C57 mice compared to control. We demonstrated the same result in Figure 20. From the same blot we saw that p53 protein level was drastically increased in $\mathrm{HO}-1 \mathrm{KO}$ control, $\mathrm{HO}-1 \mathrm{KO} \mathrm{Ml}$ and $\mathrm{HO}-1 \mathrm{KO} \mathrm{Ml}$ mice treated with CLA and nitrite (Fig. 20). The protein level was low in HO-1 Tg Control and MI mice (Fig. 20). 


\subsection{HO-1 induces miNRA-499 expression in mice following MI.}

To investigate the relationship between $\mathrm{HO}-1$ and miRNA-499 we measured miRNA-499 level in $\mathrm{HO}-1 \mathrm{Tg}$ and $\mathrm{KO}$ mice following treatment and $\mathrm{MI}$ surgery. miRNA-499 was high in $\mathrm{HO}-1 \mathrm{Tg}$ control mice and was further increased after $\mathrm{MI}$ in HO-1 Tg mice (Fig. 21). miRNA-499 level was not expressed in HO-1 $\mathrm{KO}$ mice regardless of treatment or surgery (Fig. 21).

\subsection{HO-1 attenuates ratio of $\mathrm{Bax} / \mathrm{Bcl}-2$ following $\mathrm{MI}$}

The total Bax mRNA level was increased and the Bcl-2 mRNA level was

decreased in the HO-1 KO mice regardless of the treatment (Fig. 22). mRNA level of Bax was increased in $\mathrm{HO}-1 \mathrm{KO}$ mice compared to control, levels were higher compared to C57 MI mice (Fig. 22) and mRNA of Bcl-2 was low in HO-1 $\mathrm{KO}$ mice (Fig. 22). Ratio of Bax/Bcl-2 was induced in HO-1 Tg control and Ml mice (Fig. 22).

\subsection{The heart failure markers (ANP and BNP) are lowered in HO-1 Tg mice after MI.}

To evaluate heart failure in $\mathrm{HO}-1 \mathrm{Tg}$ and $\mathrm{HO}-1 \mathrm{KO}$ mice after $\mathrm{MI}$ we measured expression of ANP and BNP (Fig. 23). Expression of ANP and BNP were markedly increased in C57 MI mice, those markers were farther increased 
in $\mathrm{HO}-1 \mathrm{KO}$ mice, which was 5 fold higher than in C57 MI mice (Fig. 23). ANP and BNP expression was not changed in $\mathrm{HO}-1 \mathrm{Tg}$ mice after MI (Fig. 23).

\subsection{CLA and nitrite induces miRNA-499 and HO-1 expression in cardiomyocytes.}

For further investigation of the relationship between treatment miRNA-499 and HO-1 level expression, we isolated myocytes from adult C57 mice and treated with two different doses of CLA and nitrite (Fig. 25). HO-1 and miRNA-499 expression was increased in cardiomyocytes treated with $2.5 \mathrm{uM} \mathrm{CLA}$ and nitrite (Fig. 25). The expression of both HO-1 and miRNA-499 was further increased in cardiomycytes treated with 5uM cLA and nitrite (Fig. 25).

\subsection{CLA and nitrite induces miRNA-499 through HO-1 induction in cardiomycytes}

We investigated the direct relationship between $\mathrm{HO}-1$ and miRNA-499 using $\mathrm{HO}-1 \mathrm{Tg}$ and $\mathrm{HO}-1 \mathrm{KO}$ mice; we isolated myocytes and treated with CLA and nitrite. Expression of $\mathrm{HO}-1$ was very high in $\mathrm{HO}-1 \mathrm{Tg}$ control isolated cardiomyocyes compared to C57 control isolated cardiomyocytes (Fig. 27). Expression of $\mathrm{HO}-1$ was increased in $\mathrm{HO}-1 \mathrm{Tg}$ isolated cardiomyocytes treated with 5uM cLA and nitrite (Fig. 27). HO-1 was not expressed in $\mathrm{HO}-1 \mathrm{KO}$ isolated cardiomyocytes regardless of treatment (Fig. 27). Expression of miRNA-499 was 
similar in $\mathrm{HO}-1 \mathrm{Tg}$ mice. It was highly expressed in $\mathrm{HO}-1 \mathrm{Tg}$ control isolated cardiomyocytes compared to C57 control isolated cardiomyocytes (Fig. 27). It was further increased in HO-1 Tg cardiomyocytes treated with 5uM CLA and nitrite mice (Fig. 27). 
FIGURE 12

\section{miRNA-499}

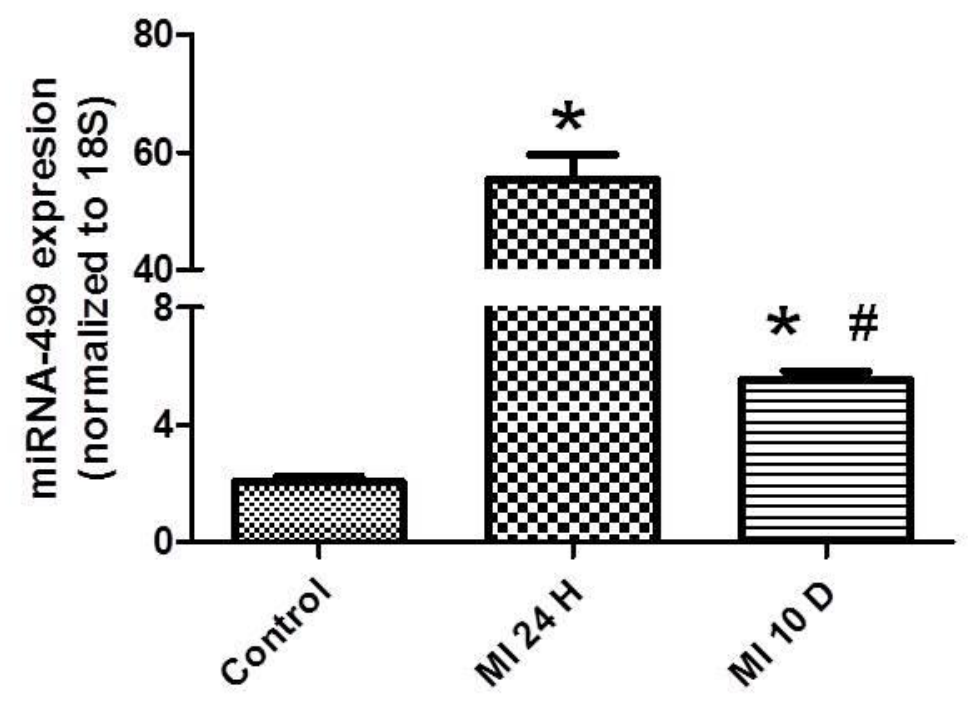

Figure 12: miRNA-499 biomarker of acute MI. miRNA-499 was drastically increased after $24 \mathrm{~h}$ of $\mathrm{Ml}$ compared to control mice, which was lowered after 10 days of $\mathrm{Ml}$ compared to $24 \mathrm{~h} \mathrm{MI}$ mice. ( ${ }^{*} \mathrm{p}<0.05$ vs Control; \# $\mathrm{p}<0.05$ vs MI $24 \mathrm{~h}$ $\mathrm{n}=6$ per group) 
FIGURE 13

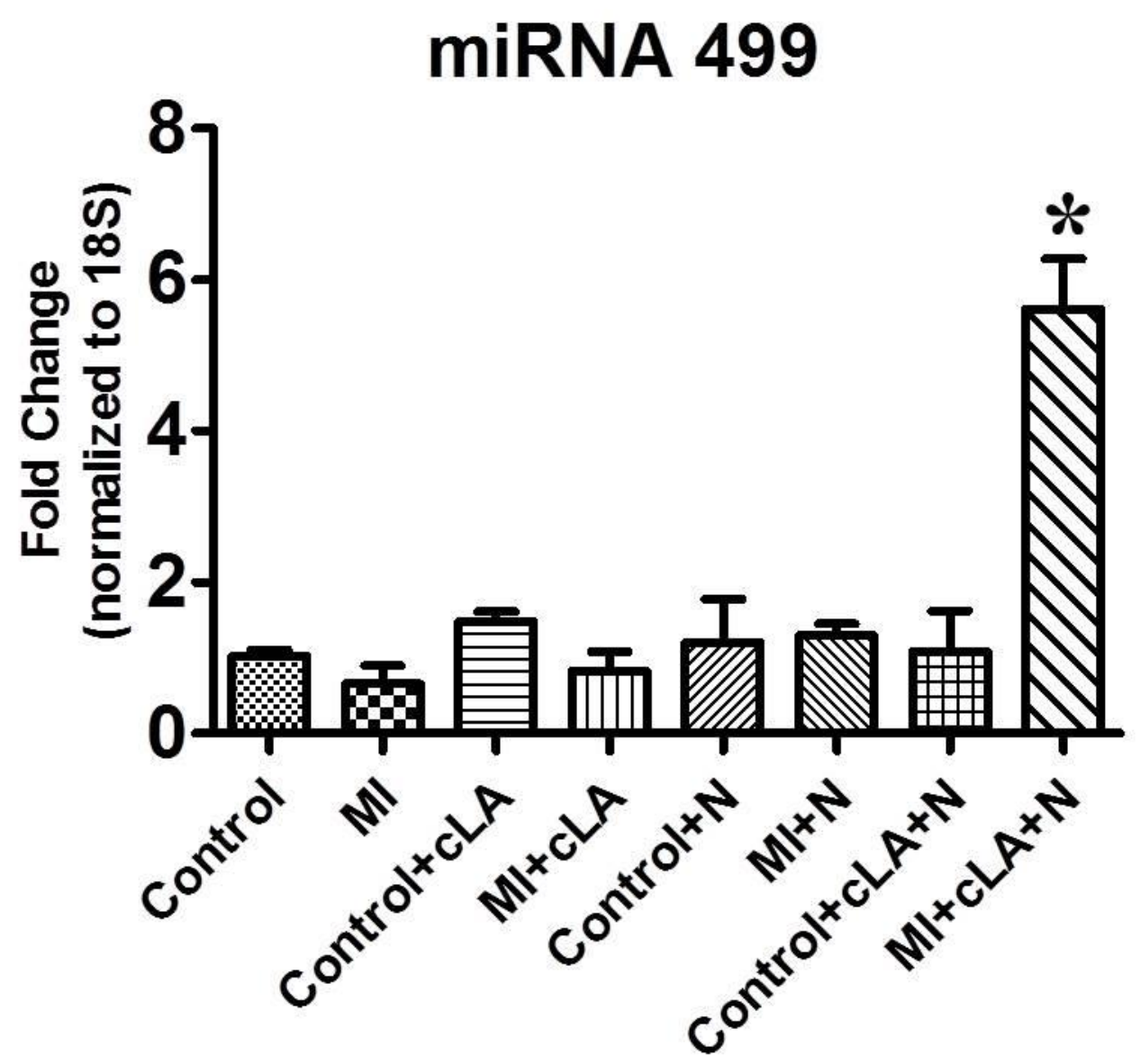

Figure13: Co-treatment with CLA and nitrite induces miRNA-499 following MI. miRNA-499 was significantly increased in MI mice after combination treatment with cLA and nitrite ( ${ }^{\star} p<0.05$ vs control, $\mathrm{n}=8$ per group). 
FIGURE 14

DRP-1

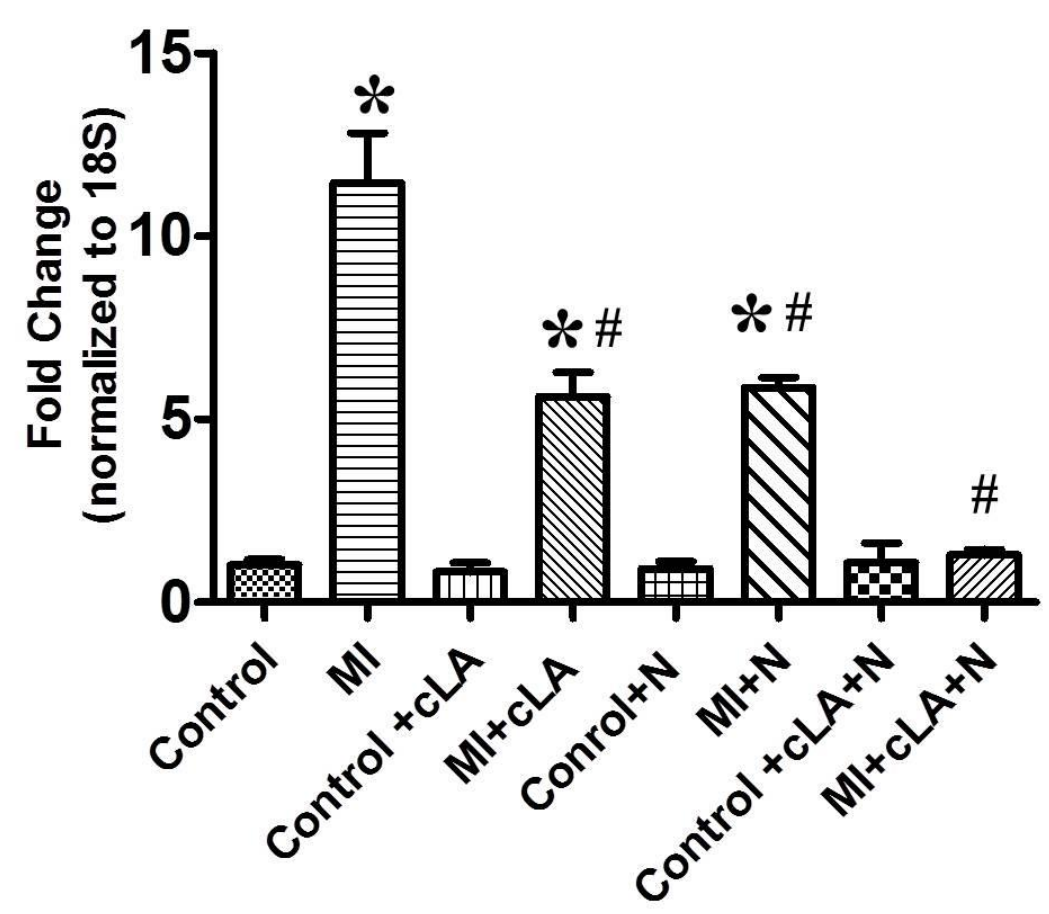

Figure 14: Mitochondrial fission factor DRP-1 is attenuated in mice treated with CLA and nitrite following MI. Nitrite or CLA-treated MI mice had decreased levels of DRP-1 compared to Ml alone. Combination treatment with $\mathrm{CLA}$ and nitrite significantly lowered the level of Drp-1 in MI mice, comparable to control values ( ${ }^{*} p<0.05$ to control, ${ }^{\#} p<0.05$ to $\mathrm{Ml}, \mathrm{n}=8$ per group). 
FIGURE 15

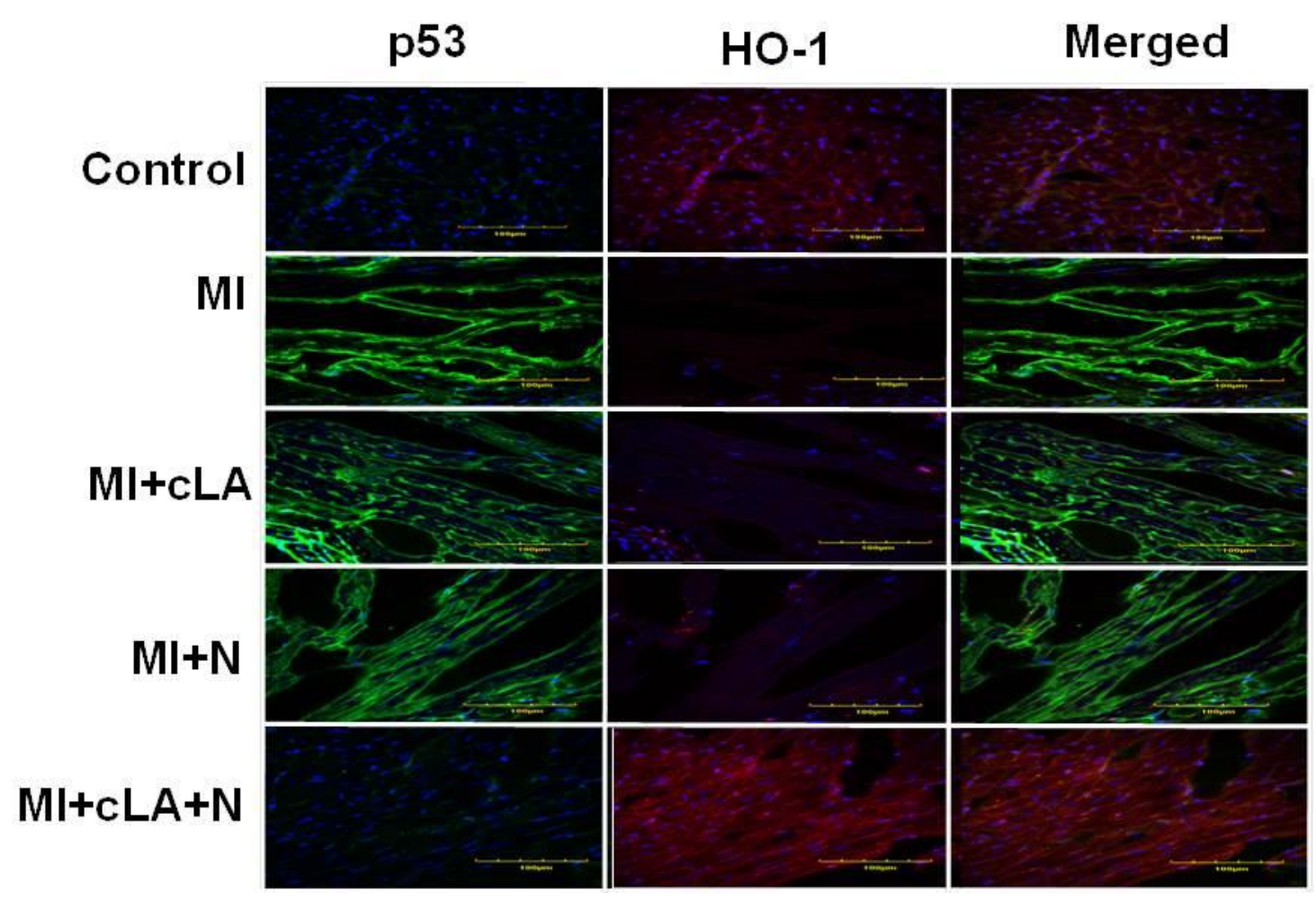

Figure $15 \mathrm{~A}$ : Co-treatment with cLA and nitrite attenuates p53 and induces HO-1 expression following MI. 


\section{FIGURE 15}

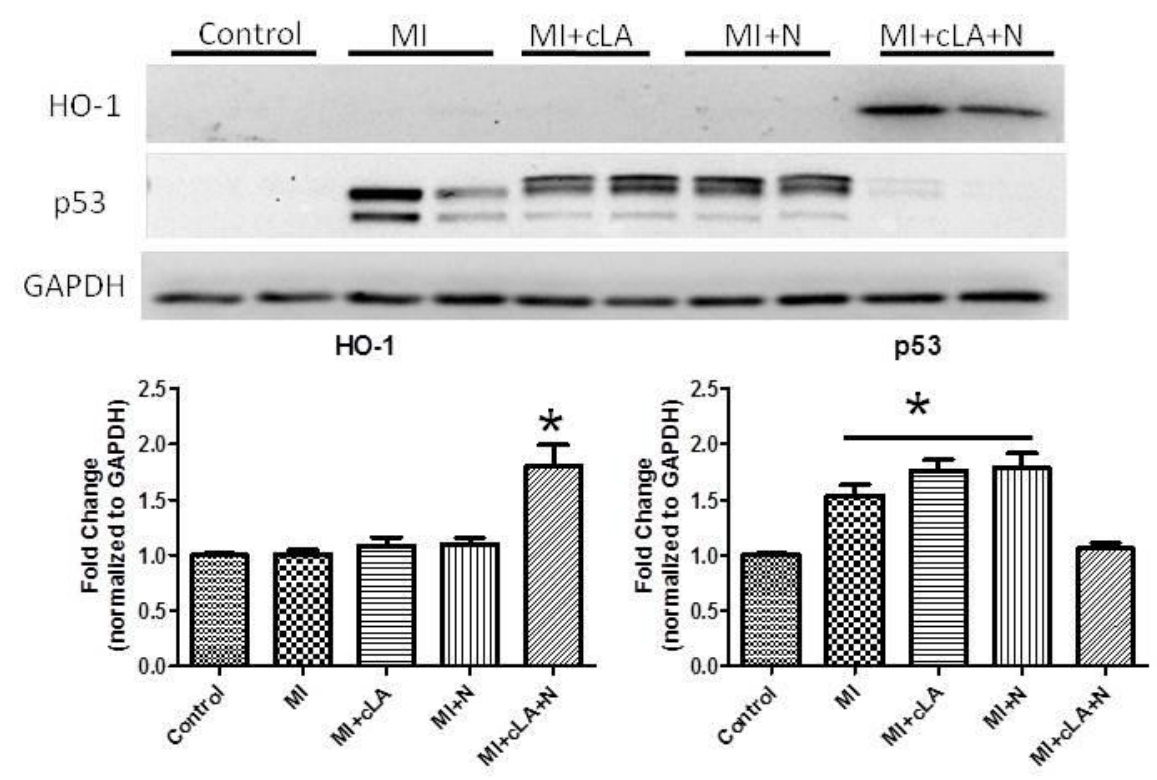

Figure 15 B: Co-treatment with cLA and nitrite attenuates p53 and induces HO-1 expression following MI. Confocal microscopy (A): heart tissue was labeled with p53 (green), HO-1 (red), and cell nuclei were labeled with DAPI (blue). Western blot analysis reveals that p53 is significantly increased in cardiac tissue following $\mathrm{Ml}$ (B). Quantitated protein expression reveals that coadministration of $\mathrm{CLA}$ and nitrite lowers p53 levels, while increasing expression of HO-1 ( ${ }^{*} p<0.05 ; n=6$ per group). 


\section{FIGURE 16}

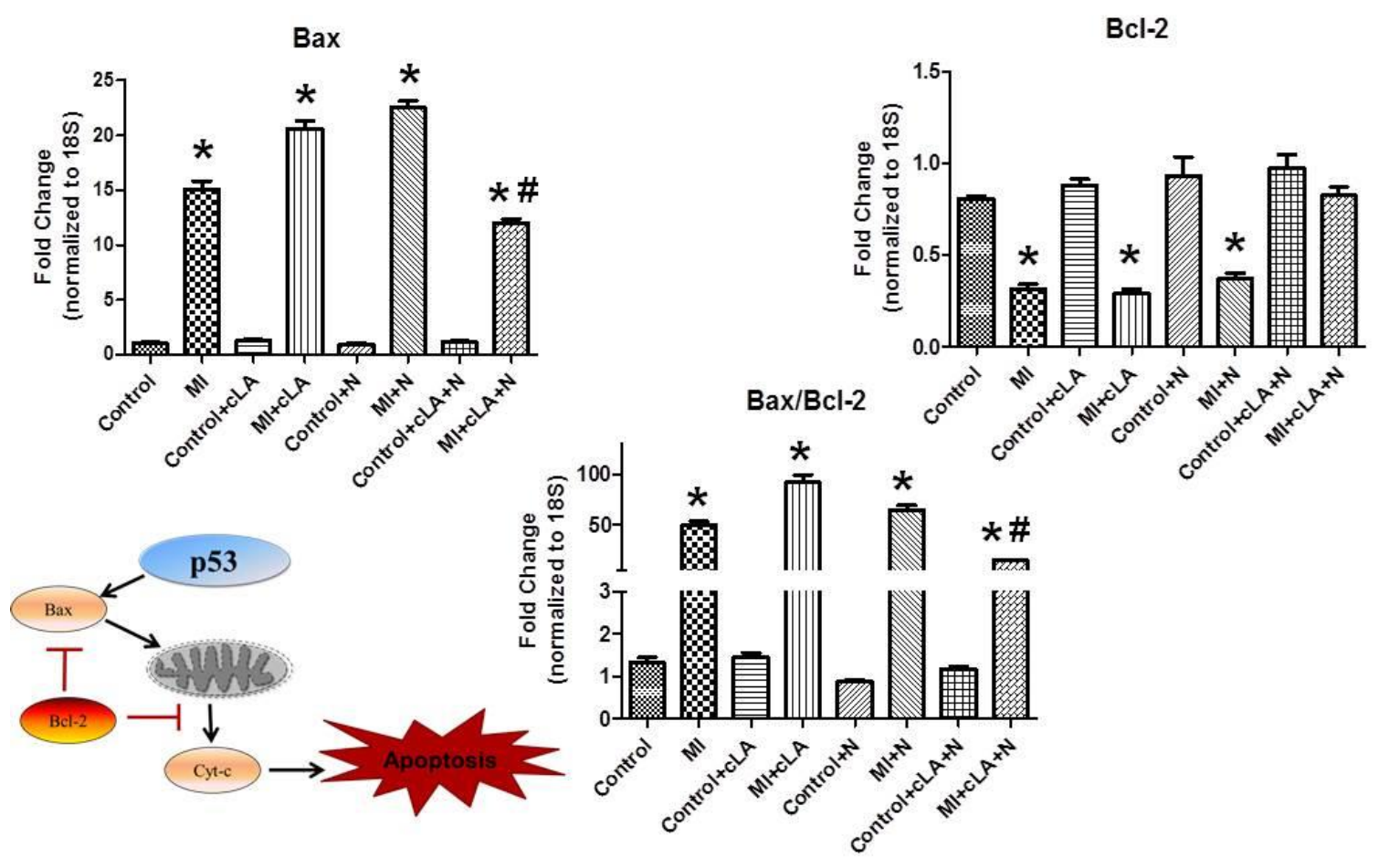

Figure 16: Co-treatment with CLA and nitrite attenuates pre-apoptotic markers following Ml. Expression of $\mathrm{Bcl}-2$ and $\mathrm{Bax}$ in mice with/or without treatment following MI. (A-C) mRNA levels of Bcl-2 and Bax. (A) Higher Bax was observed in $\mathrm{MI}$ and single treated mice, which was lowered in CLA and nitrite treated mice ( ${ }^{*} \mathrm{p}=0.05$ vs control; $\# \mathrm{p}=0.05$ vs $\mathrm{MI}, \mathrm{N}=6$ ) and (B) lower $\mathrm{Bcl}-2$ was observed in $\mathrm{Ml}$ and single treated mice, which was restored in $\mathrm{Ml}$ mice treated 
with cLA and nitrite ( ${ }^{*} \mathrm{p}=0.05$ vs control; $\# \mathrm{p}=0.05$ vs $\mathrm{MI}, \mathrm{n}=6$ per group). (C) Ratio of $\mathrm{Bax} / \mathrm{Bcl}-2$ was high in $\mathrm{Ml}$ and single treated mice which were lowered in $\mathrm{Ml}$ mice treated with $\mathrm{cLA}$ and nitrite ( ${ }^{*} \mathrm{p}=0.05$ vs control; $\# \mathrm{p}=0.05$ vs $\mathrm{Ml}, \mathrm{n}=6$ per group). (D) Schematic representation of relationship between Bax and Bcl-2. 
FIGURE 17

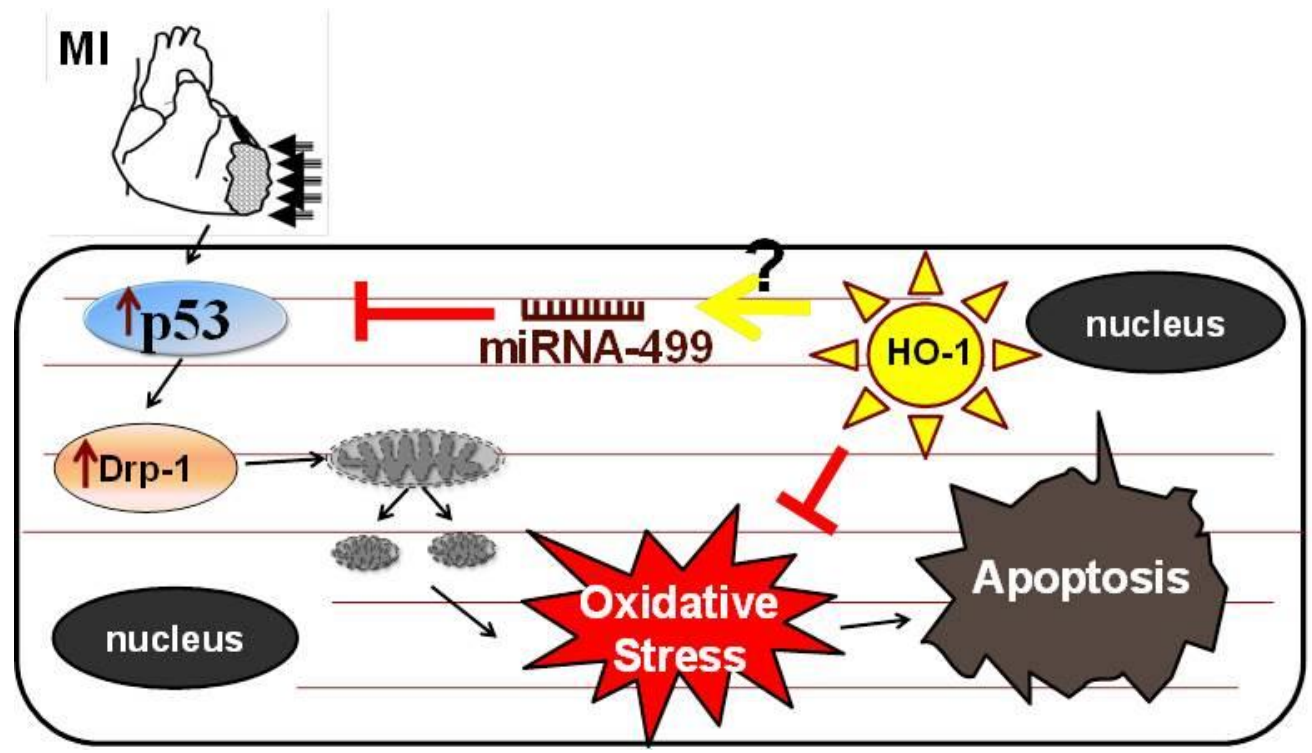

Figure 17: Schematic diagram of specific aim 2.2 hypothesis. Overexpression of HO-1 increased levels of miRNA-499 in heart after Ml, resulting in inhibition of p53 and an overall improvement of heart function in $\mathrm{Ml}$ mice. 


\section{FIGURE 18}

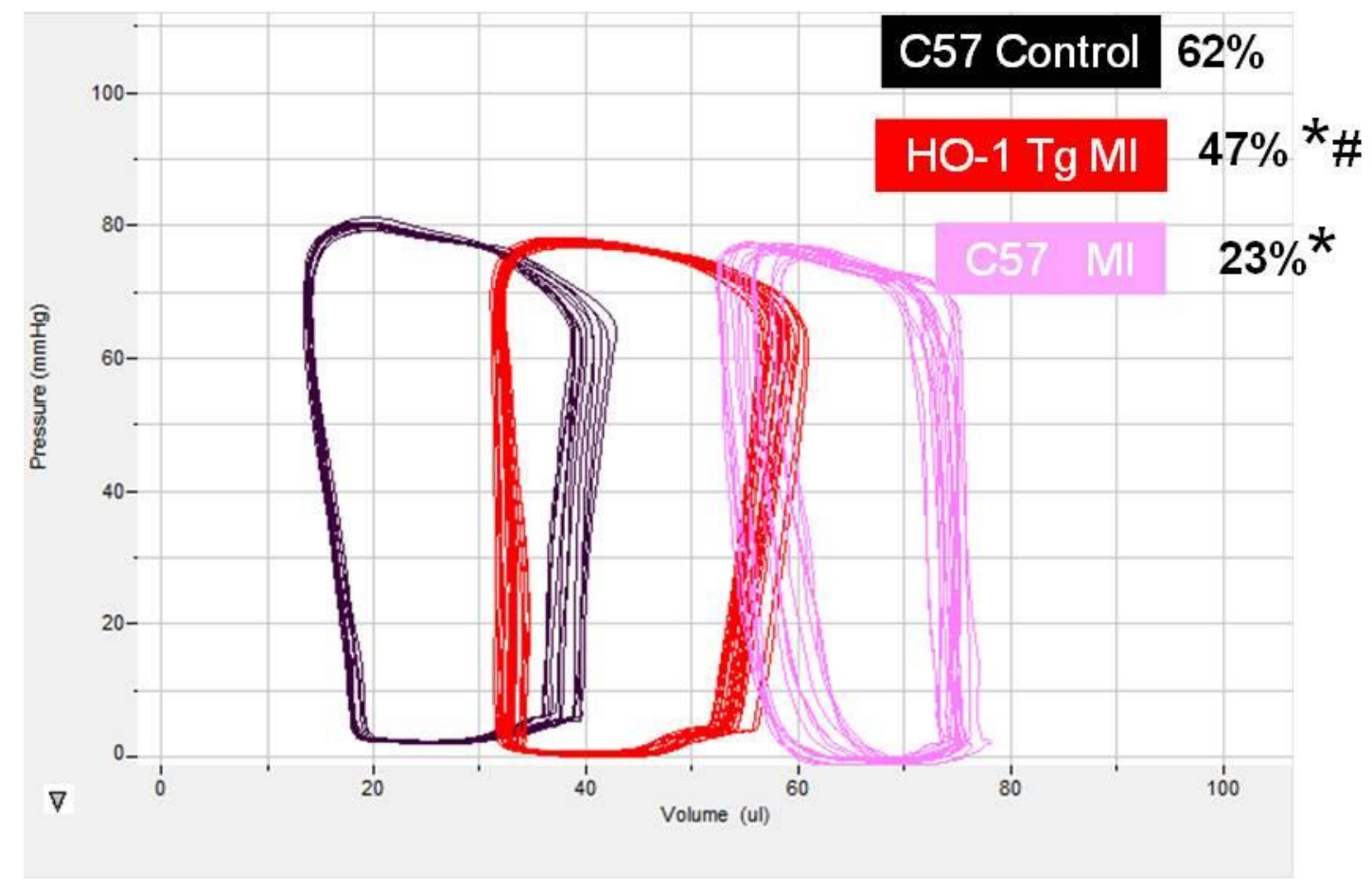

Figure 18: Induction of HO-1 attenuates LV dysfunction following MI. MI causes a drastic increase of End-diastolic volume in C57 mice (pink lines), which was protected in HO-1 Tg mice (red lines) compared to control (black lines). EF of C57 MI mice was decreased, $23 \%$, $\mathrm{HO}-1 \mathrm{Tg}$ mice EF-47\% was decreased compared to control mice (EF-62\%) but it was not as low as C57 MI mice. ( ${ }^{*} p<0.05$ to control, $\# p<0.05$ to $\mathrm{Ml}, n=10$ per group) 
FIGURE 19

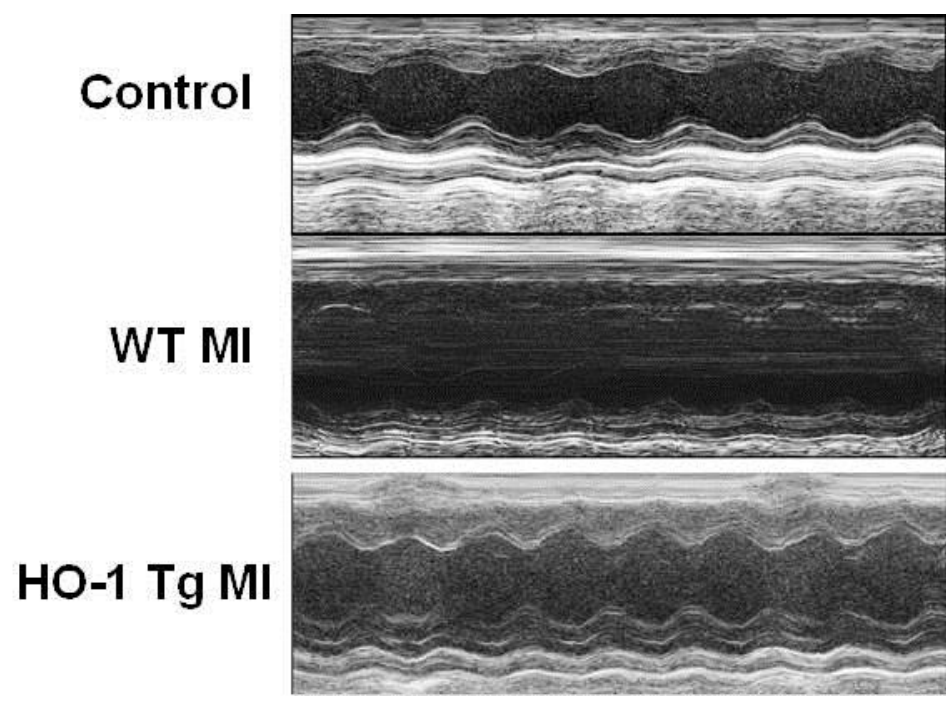

FS $\% 52 \pm 1.7 \%$

FS $\% 23 \pm 2.3 \%$ *

FS $\% 47 \pm 1.9 \%{ }^{*} \#$

Figure 19: Fraction shortening is protected in HO-1 Tg mice following MI. FS was decreased in C57 mice- $23 \%$ compared to control C57 mice-52\%. FS of HO-1 Tg mice- $47 \%$ was lower compared to C57 control mice-52\%, but was higher than in $\mathrm{C} 57 \mathrm{MI}$ mice-23\%. ( ${ }^{*} p<0.05$ to control, $\# p<0.05$ to $\mathrm{MI}, n=24$ per group) 


\section{FIGURE 20}

A

HO-1

p53

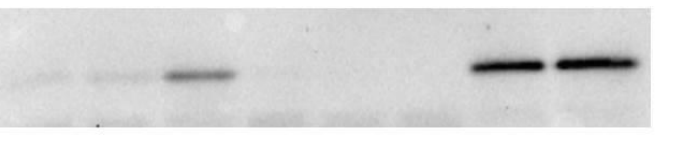

53
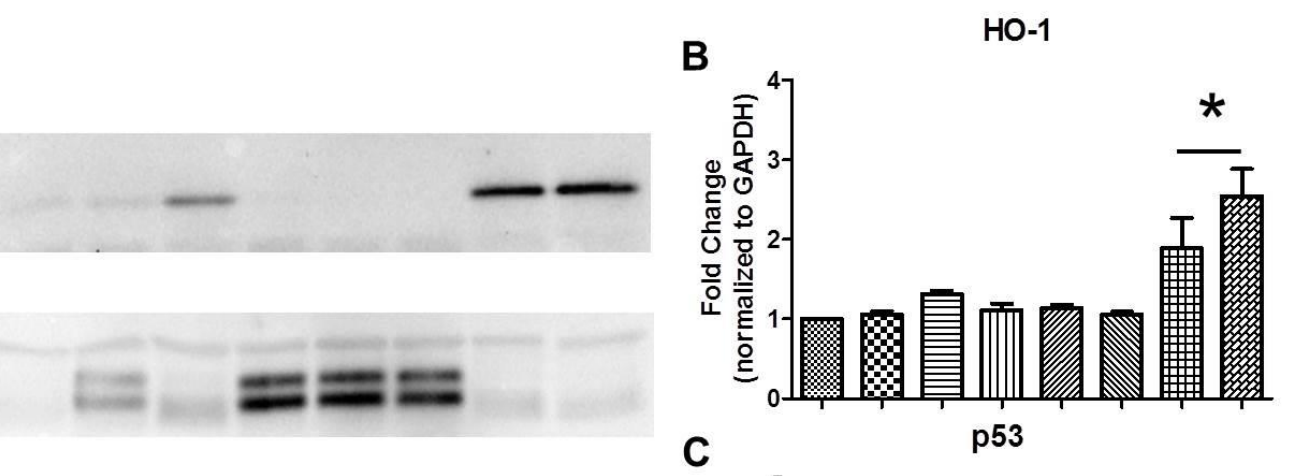

GAPDH

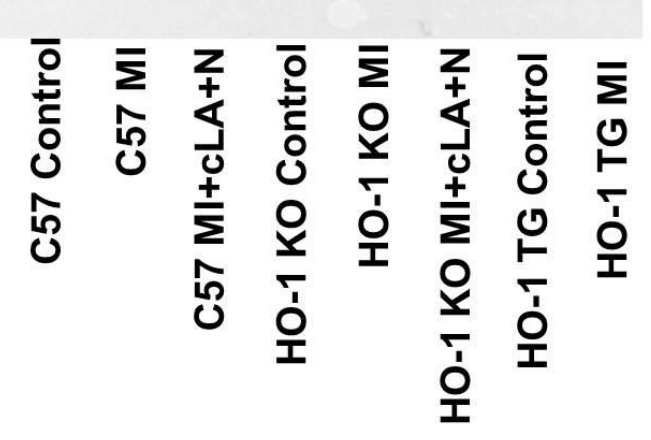

C

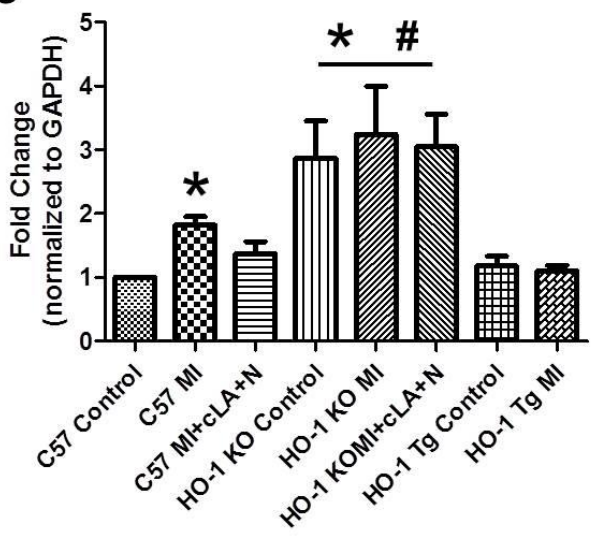

Figure 20: Ml does not alter $\mathrm{HO}-1$ levels in $\mathrm{HO}-1 \mathrm{Tg}$ mice following $\mathrm{MI}$. Examples of Western Blot images of the protein studied and contents of GAPDH in the respective samples (A). Relative protein expression is reported as fold change $(\mathrm{B})$, alone ( ${ }^{*} p<0.05$ to control, $\# p<0.05$ to $\mathrm{MI}, n=24$ per group) 
FIGURE 21

\section{miRNA 499}

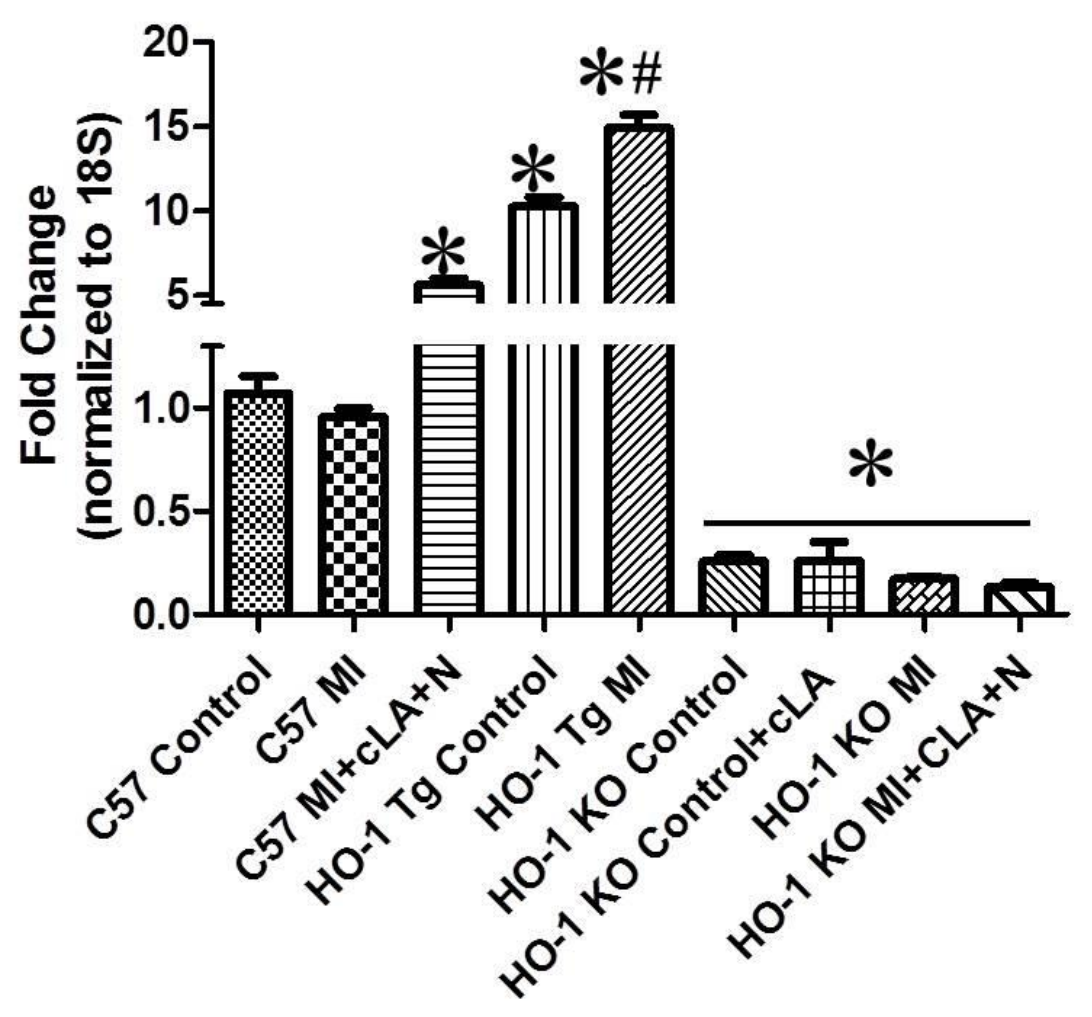

Figure 21: HO-1 induces miRNA-499 expression in mice following MI. The bar graph represents real-time PCR amplification of miRNA-499. miRNA-499 was highly expressed in MI mice treated with cLA and nitrite and in $\mathrm{HO}-1 \mathrm{Tg}$ mice with or without MI, miRNA-499 was not expressed in HO-1 KO mice regardless of treatment. ( ${ }^{\star} p<0.05$ to control, ${ }_{\#} p<0.05$ to $\mathrm{Ml}, n=6$ per group) 


\section{FIGURE 22}

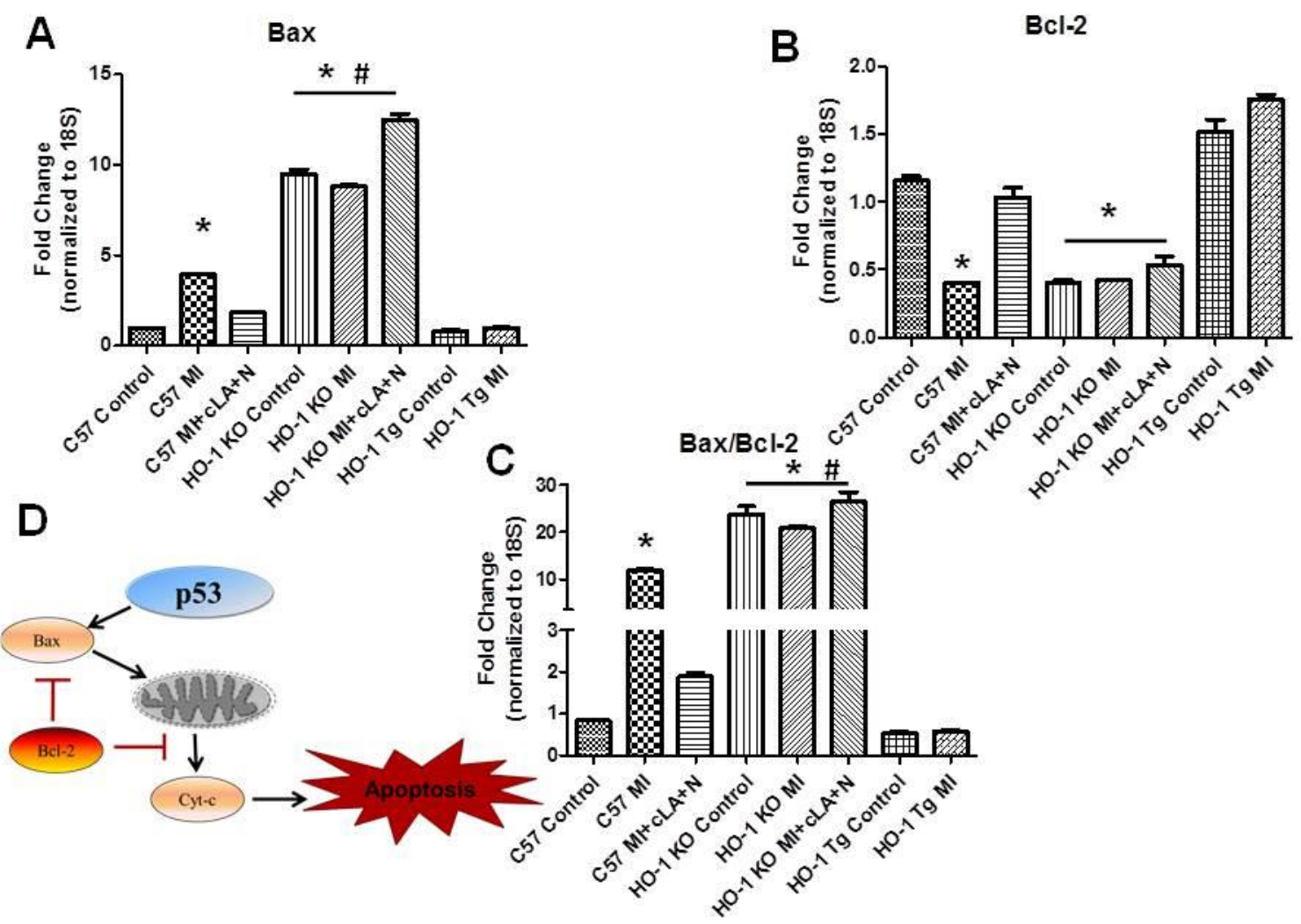

Figure 22: HO-1 attenuates apoptosis following MI. Expression of $\mathrm{Bcl}-2$ and Bax in $\mathrm{C} 57, \mathrm{HO}-1 \mathrm{KO}$ and $\mathrm{HO}-1 \mathrm{Tg}$ mice with/or without treatment following $\mathrm{MI}$. (A-C). Higher Bax was observed in $\mathrm{C} 57 \mathrm{MI}$ and $\mathrm{HO}-1 \mathrm{KO}$ mice $(\mathrm{A})$, which was lowered in $\mathrm{cLA}$ and nitrite treated mice and HO-1 Tg mice $\left({ }^{*} \mathrm{p}=0.05\right.$ vs control; $\# p=0.05$ vs $\mathrm{Ml}, \mathrm{n}=6$ per group). Lower $\mathrm{Bcl}-2$ was observed in $\mathrm{C} 57 \mathrm{MI}$ and $\mathrm{HO}-1$ $\mathrm{KO}$ mice, which was restored in MI mice treated with CLA and nitrite and HO-Tg mice (B) ( ${ }^{*} \mathrm{p}=0.05$ vs control; $\# \mathrm{p}=0.05$ vs $\mathrm{Ml}, \mathrm{n}=6$ per group). (C) Ratio of 
$\mathrm{Bax} / \mathrm{Bcl}-2$ was high in $\mathrm{C} 57 \mathrm{Ml}$ and $\mathrm{HO}-1 \mathrm{KO}$ mice which were lowered in $\mathrm{Ml}$ mice treated with cLA and nitrite and HO-1 Tg mice $\left({ }^{*} \mathrm{p}=0.05\right.$ vs control; $\# \mathrm{p}=0.05$ vs Ml, $n=6$ per group). (D) Schematic representation of relationship between Bax and Bcl-2. 


\section{FIGURE 23}
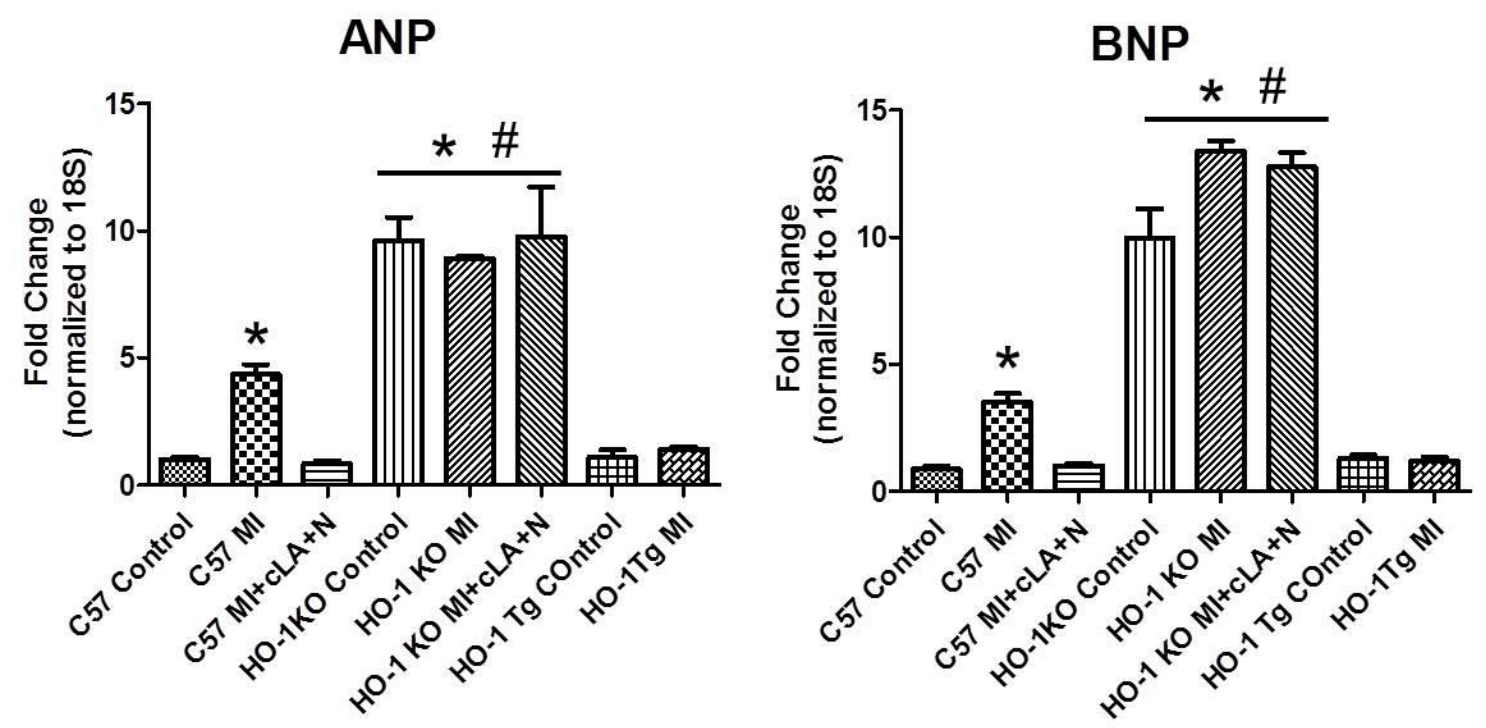

Figure 23: HO-1 reduces heart failure markers after MI. Relative fold change of (A) ANP and (B) BNP in $\mathrm{C} 57, \mathrm{HO}-1 \mathrm{KO}$, and $\mathrm{HO}-1 \mathrm{Tg}$ mice before and after $\mathrm{MI}$ with/without treatment with $\mathrm{CLA}$ and nitrite. ANP-atrial natriuretic peptide; BNP- B-type natriuretic peptide. ( ${ }^{*} \mathrm{p}=0.05$ vs control; $\# \mathrm{p}=0.05$ vs $\mathrm{Ml}, \mathrm{n}=6$ per group). 
FIGURE 24

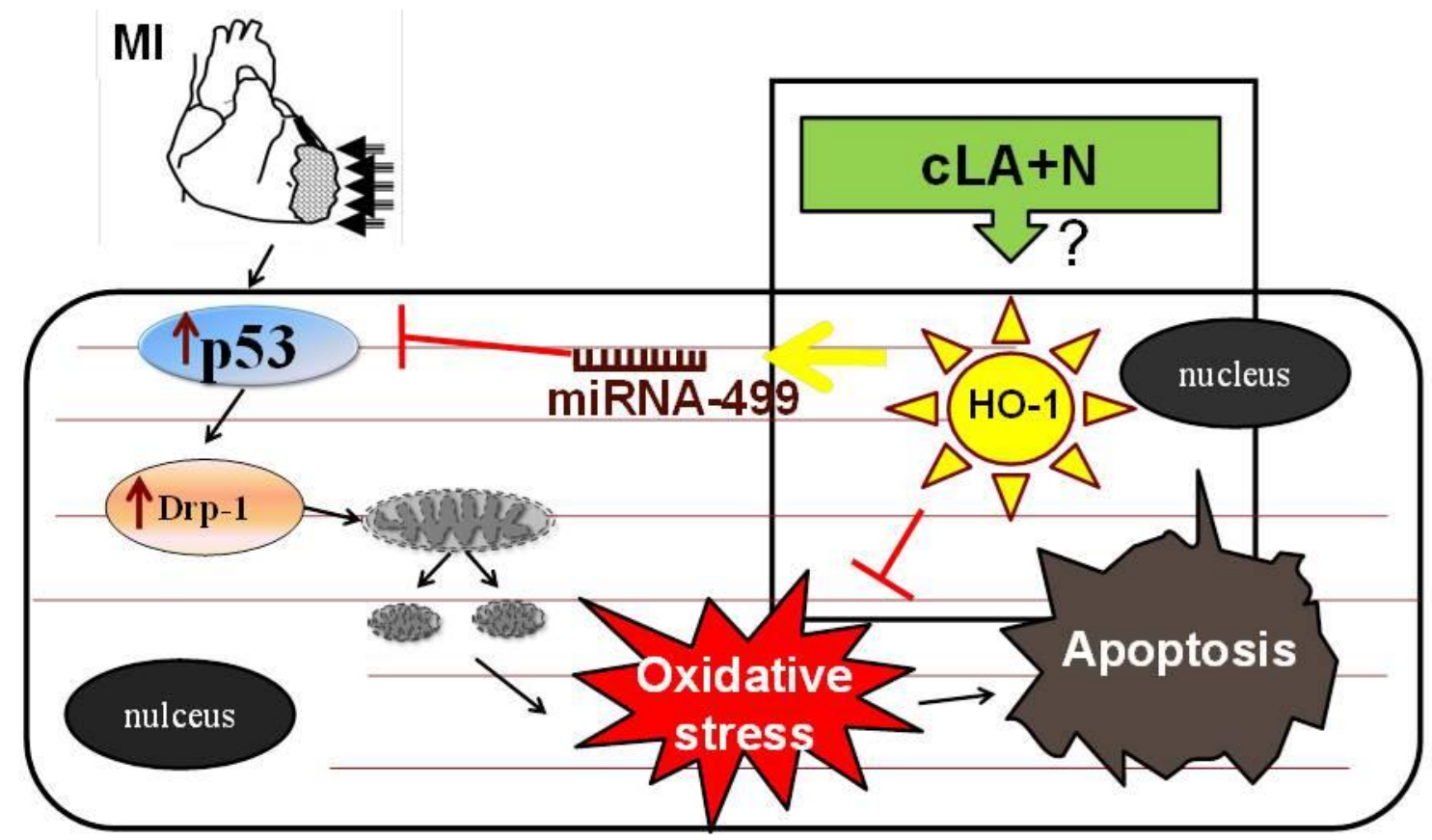

Figure 24: Schematic diagram of specific aim 2 hypothesis.

Co- treatment with cLA and nitrite induces level of HO-1 in myocytes. 


\section{FIGURE 25}

A

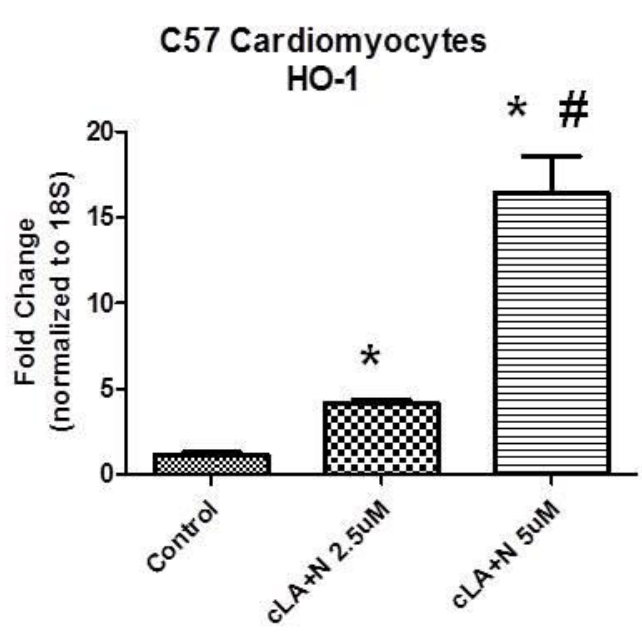

B
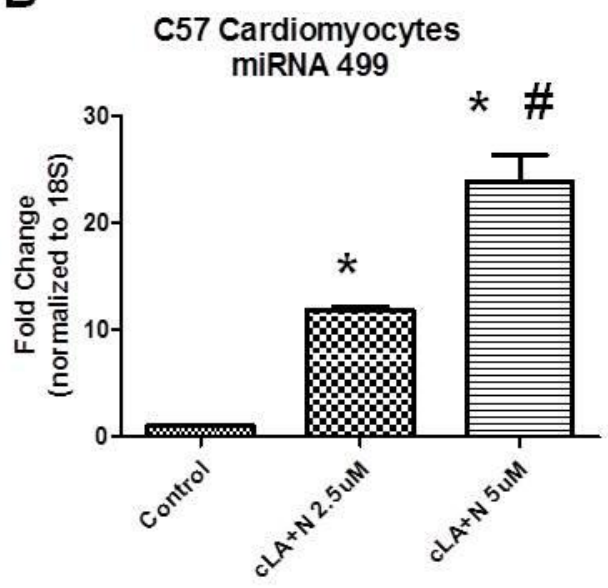

Figure 25: cLA and nitrite induces miRNA-499 and HO-1 expression in mice following MI. HO-1 expression was increased by 4 fold after $2.5 \mathrm{u \mu M} \mathrm{CLA}$ and nitrite treatment. $5 \mu \mathrm{M}$ cLA and nitrite administration caused a 15 fold increase of HO-1 expression in C57 myocytes (A). miRNA-499 expression was increased for 10 fold after $2.5 \mu \mathrm{M} c L A$ and nitrite treatment. $5 \mu \mathrm{M}$ cLA and nitrite administration caused more than a 22 fold increase of miRNA-499 expression in C57 myocytes (B). ( ${ }^{*} \mathrm{p}=0.05$ vs control; $\# p=0.05$ vs $\mathrm{Ml}, \mathrm{n}=6$ per group). 
FIGURE 26

\section{Does $\mathrm{HO}-1$ regulate expression of miRNA-499?}

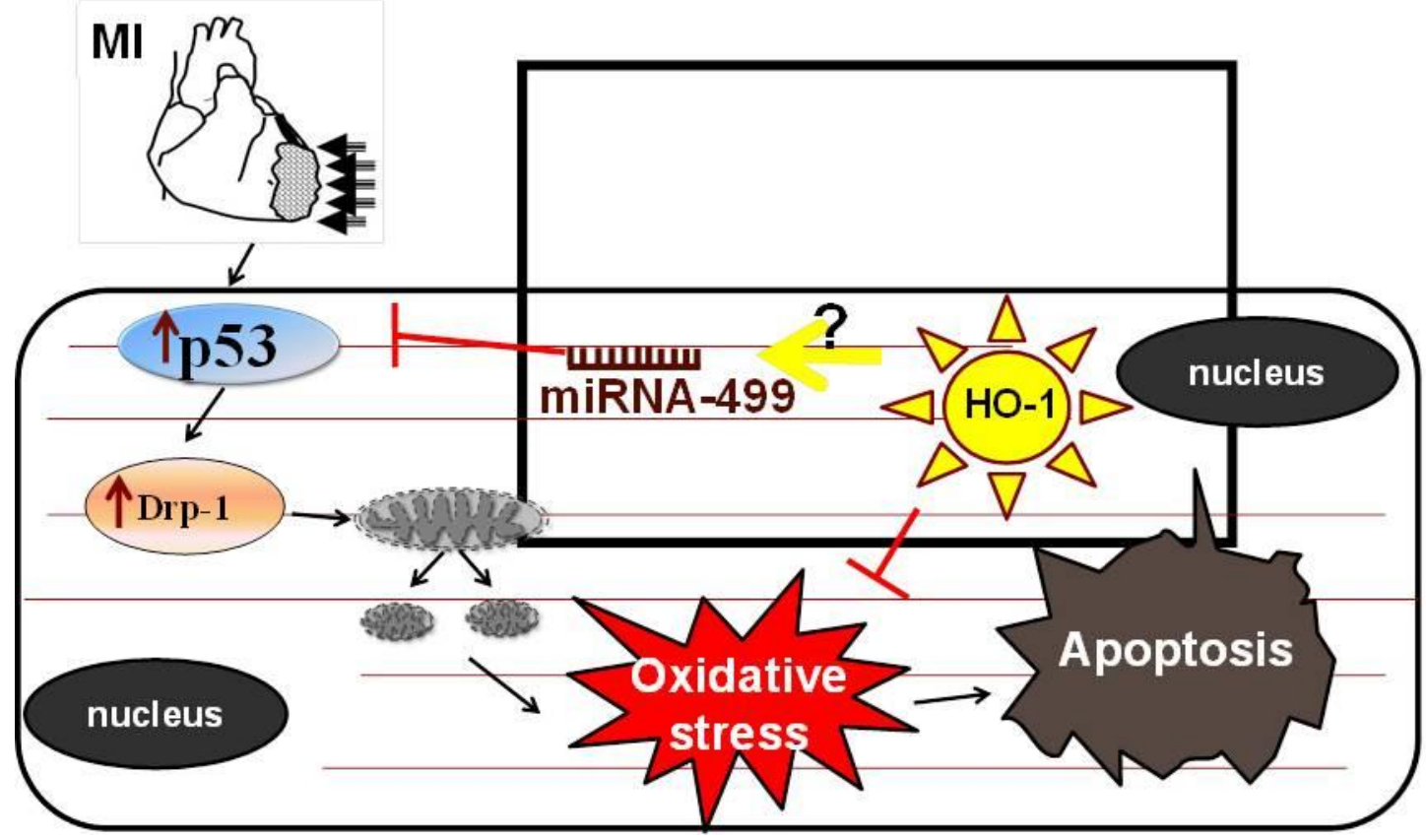

Figure 26: Schematic diagram of specific aim 2 hypothesis. HO-1 is regulating the expression of miRNA-499 
FIGURE 27

A

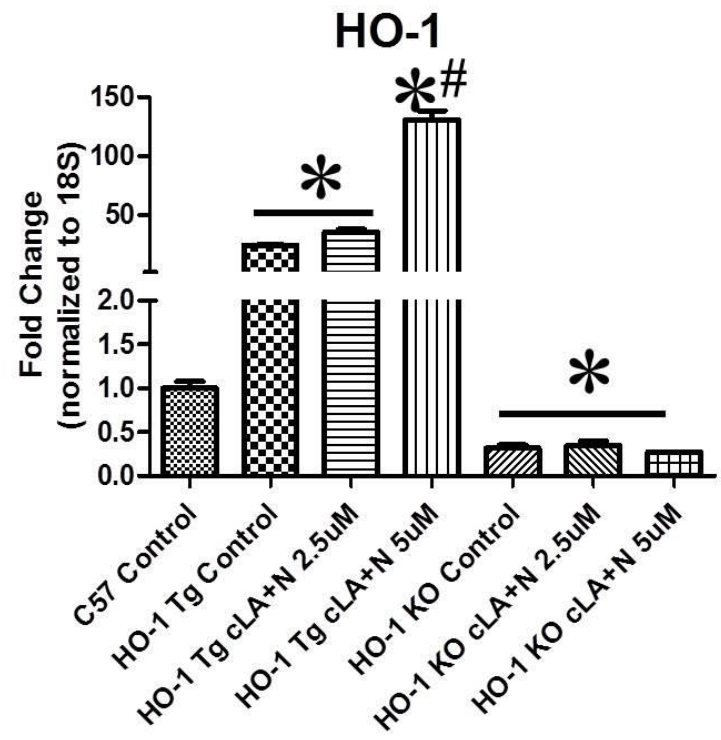

B

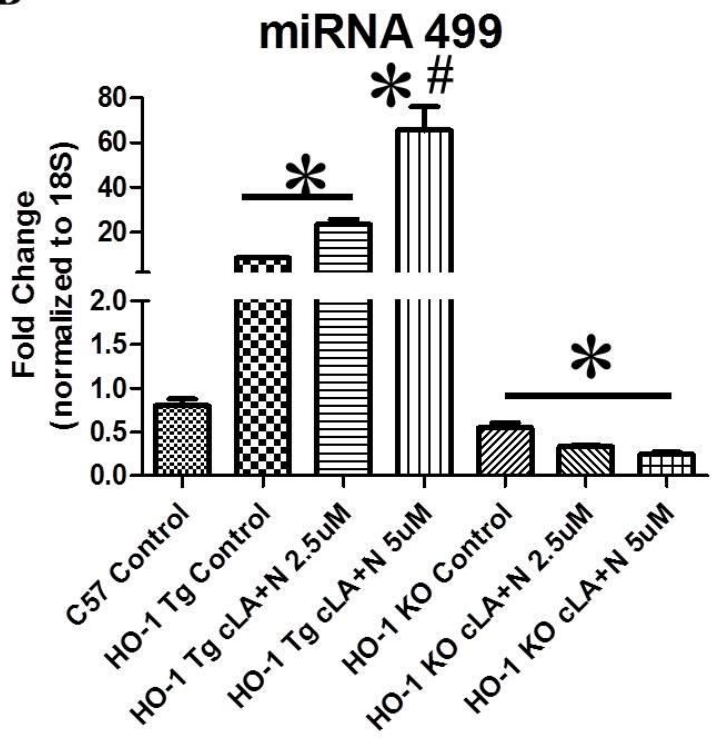

Figure 27: cLA and nitrite induces miRNA-499 level through HO-1. HO-1 expression was high before $\mathrm{CLA}$ and nitrite treatment in $\mathrm{HO}-1 \mathrm{Tg}$ cardiomyocytes, $\mathrm{HO}-1$ expression was increased further after $5 \mu \mathrm{M} \mathrm{CLA}$ and nitrite administration (A). miRNA-499 expression was high in HO-1 Tg cardiomyocytes before treatment, which was increased further after $5 \mu \mathrm{M}$ cLA and nitrite administration (B). ( ${ }^{*} \mathrm{p}=0.05$ vs control; $\# \mathrm{p}=0.05$ vs $\mathrm{Ml}, \mathrm{n}=6$ per group). 


\section{TABLE 2}

\begin{tabular}{|c|c|c|c|c|c|c|c|c|}
\hline & HR & ESP & EDP & ESV & EDV & SV & CO \\
\hline & BPM & $\mathrm{mmHg}$ & $\mathrm{mmHg}$ & $\mathrm{uL}$ & $\mathrm{uL}$ & $\mathrm{uL}$ & $\mathrm{Ul} / \mathrm{min}$ \\
\hline $\begin{array}{c}\text { C57 } \\
\text { control }\end{array}$ & $552 \pm 1.788$ & $80.877 \pm 0.488$ & $6.949 \pm 0.669$ & $15.431 \pm 0.369$ & $40.661 \pm 1.722$ & $25.23 \pm 1.533$ & $13926.93 \pm 449.698$ & $62.048 \pm 2.127$ \\
\hline $\begin{array}{c}\text { C57 Ml } \\
\text { HO-1 TG } \\
\text { Ml }\end{array}$ & $555.779 \pm 8.673$ & $78.361 \pm 3.719$ & $2.734 \pm 1.247$ & $55.431 \pm 3.719 *$ & $72.773 \pm 2.398$ * & $17.658 \pm 3.716$ * & $9800.19 \pm 1218.053$ * & $23 \pm 4.168$ * \\
\hline
\end{tabular}

Table 2: Hemodynamics of $\mathrm{C} 57$ control, $\mathrm{C} 57 \mathrm{MI}$ and HO-1Tg MI mice based on pressure-volume. All values are expressed as mean \pm SD. BPM - beats per minute; ESP - end-systolic pressure; EDP - end-diastolic pressure; ESV - endsystolic volume; EDV- end-diastolic volume, SV - stroke volume; CO - cardiac output; EF -ejection fraction; ( ${ }^{*} p<0.05$ to control, $\# p<0.05$ to $\mathrm{MI}, n=10$ per group). 


\section{Discussion}

This thesis examines the effects of $\operatorname{cLA}$ with and without nitrite supplementation on cardiovascular injury following MI. Considering the initiative to replace saturated fats with so-called 'healthy fats', to promote overall weight loss and maintenance, the health effects of fats such as cLA require investigation. The principal findings demonstrated here is that $\mathrm{CLA}$ and nitrite cotreatment significantly increases miRNA-499 and blocks mitochondrial fission through inhibition of p53 (Fig. 13, 14 and 15). Further, co-treatment with CLA and nitrite also induces HO-1 protein expression (Fig. 15), which supports cardioprotection in this $\mathrm{MI}$ model. Overall, CLA and nitrite mediate protection and result in improved heart function in this murine model of $\mathrm{MI}$.

It is known that mitochondria undergo fission and fusion events continuously in non-disease states [126]. Mitochondrial morphological dynamics affect the outcome of ischemic heart damage and pathogenesis [126]. The Drp1 protein plays an important role in fission, regulating mitochondrial membrane dynamics [65, 126, 127]. Drp1 exists as small oligomers, located primarily at the mitochondrial outer membrane. These oligomers can connect to each other, forming larger multimeric structures, thus mediating mitochondrial division [16, $65,127,128]$. In previous studies Drp1 has been identified as a mediator of mitochondrial morphological changes and cell death during cardiac ischemic injury [128]. It has been reported that miRNA-499 affects DRP-1 mediated apoptosis and the severity of $\mathrm{Ml}$ and cardiac dysfunction during heart disease 
[57]. Our data suggest that MI significantly increases Drp1 expression in the heart of single treatment with CLA- and nitrite-treated, as well as in non-treated mice (Fig. 13). Drp1 expression was abolished following co-treatment with cLA and nitrite in MI mice (Fig. 13).

Bcl-2 gene families are identified as apoptosis regulating genes. Of these genes, Bax promotes cell death, whereas Bcl-2 inhibits apoptosis and promotes cell survival $[108,129]$. The pro-apoptotic Bax gene shares structural similarities with $\mathrm{Bcl}-2$ and is thought to inactivate $\mathrm{Bcl}-2$ by binding to it [130]. The expression of Bax is dramatically increased in MI mice (Fig. 16), whereas a tendency toward a decrease in Bcl-2 expression is also revealed (Fig. 16). Although the threshold of $\mathrm{Bax} / \mathrm{Bcl}-2$ ratio at which apoptosis is triggered in the cardiac cell is not known, our data, together with others [131, 132], suggest that an increased Bax/Bcl-2 ratio increases the probability for a myocardial cell to undergo apoptosis following MI (Fig. 16). The role of other pro-apoptotic and anti-apoptotic genes needs further investigation.

There is evidence that miRNA-499 controls the apoptotic pathway thorough regulation of p53 [57]. Our data supports the hypothesis that miRNA499 decreases Drp1 levels after combination treatment with CLA and nitrite (Fig. 11). $\mathrm{Ml}$ is known to cause cardiomyocyte ischemia, in turn, leading to p53dependent cardiomyocyte apoptosis [1, 2]. The current study extends previous findings by demonstrating that ischemia causes increased expression of p53 following $\mathrm{MI}$ in non-treated and CLA or nitrite-treated mice and provides 
significant implications with regard to the molecular mechanism of cardiomyocyte apoptosis following MI (Fig. 15).

Previous studies have shown that pharmacological delivery of nitrated fatty acids leads to protection from cardiovascular injury [133, 134]. These studies have focused on protective signaling pathways including inhibition of p65 subunit of NFKB and increased expression of HO-1. In a model of stenosis femoral artery injury, nitrated oleic acid induced vascular expression of $\mathrm{HO}-1$, mediating protection against neointimal hyperplasia [134]. Nitrated oleic acid inhibited activation of NFKB in a murine model of ischemia reperfusion injury, resulting in reduction of infarct size [133]. More recent data suggests that dietary CLA is a privileged substrate for nitration reactions facilitated by mitochondria, digestion, and macrophage activation and following metabolic stress such as $\mathrm{Ml}$ [86]. Co-administration of dietary cLA and nitrite supplementation raises $\mathrm{NO}_{2-}$ cLA levels in plasma and tissues, which in turn induces HO-1 expression in target organs [86].

In the failing heart, $\mathrm{HO}-1$ has anti-apoptotic effects by attenuating cell loss, p53 expression, and pathological heart remodeling [90]. Our data suggest that ratio of $\mathrm{Bax} / \mathrm{Bcl}-2$ was low in $\mathrm{HO}-1 \mathrm{Tg}$ mice (Fig. 22), and it was drastically increased in HO-1KO mice after MI. Treatment with CLA and nitrite could not protect $\mathrm{HO}-1 \mathrm{KO}$ hearts from apoptosis (Fig. 22). Heart failure marker expression supported apoptosis markers and physiological data (Fig. 18 and 22). ANP and BNP was low in HO-1 Tg mice following MI (Fig. 23), while those markers were 
severely high in HO-1 KO mice regardless of treatment with CLA and nitrite (Fig. 23).

The important novelty of this thesis was to answer to the question: does HO-1 overexpression increase miRNA-499 levels, resulting in inhibition of p53 level in heart tissue and an overall improvement of heart function in mice following MI (Fig. 17)?

To answer this question we used $\mathrm{HO}-1 \mathrm{Tg}$ and $\mathrm{HO}-1 \mathrm{KO}$ mice. As we mentioned before, there are many studies showing that induction of $\mathrm{HO}-1$ resulted in cardiac protection during MI [90, 135-137]. Our data demonstrates similar results: $\mathrm{Ml}$ in $\mathrm{HO}-1 \mathrm{Tg}$ does not have drastic changes in LV function as in C57 mice (Fig. 18, 19 and Table 2). Western Blots supports the physiological data; $\mathrm{HO}-1$ protein expression was markedly high in $\mathrm{HO}-1 \mathrm{Tg}$ mice and was not expressed in $\mathrm{HO}-1 \mathrm{KO}$ mice (Fig. 20), which explains the cardio-protective effect in $\mathrm{HO}-1 \mathrm{Tg}$ mice, as their heart function was preserved compared to C57 MI mice (Fig. 18, 19 and Table 2).

As we demonstrate in our study $\operatorname{CLA}$ and nitrite co-administration decreased apoptosis though the HO-1 and/or miRNA-499 pathway. To investigate more deeply the role of HO-1 and/or miRNA-499 in apoptosis, we used $\mathrm{HO}-1 \mathrm{Tg}$ and $\mathrm{HO}-1 \mathrm{KO}$ mice. Our data supported the hypothesis that $\mathrm{HO}-1$ regulates miRNA-499 levels and thus decreases apoptosis after MI. As others and we have demonstrated before, $\mathrm{Ml}$ is known to cause cardiomyocyte ischemia, in turn, leading to cardiomyocyte apoptosis [1, 2]. The current study 
extends previous findings by demonstrating that ischemia causes an increased ratio of $\mathrm{Bax} / \mathrm{Bcl}-2$ following $\mathrm{Ml}$ in non-treated $\mathrm{C} 57$ mice and in $\mathrm{HO}-1 \mathrm{KO}$ mice (Fig. 22). Our data demonstrate that in $\mathrm{HO}-1 \mathrm{KO}$ mice the expression of miRNA499 is not detectable (Fig. 21).

Treatment with $\mathrm{CLA}$ and nitrite increased expression of $\mathrm{HO}-1$ in isolated cardiomyocytes from C57 and $\mathrm{HO}-1 \mathrm{Tg}$ mice (Fig. 25 and 26), as well as increased miRNA-499 level in isolated cardiomyocytes from C57 and HO-1 TG mice (Fig. 25 and 26). Data further suggests that co-administration of CLA and nitrite cannot increase the levels of $\mathrm{HO}-1$ and meanwhile cannot change the levels of miRNA-499 in isolated cardiomyocytes from HO-1 KO mice (Fig. 25 and 26).

Overall, these data reveal mechanistic links between p53, HO-1, miRNA-499, and Drp1 with regard to regulation of the apoptotic programed cell death in the heart. Taken together, these results suggest that therapeutic treatment with $c L A$ and nitrite may provide cardiac protection during MI through the regulation of induction of cardiac specific HO-1 expression, which further regulated cardiac specific miRNA-499. Further validation studies are required in small and large preclinical animal models with the goal of clinical translation. 


\section{CHAPTER VI}

\section{IMPLICATION IN HEALTH AND DISEASE}

Multiple clinical trials support that the increased dietary intake of unsaturated fatty acids promotes a broad range of physiological benefits [86, 138]. Results from Herbel reported a mean dietary CLA intake of $139 \mathrm{mg} / \mathrm{d}$ in young men and women [139], and Park's lab showed an estimated mean cLA intake in lactating women during periods of low and high dairy consumption of 20 and $290 \mathrm{mg} / \mathrm{d}$, respectively [140]. In summary, chronic as well as acute total cLA intake in men and women has not been reported to exceed $500 \mathrm{mg} / \mathrm{d}$ [141].

Dairy products were the primary source of total CLA, followed by beef $[70$, 73]. It has been identified that conjugated linoleic acid (CLA) is the preferential substrate for fatty acid nitration in humans [86]. Most importantly, it has been reported that CLA nitration occurs in healthy humans (as measured in plasma and urine) and may be increased in experimental models of inflammation upon oral delivery of $\mathrm{CLA}$ and inorganic nitrite $\left(\mathrm{NO}_{2}\right)$ [86]. Because of the public concern with nitrite toxicity (the lethal dose in humans is about 22 milligrams per kilogram of body weight), the maximum allowed nitrite concentration in meat 
products is $200 \mathrm{ppm}$ [142]. Approximately 80 to $90 \%$ of the nitrite in the average U.S. diet is not from cured meat products, but from natural nitrite production from vegetable nitrate intake [142]. In our lab we have demonstrated that in mice, nitrite consumption together with cLA administration prevents heart failure, which may be one explanation for the apparent health effect of the Mediterranean diet [143]. 


\section{REFERENCES}

1. Long, X., et al., p53 and the hypoxia-induced apoptosis of cultured neonatal rat cardiac myocytes. The Journal of Clinical Investigation, 1997. 99(11): p. 2635-2643.

2. Kimata, M., et al., p53 and TIGAR regulate cardiac myocyte energy homeostasis under hypoxic stress. American Journal of Physiology - Heart and Circulatory Physiology, 2010. 299(6): p. H1908-H1916.

3. Rafiq, K., et al., c-Cbl inhibition improves cardiac function and survival in response to myocardial ischemia. Circulation, 2014. 129(20): p. 2031-43.

4. Nabel, E.G. and E. Braunwald, $A$ tale of coronary artery disease and myocardial infarction. N Engl J Med, 2012. 366(1): p. 54-63.

5. Mozaffarian, D., et al., Heart disease and stroke statistics--2015 update: a report from the American Heart Association. Circulation, 2015. 131(4): p. e29-322.

6. Gunnar, R.M., et al., ACC/AHA guidelines for the early management of patients with acute myocardial infarction. A report of the American College of Cardiology/American Heart Association Task Force on Assessment of Diagnostic and Therapeutic Cardiovascular Procedures (subcommittee to develop guidelines for the early management of patients with acute myocardial infarction). Circulation, 1990. 82(2): p. 664-707.

7. Jencks, S.F. and G.R. Wilensky, The health care quality improvement initiative. A new approach to quality assurance in Medicare. Jama, 1992. 268(7): p. 900-3.

8. National Hospital Ambulatory Medical Care Survey,. (CDCINCHS). , 1996

9. $\quad$ Phase I, National Heath and Nutrition Examination Survey 11. 1988-91.

10. The National Heart Lung and Blood Institute 2015.

11. Go, A.S., et al., Heart disease and stroke statistics--2014 update: a report from the American Heart Association. Circulation, 2014. 129(3): p. e28-e292.

12. Hori, M. and K. Nishida, Oxidative stress and left ventricular remodelling after myocardial infarction. Cardiovascular Research, 2009. 81(3): p. 457-464.

13. Mateus, P.S., et al., Left ventricular dysfunction after acute myocardial infarction--the impact of cardiovascular risk factors. Rev Port Cardiol, 2005. 24(5): p. 727-34.

14. Cotran RS, K.V., Robbins SL Robbins Pathologic Basis of Disease. 5th ed. Philadelphia: WB Saunders, 1994.

15. Krijnen, P.A., et al., Apoptosis in myocardial ischaemia and infarction. J Clin Pathol, 2002. 55(11): p. 801-11.

16. Choong-Chin, L. and J.D. Victor, Molecular genetics and genomics of heart failure. Nature Reviews Genetics, 2004. 5(11): p. 811-825.

17. Lowes, B.D., et al., Myocardial Gene Expression in Dilated Cardiomyopathy Treated with Beta-Blocking Agents. New England Journal of Medicine, 2002. 346(18): p. 1357-1365. 
18. Kaab, S., et al., Global gene expression in human myocardium-oligonucleotide microarray analysis of regional diversity and transcriptional regulation in heart failure. Journal of Molecular Medicine, 2004. 82(5): p. 308-316.

19. Barth, A.S., et al., Identification of a Common Gene Expression Signature in Dilated Cardiomyopathy Across Independent Microarray Studies. Journal of the American College of Cardiology, 2006. 48(8): p. 1610-1617.

20. Movassagh, M., et al., Differential DNA Methylation Correlates with Differential Expression of Angiogenic Factors in Human Heart Failure. PLoS ONE, 2010. 5(1): p. e8564.

21. Izumo, S., B. Nadal-Ginard, and V. Mahdavi, Protooncogene induction and reprogramming of cardiac gene expression produced by pressure overload. Proceedings of the National Academy of Sciences, 1988. 85(2): p. 339-343.

22. van Empel, V.P.M., et al., Myocyte apoptosis in heart failure. Cardiovascular Research, 2005. 67(1): p. 21-29.

23. Wencker, D., et al., A mechanistic role for cardiac myocyte apoptosis in heart failure. The Journal of Clinical Investigation, 2003. 111(10): p. 1497-1504.

24. Dorn, G.W., 2nd, Mechanisms of non-apoptotic programmed cell death in diabetes and heart failure. Cell Cycle, 2010. 9(17): p. 3442-8.

25. Saraste, A. and K. Pulkki, Morphologic and biochemical hallmarks of apoptosis. Vol. 45. 2000. 528-537.

26. Elmore, S., Apoptosis: A Review of Programmed Cell Death. Toxicologic Pathology, 2007. 35(4): p. 495-516.

27. Ibe, W., et al., Cardiomyocyte apoptosis is related to left ventricular dysfunction and remodelling in dilated cardiomyopathy, but is not affected by growth hormone treatment. Eur J Heart Fail, 2007. 9(2).

28. Pantos, C. and I. Mourouzis, The Emerging Role of TR1 in Cardiac Repair: Potential Therapeutic Implications. Oxidative Medicine and Cellular Longevity, 2014. 2014: p. 8.

29. Fulda, S., et al., Cellular Stress Responses: Cell Survival and Cell Death. International Journal of Cell Biology, 2010. 2010: p. 23.

30. $\mathrm{Pu}, \mathrm{J}$, , et al., Cardiomyocyte-expressed farnesoid-X-receptor is a novel apoptosis mediator and contributes to myocardial ischaemia/reperfusion injury. Eur Heart J, 2013. 34(24): p. 1834-45.

31. Sabbah, H.N., Apoptotic cell death in heart failure. Vol. 45. 2000. 704-712.

32. Taimor, G., et al., Induction of necrosis but not apoptosis after anoxia and reoxygenation in isolated adult cardiomyocytes of rat. Vol. 41. 1999. 147-156.

33. Kajstura, J., et al., Apoptotic and necrotic myocyte cell deaths are independent contributing variables of infarct size in rats. Lab Invest, 1996. 74(1): p. 86-107.

34. Fliss, H. and D. Gattinger, Apoptosis in Ischemic and Reperfused Rat Myocardium. Circulation Research, 1996. 79(5): p. 949-956.

35. Cheng, W., et al., Programmed myocyte cell death affects the viable myocardium after infarction in rats. Exp Cell Res, 1996. 226(2): p. 316-27.

36. Saraste, A.A., Apoptosis in human acute myocardial infarction. Circulation, 1997. 95(2): p. 320-3.

37. Olivetti, G., Acute Myocardial Infarction in Humans is Associated with Activation of Programmed Myocyte Cell Death in the Surviving Portion of the Heart. Journal of Molecular and Cellular Cardiology, 1996. 28(9): p. 2005. 
38. Krijnen, P.A.J., et al., Apoptosis in myocardial ischaemia and infarction. Journal of Clinical Pathology, 2002. 55(11): p. 801-811.

39. Fridman, J.S. and S.W. Lowe, Control of apoptosis by p53. Oncogene, 2003. 22(56): p. 9030-9040.

40. Crow, M.T., et al., The Mitochondrial Death Pathway and Cardiac Myocyte Apoptosis. Circulation Research, 2004. 95(10): p. 957-970.

41. Cheng, W.W., Stretch-induced programmed myocyte cell death. Journal of Clinical Investigation, 1995. 96(5): p. 2247-59.

42. Saraste, A., et al., Apoptosis in Human Acute Myocardial Infarction. Circulation, 1997. 95(2): p. 320-323.

43. Díez, J., et al., Cardiomyocyte Apoptosis and Cardiac Angiotensin-Converting Enzyme in Spontaneously Hypertensive Rats. Hypertension, 1997. 30(5): p. 1029-1034.

44. Lu, J., et al., Changes in apoptosis-related protein (p53, Bax, Bcl-2 and Fos) expression with DNA fragmentation in the central nervous system in rats after closed head injury. Neuroscience Letters, 2000. 290(2): p. 89-92.

45. Misao, J., et al., Expression of bcl-2 protein, an inhibitor of apoptosis, and Bax, an accelerator of apoptosis, in ventricular myocytes of human hearts with myocardial infarction. Circulation, 1996. 94(7): p. 1506-12.

46. Oltvai, Z.N., C.L. Milliman, and S.J. Korsmeyer, Bcl-2 heterodimerizes in vivo with a conserved homolog, Bax, that accelerates programmed cell death. Cell, 1993. 74(4): p. 609-19.

47. Porebska, I., et al., Apoptotic markers p53, Bcl-2 and Bax in primary lung cancer. In Vivo, 2006. 20(5): p. 599-604.

48. Xue, X., et al., Bcl-xL Genetic Modification Enhanced the Therapeutic Efficacy of Mesenchymal Stem Cell Transplantation in the Treatment of Heart Infarction. Stem Cells International, 2015. 2015.

49. Huang, J., et al., BCl-xL gene transfer protects the heart against ischemia/reperfusion injury. Biochem Biophys Res Commun, 2003. 311(1): p. 64-70.

50. Huang, J., et al., BCl-xL gene transfer inhibits Bax translocation and prolongs cardiac cold preservation time in rats. Circulation, 2005. 112(1): p. 76-83.

51. Zhao, Z.-Q. and J. Vinten-Johansen, Myocardial apoptosis and ischemic preconditioning. Vol. 55. 2002. 438-455.

52. Zhao, Z.Q., et al., Dynamic progression of contractile and endothelial dysfunction and infarct extension in the late phase of reperfusion. J Surg Res, 2000. 94(2): p. 133-44.

53. Zhao, Z.Q., et al., Progressively developed myocardial apoptotic cell death during late phase of reperfusion. Apoptosis, 2001. 6(4): p. 279-90.

54. Zhao, T., et al., Central Role of Mitofusin 2 in Autophagosome-Lysosome Fusion in Cardiomyocytes. Journal of Biological Chemistry, 2012. 287(28): p. 23615-23625.

55. Shieh, J.T.C., et al., Elevated miR-499 Levels Blunt the Cardiac Stress Response. PLoS ONE, 2011. 6(5).

56. Zhu, H. and G.-C. Fan, Role of microRNAs in the reperfused myocardium towards postinfarct remodelling. Cardiovascular Research, 2012. 94(2): p. 284-292.

57. Wang, J.X., et al., miR-499 regulates mitochondrial dynamics by targeting calcineurin and dynamin-related protein-1. Nat Med, 2011. 17(1): p. 71-8.

58. Adachi, T., et al., Plasma MicroRNA 499 as a Biomarker of Acute Myocardial Infarction. Clinical Chemistry, 2010. 56(7): p. 1183-1185. 
59. Olivieri, F., et al., Diagnostic potential of circulating miR-499-5p in elderly patients with acute non ST-elevation myocardial infarction. Int J Cardiol, 2013. 167(2): p. 531-6.

60. Chen, X., et al., Kinetics of plasma microRNA-499 expression in acute myocardial infarction. Journal of Thoracic Disease, 2015. 7(5): p. 890-896.

61. Li, X., et al., MiR-499 regulates cell proliferation and apoptosis during late-stage cardiac differentiation via Sox6 and cyclin D1. PLoS One, 2013. 8(9).

62. Ong, S.-B., et al., Inhibiting Mitochondrial Fission Protects the Heart Against Ischemia/Reperfusion Injury. Circulation, 2010. 121.

63. Dimmer, K.S. and L. Scorrano, (De)constructing Mitochondria: What For? Physiology, 2006. 21(4): p. 233-241.

64. Hausenloy, D.J. and L. Scorrano, Targeting Cell Death. Clinical Pharmacology \& Therapeutics, 2007. 82(4): p. 370-373.

65. Chen, H. and D.C. Chan, Mitochondrial dynamics-fusion, fission, movement, and mitophagy-in neurodegenerative diseases. Human Molecular Genetics, 2009. 18.

66. Suen, D.-F., K.L. Norris, and R.J. Youle, Mitochondrial dynamics and apoptosis. Genes \& Development, 2008. 22.

67. Liesa, M., M. Palacín, and A. Zorzano, Mitochondrial Dynamics in Mammalian Health and Disease. Physiological Reviews, 2009.

68. Kukreja, R.C., C. Yin, and F.N. Salloum, MicroRNAs: New Players in Cardiac Injury and Protection. Molecular Pharmacology, 2011. 80(4).

69. Wang, J., et al., miR-499 protects cardiomyocytes from H2O2-induced apoptosis via its effects on Pdcd4 and Pacs2. RNA Biology, 2014. 11(4).

70. association, N.c.s.b., Human nutrition research. 2007.

71. Dhiman, T.R., S.H. Nam, and A.L. Ure, Factors affecting conjugated linoleic acid content in milk and meat. Crit Rev Food Sci Nutr, 2005. 45(6): p. 463-82.

72. Parodi, P.W., Conjugated linoleic acid in food. Advances in Conjugated Linoleic Acid Reasearch, Volume 2, Champaign, IL; AOCS Press,, 2003: p. pp. 101-122.

73. Chin, S.F., et al., Dietary sources of conjugated dienoic isomers of linoleic acid, a newly recognized class of anticarcinogens. Journal of Food Composition and Analysis, 1992. 5(3): p. 185-197.

74. Chen, S., et al., Anti-aromatase activity of phytochemicals in white button mushrooms (Agaricus bisporus). Cancer Res, 2006. 66(24): p. 12026-34.

75. Banni, S., Conjugated linoleic acid metabolism. Curr Opin Lipidol, 2002. 13(3): p. 261-6.

76. Shen, W., et al., Conjugated linoleic acid reduces adiposity and increases markers of browning and inflammation in white adipose tissue of mice. Journal of Lipid Research, 2013. 54(4): p. 909-922.

77. Cook, M.E., et al., Immune Modulation by Altered Nutrient Metabolism: Nutritional Control of Immune-Induced Growth Depression. Poultry Science, 1993. 72(7): p. 13011305.

78. Miller, C.C., et al., Feeding Conjugated Linoleic Acid to Animals Partially Overcomes Catabolic Responses Due to Endotoxin Injection. Biochemical and Biophysical Research Communications, 1994. 198(3): p. 1107-1112.

79. Wahle, K.W.J., S.D. Heys, and D. Rotondo, Conjugated linoleic acids: are they beneficial or detrimental to health? Progress in Lipid Research, 2004. 43(6): p. 553-587.

80. Lee, K.N., D. Kritchevsky, and M.W. Parizaa, Conjugated linoleic acid and atherosclerosis in rabbits. Atherosclerosis, 1994. 108(1): p. 19-25. 
81. Toomey, S., et al., Profound resolution of early atherosclerosis with conjugated linoleic acid. Atherosclerosis, 2006. 187(1): p. 40-49.

82. Mooney, D., C. McCarthy, and O. Belton, Effects of conjugated linoleic acid isomers on monocyte, macrophage and foam cell phenotype in atherosclerosis. Prostaglandins \& Other Lipid Mediators, 2012. 98(3-4): p. 56-62.

83. Houseknecht, K.L., et al., Dietary Conjugated Linoleic Acid Normalizes Impaired Glucose Tolerance in the Zucker Diabetic Fattyfa/faRat. Biochemical and Biophysical Research Communications, 1998. 244(3): p. 678-682.

84. Belury, M.A., A. Mahon, and S. Banni, The Conjugated Linoleic Acid (CLA) Isomer, t10c12CLA, Is Inversely Associated with Changes in Body Weight and Serum Leptin in Subjects with Type 2 Diabetes Mellitus. The Journal of Nutrition, 2003. 133(1): p. 257S-260S.

85. Piell, K.M., et al., Nitrite treatment rescues cardiac dysfunction in aged mice treated with conjugated linoleic acid. Free Radical Biology and Medicine, 2014. 72(0): p. 66-75.

86. Bonacci, G., et al., Conjugated Linoleic Acid Is a Preferential Substrate for Fatty Acid Nitration. Journal of Biological Chemistry, 2012. 287(53): p. 44071-44082.

87. Ryter, S.W., J. Alam, and A.M.K. Choi, Heme Oxygenase-1/Carbon Monoxide: From Basic Science to Therapeutic Applications. Physiological Reviews, 2006. 86(2): p. 583-650.

88. Maines, M.D., THE HEME OXYGENASE SYSTEM:A Regulator of Second Messenger Gases. Annual Review of Pharmacology and Toxicology, 1997. 37(1): p. 517-554.

89. Paine, A., et al., Signaling to heme oxygenase-1 and its anti-inflammatory therapeutic potential. Biochemical Pharmacology, 2010. 80(12): p. 1895-1903.

90. Wang, G., et al., Cardioprotective and Antiapoptotic Effects of Heme Oxygenase-1 in the Failing Heart. Circulation, 2010. 121(17): p. 1912-1925.

91. Collino, M., et al., Beneficial effect of prolonged heme oxygenase 1 activation in a rat model of chronic heart failure. Dis Model Mech, 2013. 6(4): p. 1012-20.

92. Cai, C., et al., The heme oxygenase 1 inducer (COPP) protects human cardiac stem cells against apoptosis through activation of the extracellular signal-regulated kinase (ERK)/NRF2 signaling pathway and cytokine release. J Biol Chem, 2012. 287(40): p. 33720-32.

93. Foo, R.S., K. Mani, and R.N. Kitsis, Death begets failure in the heart. J Clin Invest, 2005. 115(3): p. 565-71.

94. Landmesser, U., K.C. Wollert, and H. Drexler, Potential novel pharmacological therapies for myocardial remodelling. Cardiovascular Research, 2009. 81(3): p. 519-527.

95. Sun, Y., Myocardial repair/remodelling following infarction: roles of local factors. Cardiovascular Research, 2009. 81(3): p. 482-490.

96. Jordan, S.F. and W.L. Scott, Control of apoptosis by p53. Oncogene, 2003. 22(56): p. 9030-9040.

97. Qipshidze-Kelm, N., et al., Co-treatment with conjugated linoleic acid and nitrite protects against myocardial infarction. Redox Biology, 2013. REDOX-D-13-00066.

98. Fujimoto, K.L., et al., Engineered fetal cardiac graft preserves its cardiomyocyte proliferation within postinfarcted myocardium and sustains cardiac function. Tissue Eng Part A, 2011. 17(5-6): p. 585-96.

99. Cole, M.P., et al., The protective roles of nitric oxide and superoxide dismutase in adriamycin-induced cardiotoxicity. Cardiovascular Research, 2006. 69(1): p. 186-197.

100. Combadière, $\mathrm{C}$., et al., Comment on " $\mathrm{Ccl} 2, \mathrm{C} \times 3 \mathrm{cr} 1$ and $\mathrm{Ccl} 2 / \mathrm{C} \times 3 \mathrm{cr} 1$ chemokine deficiencies are not sufficient to cause age-related retinal degeneration" by Luhmann 
et al. (Exp. Eye Res. 2013; 107: 80.doi: 10.1016). Experimental Eye Research, 2013. 111(0): p. 134-135.

101. Castro, G.J. and A. Bhatnagar, Effect of extracellular ions and modulators of calcium transport on survival of tert-butyl hydroperoxide exposed cardiac myocytes. Cardiovasc Res, 1993. 27(10): p. 1873-81.

102. Iwanaga, Y., et al., B-type natriuretic peptide strongly reflects diastolic wall stress in patients with chronic heart failure: comparison between systolic and diastolic heart failure. J Am Coll Cardiol, 2006. 47(4): p. 742-8.

103. Kinnunen, P., O. Vuolteenaho, and H. Ruskoaho, Mechanisms of atrial and brain natriuretic peptide release from rat ventricular myocardium: effect of stretching. Endocrinology, 1993. 132(5): p. 1961-70.

104. Yunis, J.J., et al., Distinctive chromosomal abnormalities in histologic subtypes of nonHodgkin's lymphoma. N Engl J Med, 1982. 307(20): p. 1231-6.

105. Maeda, K., et al., Plasma brain natriuretic peptide as a biochemical marker of high left ventricular end-diastolic pressure in patients with symptomatic left ventricular dysfunction. Am Heart J, 1998. 135(5 Pt 1): p. 825-32.

106. Zhu, H. and G.C. Fan, Role of microRNAs in the reperfused myocardium towards postinfarct remodelling. Cardiovasc Res, 2012. 94(2): p. 284-92.

107. Morita, E., et al., Increased plasma levels of brain natriuretic peptide in patients with acute myocardial infarction. Circulation, 1993. 88(1): p. 82-91.

108. Yasue, H., et al., Localization and mechanism of secretion of B-type natriuretic peptide in comparison with those of A-type natriuretic peptide in normal subjects and patients with heart failure. Circulation, 1994. 90(1): p. 195-203.

109. Schaur, R.J., Basic aspects of the biochemical reactivity of 4-hydroxynonenal. Mol Aspects Med, 2003. 24(4-5): p. 149-59.

110. Siems, W. and T. Grune, Intracellular metabolism of 4-hydroxynonenal. Mol Aspects Med, 2003. 24(4-5): p. 167-75.

111. Gutteridge, J.M. and B. Halliwell, Antioxidants: Molecules, medicines, and myths. Biochem Biophys Res Commun, 2010. 393(4): p. 561-4.

112. Zarkovic, K., 4-hydroxynonenal and neurodegenerative diseases. Mol Aspects Med, 2003. 24(4-5): p. 293-303.

113. Uchida, K., et al., Activation of stress signaling pathways by the end product of lipid peroxidation. 4-hydroxy-2-nonenal is a potential inducer of intracellular peroxide production. J Biol Chem, 1999. 274(4): p. 2234-42.

114. Poli, G. and R.J. Schaur, 4-Hydroxynonenal in the pathomechanisms of oxidative stress. IUBMB Life, 2000. 50(4-5): p. 315-21.

115. French, C.J., et al., The magnitude and temporal dependence of apoptosis early after myocardial ischemia with or without reperfusion. The FASEB Journal, 2009. 23(4): p. 1177-1185.

116. Qipshidze-Kelm, N., et al., Co-treatment with conjugated linoleic acid and nitrite protects against myocardial infarction. Redox Biology, 2014. 2(0): p. 1-7.

117. Qipshidze, N., et al., Hydrogen Sulfide Mitigates Cardiac Remodeling During Myocardial Infarction via Improvement of Angiogenesis. International Journal of Biological Sciences, 2012. 8(4): p. 430-441.

118. Qipshidze, N., et al., Folic acid improves acetylcholine-induced vasoconstriction of coronary vessels isolated from hyperhomocysteinemic mice: An implication to coronary vasospasm. Journal of Cellular Physiology, 2011. 226(10): p. 2712-2720. 
119. Qin, F., M.C. Liang, and C.-s. Liang, Progressive left ventricular remodeling, myocyte apoptosis, and protein signaling cascades after myocardial infarction in rabbits.

Biochimica et Biophysica Acta (BBA) - Molecular Basis of Disease, 2005. 1740(3): p. 499513.

120. Stampfer, M.J., et al., Primary Prevention of Coronary Heart Disease in Women through Diet and Lifestyle. New England Journal of Medicine, 2000. 343(1): p. 16-22.

121. Gebauer, S.K., et al., Effects of Ruminant trans Fatty Acids on Cardiovascular Disease and Cancer: A Comprehensive Review of Epidemiological, Clinical, and Mechanistic Studies.

Advances in Nutrition: An International Review Journal, 2011. 2(4): p. 332-354.

122. van de Vossenberg, J.L.C.M. and K.N. Joblin, Biohydrogenation of C18 unsaturated fatty acids to stearic acid by a strain of Butyrivibrio hungatei from the bovine rumen. Letters in Applied Microbiology, 2003. 37(5): p. 424-428.

123. Campbell, W., M.A. Drake, and D.K. Larick, The Impact of Fortification with Conjugated Linoleic Acid (CLA) on the Quality of Fluid Milk. Journal of Dairy Science, 2003. 86(1): p. 43-51.

124. Pariza, M.W., Y. Park, and M.E. Cook, The biologically active isomers of conjugated linoleic acid. Progress in Lipid Research, 2001. 40(4): p. 283-298.

125. Freeman, B.A., et al., Nitro-fatty Acid Formation and Signaling. Journal of Biological Chemistry, 2008. 283(23): p. 15515-15519.

126. Chang, C.-R. and C. Blackstone, Dynamic regulation of mitochondrial fission through modification of the dynamin-related protein Drp1. Annals of the New York Academy of Sciences, 2010. 1201(1): p. 34-39.

127. Zhu, P.-P., et al., Intra- and Intermolecular Domain Interactions of the C-terminal GTPase Effector Domain of the Multimeric Dynamin-like GTPase Drp1. Journal of Biological Chemistry, 2004. 279(34): p. 35967-35974.

128. Din, S., et al., Pim-1 preserves mitochondrial morphology by inhibiting dynamin-related protein 1 translocation. Proceedings of the National Academy of Sciences, 2013. 110(15): p. 5969-5974.

129. Vaux, D.L., S. Cory, and J.M. Adams, Bcl-2 gene promotes haemopoietic cell survival and cooperates with c-myc to immortalize pre-B cells. Nature, 1988. 335(6189): p. 440-2.

130. Green, D.R. and J.C. Reed, Mitochondria and apoptosis. Science, 1998. 281(5381): p. 1309-12.

131. Leri, A., et al., Stretch-mediated release of angiotensin II induces myocyte apoptosis by activating $p 53$ that enhances the local renin-angiotensin system and decreases the Bcl-2to-Bax protein ratio in the cell. J Clin Invest, 1998. 101(7): p. 1326-42.

132. Leri, A., et al., Pacing-induced heart failure in dogs enhances the expression of $p 53$ and p53-dependent genes in ventricular myocytes. Circulation, 1998. 97(2): p. 194-203.

133. Rudolph, V., et al., Endogenous generation and protective effects of nitro-fatty acids in a murine model of focal cardiac ischaemia and reperfusion. Cardiovascular Research, 2010. 85(1): p. 155-166.

134. Cole, M.P., et al., Nitro-Fatty Acid Inhibition of Neointima Formation After Endoluminal Vessel Injury. Circulation Research, 2009. 105(10): p. 965-972.

135. Yoshida, T., et al., Hmox-1 Constitutes an Adaptive Response to Effect Antioxidant Cardioprotection : A Study With Transgenic Mice Heterozygous for Targeted Disruption of the Heme Oxygenase-1 Gene. Circulation, 2001. 103(12): p. 1695-1701. 
136. Yet, S.-F., et al., Cardiac-Specific Expression of Heme Oxygenase-1 Protects Against Ischemia and Reperfusion Injury in Transgenic Mice. Circulation Research, 2001. 89(2): p. 168-173.

137. Melo, L.G., et al., Gene Therapy Strategy for Long-Term Myocardial Protection Using Adeno-Associated Virus-Mediated Delivery of Heme Oxygenase Gene. Circulation, 2002. 105(5): p. 602-607.

138. Harris, W.S., et al., Omega-6 Fatty Acids and Risk for Cardiovascular Disease: A Science Advisory From the American Heart Association Nutrition Subcommittee of the Council on Nutrition, Physical Activity, and Metabolism; Council on Cardiovascular Nursing; and Council on Epidemiology and Prevention. Circulation, 2009. 119(6): p. 902-907.

139. Herbel, B.K., et al., Safflower oil consumption does not increase plasma conjugated linoleic acid concentrations in humans. Am J Clin Nutr, 1998. 67(2): p. 332-7.

140. Park, Y., et al., High-fat dairy product consumption increases delta 9c,11t-18:2 (rumenic acid) and total lipid concentrations of human milk. Lipids, 1999. 34(6): p. 543-9.

141. Ritzenthaler, K.L., et al., Estimation of conjugated linoleic acid intake by written dietary assessment methodologies underestimates actual intake evaluated by food duplicate methodology. J Nutr, 2001. 131(5): p. 1548-54.

142. Jakszyn, P. and C.A. González, Nitrosamine and related food intake and gastric and oesophageal cancer risk: A systematic review of the epidemiological evidence. World Journal of Gastroenterology : WJG, 2006. 12(27): p. 4296-4303.

143. Charles, R.L., et al., Protection from hypertension in mice by the Mediterranean diet is mediated by nitro fatty acid inhibition of soluble epoxide hydrolase. Proceedings of the National Academy of Sciences, 2014. 111(22): p. 8167-8172. 


\section{CURRICULUM VITAE \\ Natia Qipshidze Kelm \\ University of Louisville}

$\begin{array}{ll}\text { 1/2013- present } & \begin{array}{l}\text { PhD student. Department of Physiology and Biophysics } \\ \text { University of Louisville }\end{array} \\ & \text { Supervisor: Assistant Professor: Marsha P. Cole } \\ 10 / 2012-1 / 2013 & \underline{\text { PhD student. Department of Physiology and Biophysics }}\end{array}$

University of Louisville

Supervisor: Prof. Suresh C. Tyagi, Ph.D.

10/2008 - 1/2012 Postdoctoral Fellow. Department of Physiology and

Biophysics University of Louisville

Supervisor: Prof. Suresh C. Tyagi, Ph.D.

4/2005 - 10/2008 Junior Physician Hospital \#1 at the Tbilisi State Medical University Specialty: Cardiology (equals to a clinical residency) Job requirements: 
a) Record EKG, read the EKG, and based on the results make appropriate diagnoses and treatment

b) Use of Electroshock during ventricular fibrillations.

c) Perform percutaneous coronary intervention.

d) Perform Echocardiography

4/2008 - 10/2008 Medical Representative, PSP Group at the GMP (Pharmaceutical company)

Job requirements: Provide full specifications of the company drugs to doctors in hospitals. Oversee effects of the treatments

Conduct clinical studies on drug effects and evaluate efficacy of the drug.

$3 / 2007-4 / 2008$ Medical Representative, "Spespharma" (Pharmaceutical company)

Job requirements: Provide full specifications of the company drugs to doctors in hospitals. Oversee effects of the treatments conduct clinical studies on drug effects and evaluate efficacy of the drug. 


\section{TEACHING}

1/2005 - 10/2008 Graduate students training in techniques of EKG and percutaneous coronary intervention, Tbilisi State Medical University

\section{EDUCATION}

8/2012- present PhD student - Department of Physiology and Biophysics GPA: 3.535

9/1998 - 8/2004 Attended and graduated from Tbilisi State Medical

University,

Tbilisi, Georgia Specialty: General physician

GPA: 3.85

\section{PUBLICATIONS}

1. Qipshidze N, Tyagi N, Sen U, Givvimani S, Metreveli N, Lominadze D, Tyagi SC. Folic acid mitigated cardiac dysfunction by normalizing the levels of tissue inhibitor of metalloproteinase and homocysteine-metabolizing enzymes. Post 
Myocardial Infarction in Mice. American Journal of Physiology, Heart and Circulatory Physiology. 2010; 299(5): H1484-1493.

2. Qipshidze N, Metreveli N, Lominadze D, Tyagi SC. Folic acid improves acetylcholine-induced vasoconstriction of coronary vessels isolated from hyperhomocysteinemic mice: An Implication to Coronary Vasospasm. J Cell Physiol. 2011 Oct;226(10):2712-20. doi: 10.1002/jcp.22621 .

3. Qipshidze N, Tyagi N, Metreveli N, Lominadze D, Tyagi SC. Mechanism of right ventricular remodeling in murine model during right ventricular failure (In press: American Journal of Physiology, Heart and Circulatory Physiology 2011)

4. Qipshidze N, Metreveli N, Mishra P, Lominadze D, Tyagi SC. Hydrogen sulfide regulates cardiac function and structure during myocardial infarction in mice via improvement of angiogenesis. (International Journal of Biological Sciences

2012 in press)

5. Qipshidze-Kelm N, Piell KM, Solinger J, Cole MP. Combination Treatment with Conjugated Linoleic Acid and Nitrite Protects Against Myocardial Infarction. 10.1015/J.redox.2013.10.009

as a Co-Author (Selected):

1. Tyagi N, Givvimani S, Qipshidze N, Kundu S, Kapoor S, Vacek JC, Tyagi SC. Hydrogen sulfide mitigates matrix metalloproteinase- 9 activity and neurovascular permeability in hyperhomocysteinemic mice. Neurochem Int. 2010 Jan;56(2):301-7 
2. Givvimani S, Tyagi N, Sen U,MishraPK, Qipshidze N, Munjal C, Abe QA, Tyagi SC. MMP-2/TIMP-2/TIMP-4 versus MMP-9/TIMP-3 in Transition from Compensatory hypertrophy and angiogenesis to decompensatory heart failure. Arch Physiol Biochem. 116 (2): 63- 72: 2010. PMID: 20230216

3. Sen U, Munjal C, Qipshidze N, Abe O, Gargoum R, Tyagi SC. Hydrogen sulfide regulates homocysteine-mediated glomerulosclerosis. Am J Nephrol. 2010; 31(5):442-55

4. Munjal C, Givvimani S, Qipshidze N,Tyagi N, Falcone JC, Tyagi SC. Mesenteric Vascular Remodeling in Hyperhomocysteinemia. Cellular and Molecular Biology, Mol Cell Biochem. 2010 Nov 13

5. Tyagi N, Kandel M, Munjal C, Qipshidze N, Vacek JC, Pushpakumar SB, Metreveli N, Tyagi SC. Homocysteine mediated decrease in bone blood flow and remodeling: Role of folic acid. J Orthop Res. 2011 Apr 5. doi: 10.1002/jor.21415. 6. Givvimani S, Qipshidze N, Tyagi N, Mishra PK, Sen U, Tyagi SC. Synergism between arrhythmia and hyperhomocysteinemia in structural heart disease, Intern J of Physiol, Pathophysiol \& Pharmacology, 3(2):107-119, 2011.

7. MishraPK, Olubusayo Awe, Metreveli N, Quipshidze N, Joshua IG, Tyagi SC: Exercise mitigates the homocysteine - beta2-adrenergic receptor interactions to ameliorate contractile dysfunction in diabetes. Int J Physiol Pathophysiol Pharmacol 2011;3(2):97-106.

8. Dahiya S, Givvimani S, Bhatnagar S, Qipshidze N, Tyagi SC, Kumar A. Osteopontin-stimulated expression of matrix metalloproteinase-9 causes 
cardiomyopathy in the mdx model of Duchenne muscular dystrophy. J Immunol. 2011 Sep 1;187(5):2723-31. Epub 2011 Aug 1.

9. Basu P, Qipshidze N, Sen U, Givvimani S, Munjal C, Mishra PK, Tyagi SC. Chronic hyperhomocysteinemia causes vascular remodelling by instigating vein phenotype in artery Arch Physiol Biochem. 2011 Aug 13. [Epub ahead of print] 10. Muradashvili N, Qipshidze N, Munjal C, Givvimani S, Benton R, Roberts AM, Tyagi SC, and Lominadze D. Fibrinogen-Induced Increased Pial Venular Permeability in Mice. J Cereb Blood Flow Metab. 2011 Oct 12. doi:

10.1038/jcbfm.2011.144

11. Tyagi N, Qipshidze N, Sen U, Rodriguez W, Ovechkin A, Tyagi SC. Cystathionine beta synthase gene dose dependent vascular remodeling in murine model of hyperhomocysteinemia. nt J Physiol Pathophysiol Pharmacol. 2011 Sep 30;3(3):210-22. Epub 2011 Sep 8.

12. Basu P, Qipshidze N, Tyagi SC, Sen U. Remodeling in vein expresses arterial phenotype in hyperhomocysteinemia. Int J Physiol Pathophysiol Pharmacol. 2011;3(4):266-79. Epub 2011 Nov 15.

13. Tyagi N, Qipshidze N, Munjal C, Vacek JC, Metreveli N, Givvimani S, Tyagi SC. Tetrahydrocurcumin Ameliorates Homocysteinylated Cytochrome-c Mediated Autophagy in Hyperhomocysteinemia Mice after Cerebral Ischemia. J Mol Neurosci. 2012 Jan 3. [Epub ahead of print] 
14. Sen U, Sathnur PB, Kundu S, Givvimani S, Coley DM, Mishra PK, Qipshidze N, Tyagi N, Metreveli N, Tyagi SC.ncreased endogenous H2S generation by CBS, CSE, and 3MST gene therapy improves ex vivo renovascular relaxation in hyperhomocysteinemia. Am J Physiol Cell Physiol. 2012 Jul 1;303(1):C41-51. doi: 10.1152/ajpcell.00398.2011. Epub 2012 Apr 18.

15. Givvimani S, Kundu S, Narayanan N, Armaghan F, Qipshidze N, Pushpakumar S, Vacek TP, Tyagi SC. TIMP-2 mutant decreases MMP-2 activity and augments pressure overload induced LV dysfunction and heart failureArch Physiol Biochem. 2013 May;119(2):65-74. doi: 10.3109/13813455.2012.755548. Epub 2013 Feb 11.

16. Vacek TP, Qipshidze N, Tyagi SC Hydrogen sulfide and sodium nitroprusside compete to activate/deactivate MMPs in bone tissue homogenates, Vasc Health Risk Manag. 2013;9:117-23. doi: 10.2147/VHRM.S39508. Epub 2013 Mar 19.

17. Piell KM, Qipshidze-Kelm N, Caroway MP, Aman M, Cole MP. Nitrite Treatment Rescues Cardiac Dysfunction in Aged Mice Treated with Conjugated Linoleic Acid, Free Radic Biol Med. 2014 Jul;72:66-75. doi:

10.1016/j.freeradbiomed.2014.03.043. Epub 2014 Apr 8. 
18. Khundmiri SJ, Salyer SA, Farmer B, Qipshidze-Kelm N, Murray RD, Clark BJ, Xie Z, Pressley TA, Lederer ED.Structural determinants for the ouabainstimulated increase in Na-K ATPase activity,

\section{Submitted:}

1. Natia Qipshidze Kelm, Shephali Bhatnagar, Vikranth Shetty, Eugenia Wang and Marsha P. Cole. Predictive MicroRNA Biomarkers for Myocardial Injury in Aged Mice Following Myocardial Infarction (Submitted Journal of Cellular Physiology)

\section{Abstracts Presented in Symposium/Seminar (since2009):}

\section{Oral presentations:}

1. Qipshidze N, Tyagi N, Metreveli N, Lominadze D, Tyagi SC. Folic acid improves acetylcholine- induced vasoconstriction of coronary vessels isolated from hyperhomocyteinemic mice: implications to coronary vasospasm. 9th World Congress for Microcirculation. Abstract Book. 2010, SY5-1, 26

2. Tyagi N, Qipshidze N, Givvimani S, Kandel M, Mishra PK, Sen U, Johar A, Tyagi SC. Tetrahydrocucrumin ameliorates mtMMP-9-mediated mitophagy and mitochondria remodeling in stroke. . Experimental Biology 2010; S 145.

3, Qipshidze N and Tyagi SC Mitophagy causes coronary artery endothelial dysfunction in oxidative stress dose-dependent (i.e. C57>FVB>C3H mice) manner during right ventricle failure. Experimental Biology 2011888.10 
4. Natia Qipshidze, Ankur Kanotra, and Suresh C. Tyagi,Mitochondrial

Division/Mitophagy Inhibitor (Mdivi-1) Protects Right Ventricle from Severe Heart Failure Experimental Biology 2012.

5. Qipshidze-Kelm N, Piell KM, Solinger j, Cole MP. Combination Treatment with Conjugated Linoleic Acid and Nitrite Protects Against Myocardial Infarction. BMB retreat 2013. AWARD: Best postdoctoral presentation 2013

\title{
National / International Meetings
}

1. Qipshidze N, Tyagi N, Sen U, Givvimani S, Metreveli N, Abe OA, Lominadze D, Tyagi SC. Folic acid mitigated cardiac dysfunction by normalizing the levels of tissue inhibitor of metalloproteinase and homocysteine-metabolizing enzymes post myocardial infarction in mice. Experimental Biology 2010;S 139

\author{
Abstracts: \\ 1. Basu P, Sen U, Kundu S, Mishra PK, Qipshidze N, Abe OA, Vacek J, Tyagi \\ SC. Blood flow mediated vascular remodeling in arteries and vein. 63rd High \\ Blood Pressure Conference, 2009, P316.
}


2. Sen U, Qipshidze N, Givvimani S, Abe OA, Metreveli N, Tyagi SC. Ang IIinduced hypertension: Role of homocysteine in vasculogenesis and cortical blood flow. 63rd High Blood Pressure Conference, 2009, P433.

3. Mishra PK, Metreveli N, Givvimani S, Kundu S, Tyagi N, Qipshdze N, Sen U, Basu P, Abe OA, Gillespie WM, Munjal C, Vacek J, Tyagi SC. Downregulation of dicer involved in MMP-9 mediated cardiomyocytes dysfunction. 63rd High Blood Pressure Conference, 2009, P111.

4. Tyagi N, Kundu S, Qipshidze N, Paras Mishra, S. Givvimani, S. Tyagi.

Cardiac- specific deletion of N-methyl-D-aspartate R1 ameliorates mitochondrial connexin-43 translocation and mitochondrial MMP-9 activity in hyperhomocysteinemia. Basic cardiovascular Sciences Conference. 2009, July 20-23.

5. Givvimani S, Jala R, Mishra PK, Sen U, Tyagi N, Qipshidze N, Munjal C, Tyagi SC.Functional heterogeneity in vascular remodeling (MMP-9-/- and PAR-1/+) in hyperhomocysteinemic (CBS-/+) and diabetic (Akita, Ins2-/+) mice. FASEB J, 2010; 599.6.

6. Qipshidze N, Tyagi N, Sen U, Givvimani S, Metreveli N, Abe OA, Lominadze D, Tyagi SC. Folic Acid Mitigated Cardiac Dysfunction by Normalizing the Levels of Tissue Inhibitor of Metalloproteinase and homocysteine-metabolizing enzymes Post myocardial Infarction in Mice. FASEB J. 2010; 600.5

7. Kapoor S, Tyagi N, Qipshidze N, Givvimani S, Kandel M, Tyagi SC. Curcumin mitigated ischemic and hyperhomocysteinemic cerebral microvascular 
mitochondrial mitophagy by decreasing oxidative and inflammatory stresses. FASEB J, 2010; 604.19

8. Tyagi N, Qipshidze N, Givvimani S, Kandel M, Mishra PK, Sen U, Johar A, Tyagi SC. Tetrahydrocucrumin ameliorates mtMMP-9-mediated mitophagy and mitochondria remodeling in stroke. FASEB J. 2010;604.4

9. Kandel M, Tyagi N, Qisphidze N, Munjal C, Basu P, Givvimani S, Abe O, Mishra PK, Sen U, Tyagi SC Folic acid mitigated homocysteine-mediated decrease in bone blood flow and bone remodeling., FASEB J, 2010; 630.7 10. Munjal C, Falcon JC, Qipshidze N, Mishra PK, Tyagi SC. DDAH-2 and eNOS in mesenteric vascular remodeling: role of fenugreek. FASEB J, 2010; 774.7

11. Basu P, Qipshidze N, Sen U, Mishra PK, Tyagi SC. Blood flow regulates vasculature by maintaining collagen/elastin and MMP/TIMP ratio. FASEB J, $2010 ; 790.3$

12. Qipshidze N, Tyagi N, Sen U, Munjal C, Metreveli N, Lominadze D, Tyagi SC. Folic acid improves acetylcholine- induced vasoconstriction of coronary vessels isolated from hyperhomocyteinemic mice. 64th High Blood Pressure Research 2010 Scientific Sessions. 2010; P423

13. Basu P, Qipshidze N, Sen U, Mlshra PK, Tyagi SC, (2010). Chronic hyperhomocysteinemia cause remodeling by instigation vein phenotype in artery. 64th High Blood Pressure Research 2010 Scientific Sessions. 2010; P408 
14. Hydrogen sulfide improves angiogenesis and regulates cardiac function and structure during myocardial infarction in mice. Qipshidze N, Mlshra PK, Metreveli N, Lominadze D, Tyagi SC. FASEB J. 2011; 1092.10 15. The siRNA targeting MMP-9 mitigates homocyteine-induced disruption of barrier integrity in human intestinal microvascular cells. Munjal C, Tyagi $\mathrm{N}$, Qipshidze N, Mlshra PK, Givvimani S, Sen U, Lominadze D, Tyagi SC. FASEB J. $2011 ; 1066.7$

16. Exercise ameliorates diabetic cardiomyopathy by inducing beta2-adrenergic receptors and miR-133a, and attenuating MMP-9. Mlshra PK, Abe OA, Metreveli N, Qipshidze N, Munjal C, Tyagi N, Tyagi SC. FASEB J. 2011;1032.4 17. Qipshidze N, Tyagi N, Munjal C, Metreveli N, Lominadze D, Tyagi SC. Acetylcholine-induced coronary vasoconstriction was improved with supplementation of folic acid in hyperhomocyteinemic mice: and implication to coronary vasospasm. FASEB J. 2011; 819.1

18. Tyagi N, Qipshidze N, Munjal C, Metreveli N, Dankowski A, Mlshra PK, Sen U, Givvimani S, Tyagi SC. Hydrogen sulfide ameliorates mitochondrial MMP-9 mediated mitochondrial remodeling in cerebral ischemia. FASEB J. 2011;650.7 19. Tyagi N, Qipshidze N, Munjal C, Metreveli N, Mishra PK, Sen U, Givvimani S, Lominadze D, Tyagi SC. H2S ameliorates oxidative stress and protects the brain against cerebrovascular remodeling in ischemia/reperfusion injury. Accepted for AHA-High Blood Pressure Research 2011, Orlando, FL.P394 20. Utpal S, Givvimani S, Qipshidze N, Mishra PK, Metreveli N, and Tyagi SC. Increased endogenous $\mathrm{H} 2 \mathrm{~S}$ generation by gene therapy improves renovascular 
function in CBS +/- mice. Accepted for AHA-High Blood Pressure Research 2011, Orlando,FL. P413

21. Givvimani S, Sen U, Tyagi N, Mishra P, Munjal C, Qipshidze N, Metreveli N,Tyagi S.C. TIMP-2 mutant decreases MMP-2 activity and augments pressure overload induced left ventricular dysfunction and heart failure. Accepted for AHAHigh Blood Pressure Research 2011, Orlando,FL. P259

22. Mishra PK, Metreveli N, Tian Q, Qipshidze N, Tyagi N, Sen U, Givvimani S, Irving G. Joshua, Tyagi SC, MiRNA-133 Ameliorates MMP9 Induced Diabetic Cardiomyopathy. Accepted for AHA-High Blood Pressure Research 2011, Orlando,FL. P249

23. Qipshidze N, Munjal C, Tyagi N, Mishra PK, Sen U, Givvimani S, Metreveli N, Lominadze D, Tyagi SC, Mechanism of Right Ventricular Remodeling in Mouse Model of Pulmonary Hypertension, Accepted for AHA-High Blood Pressure Research 2011, Orlando,FL. P293

24. Tyagi N, Narayanan N, Mishra PK, Qipshidze N, Givvimani S, and Tyagi SC. Univ. of Louisville Epigenetic reprogramming of mitochondrial dysfunction in hyperhomocysteinemia. FASEB J. 701.17

25. Mishra PK, Metreveli N, Chavali V, Tyagi N, Qipshidze N, Sen U, Joshua IG and Tyagi S.C. Role of MMP9 in cardiac stem cell differentiation and autophagy FASEB J. 1060.10 
26. Qipshidze N, Tyagi N, Metreveli N and Tyagi SC. Mitochondrial mechanism of right ventricular failure FASEB J.1127.3

27. Qipshidze-Kelm N, Piell KM, Solinger j, Cole MP. Combination Treatment with Conjugated Linoleic Acid and Nitrite Protects Against Myocardial Infarction. BMB retreat 2013. AWARD: Best postdoctoral presentation 2013

28. Qipshidze-Kelm N, Piell KM, Solinger j, Cole MP. Combination Treatment with Conjugated Linoleic Acid and Nitrite Protects Against Myocardial Infarction. Research Louisville 2013

29. Qipshidze-Kelm N, Solinger j, Piell KM, , Cole MP. Conjugated linoleic acid causes disruption of Connexin-43 and leads to life threatening arrhythmias during myocardial infarction. Kentucky chapter of the American physiological society, 2013. AWARD: 2014 -Meritorious Graduate Student Poster Presentation Award. 30. Patrick Van Hoose, Kellianne Piell, Natia Qipshidze Kelm , Marsha Cole. Co-treatment of Conjugated Linoleic Acid and Nitrite alters Mitochondrial Function in vivo. Research Louisville 2014, GRD-72

31. Natia Qipshidze Kelm, Patrick M. Van Hoose, Kellianne M. Piell, Jane C. Solinger, Marsha P. Cole. Nitrite supplementation rescues life-threatening arrhythmias in conjugated linoleic acid treated mice following myocardial infarction. Research Louisville 2014, PRF-17

32. Kellianne Piell, Natia Qipshidze Kelm, Marsha Cole. Nox4 Derived Hydrogen Peroxide Contributes to Conjugated Linoleic Acid and Nitrite-Induced Cardiac Protection. Research Louisville 2014. RS-64 
33. 30. Patrick Van Hoose, Kellianne Piell, Natia Qipshidze Kelm, Marsha Cole. Co-treatment of Conjugated Linoleic Acid and Nitrite alters Mitochondrial Function in vivo. FSRBM 2014

31. Natia Qipshidze Kelm, Patrick M. Van Hoose, Kellianne M. Piell, Jane C. Solinger, Marsha P. Cole. Nitrite supplementation rescues life-threatening arrhythmias in conjugated linoleic acid treated mice following myocardial infarction. FSRBM 2014

32. Kellianne Piell, Natia Qipshidze Kelm, Marsha Cole. Nox4 Derived Hydrogen Peroxide Contributes to Conjugated Linoleic Acid and Nitrite-Induced Cardiac Protection. FSRBM 2014 